\title{
State-of-the-Art Highly Insulating Window Frames - Research and Market Review
}

Arild Gustavsen, SINTEF Building and Infrastructure,

Bjørn Petter Jelle, Norwegian University of Science and Technology (NTNU), Dariush Arasteh and Christian Kohler, Lawrence Berkeley National Laboratory (LBNL) 


\section{Summary}

This document reports the findings of a market and research review related to state-of-the-art highly insulating window frames. The market review focuses on window frames that satisfy the Passivhaus requirements (window U-value less or equal to $0.8 \mathrm{~W} / \mathrm{m}^{2} \mathrm{~K}$ ), while other examples are also given in order to show the variety of materials and solutions that may be used for constructing window frames with a low thermal transmittance (U-value). The market search shows that several combinations of materials are used in order to obtain window frames with a low U-value. The most common insulating material seems to be Polyurethane (PUR), which is used together with most of the common structural materials such as wood, aluminum, and PVC.

The frame research review also shows examples of window frames developed in order to increase the energy efficiency of the frames and the glazings which the frames are to be used together with. The authors find that two main tracks are used in searching for better solutions. The first one is to minimize the heat losses through the frame itself. The result is that conductive materials are replaced by highly thermal insulating materials and air cavities. The other option is to reduce the window frame area to a minimum, which is done by focusing on the net energy gain by the entire window (frame, spacer and glazing). Literature shows that a window with a higher U-value may give a net energy gain to a building that is higher than a window with a smaller U-value. The net energy gain is calculated by subtracting the transmission losses through the window from the solar energy passing through the windows. The net energy gain depends on frame versus glazing area, solar factor, solar irradiance, calculation period and U-value.

The frame research review also discusses heat transfer modeling issues related to window frames. Thermal performance increasing measures, surface modeling, and frame cavity modeling are among the topics discussed. The review shows that the current knowledge gives the basis for improving the calculation procedures in the calculation standards. At the same time it is room for improvement within some areas, e.g. to fully understand the natural convection effects inside irregular vertical frame cavities (jambs) and ventilated frame cavities. 


\section{Contents}

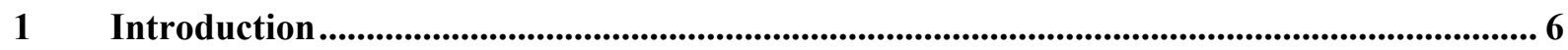

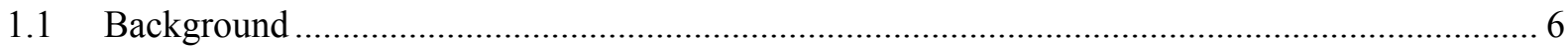

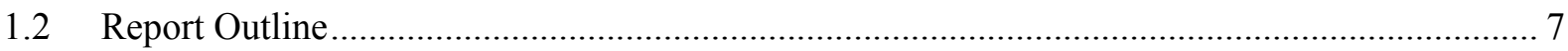

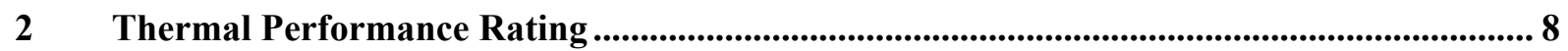

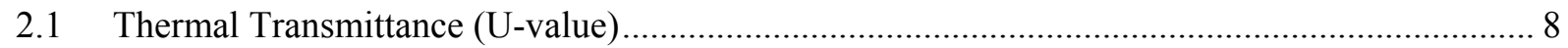

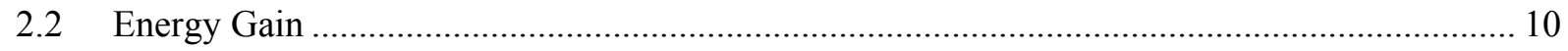

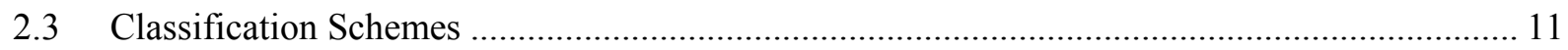

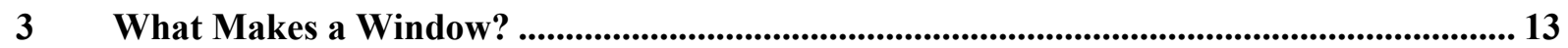

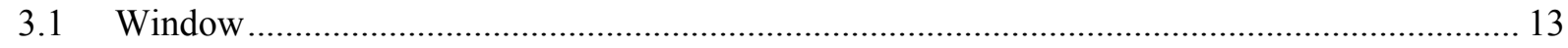

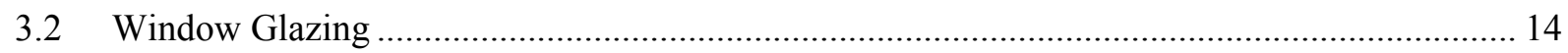

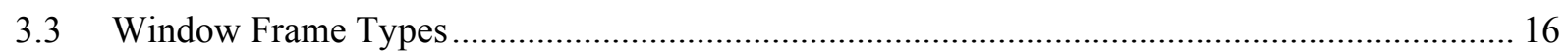

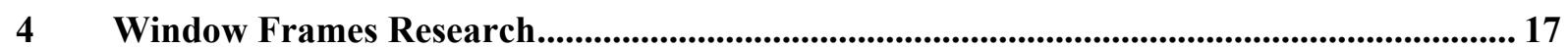

4.1 Effect of Frame and Spacer on Window U-Value …............................................................ 17

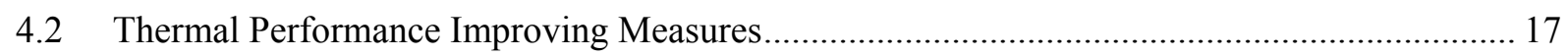

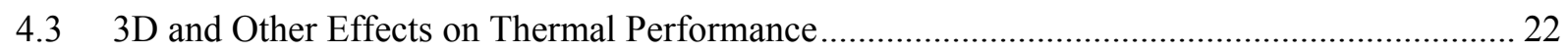

4.4 Heat Transfer Modeling of Window Frame Cavities............................................................... 22

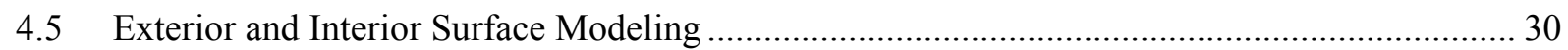

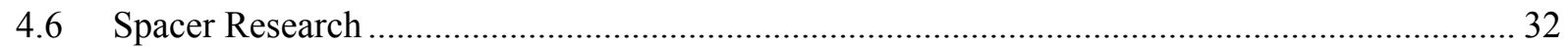

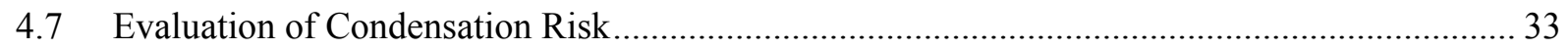

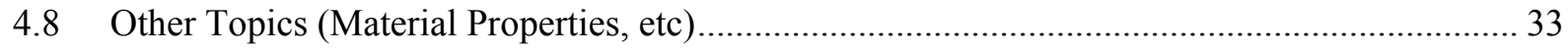

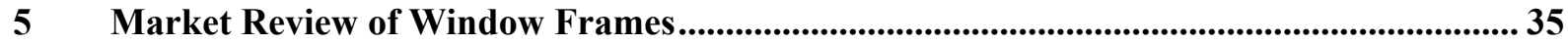

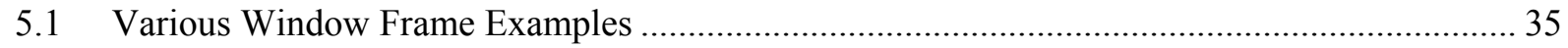

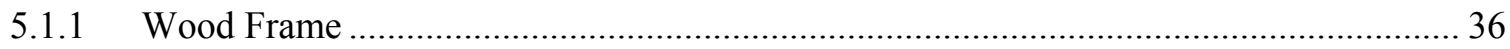

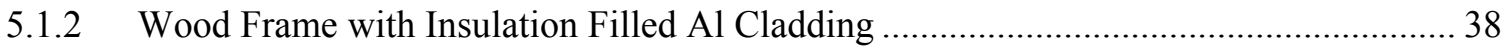

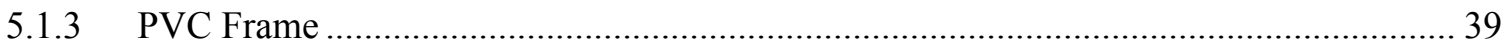

5.1.4 PVC Frame with Insulation Filled Al Cladding ............................................................ 40

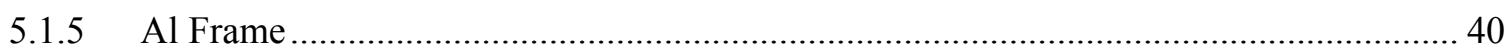

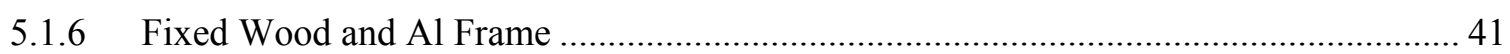

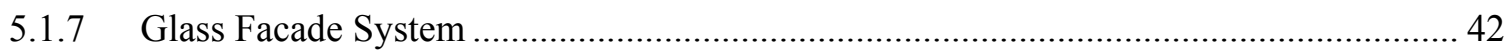

5.1.8 Window Frame Examples with Higher U-Values than the Passivhaus Requirement ..... 43

5.2 U-Value Comparison for Various Window Frame Types .......................................................... 44

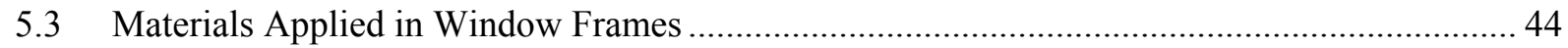




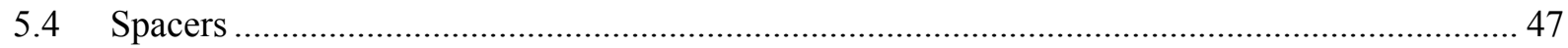

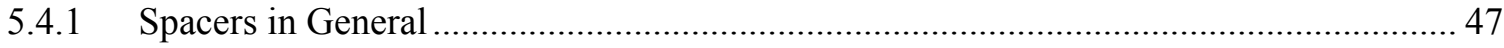

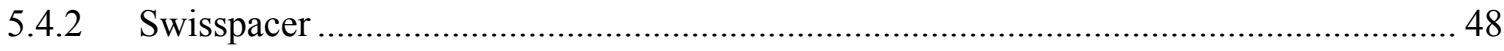

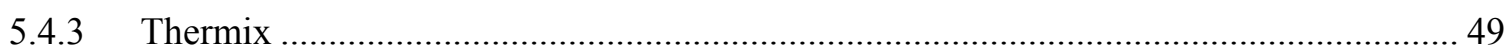

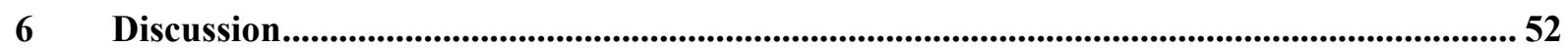

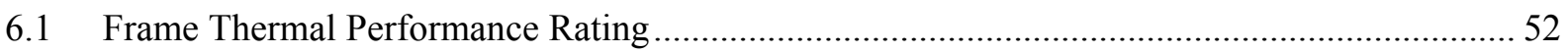

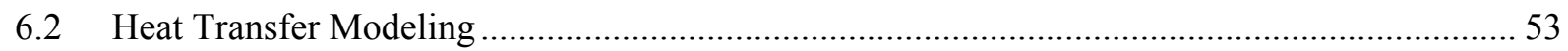

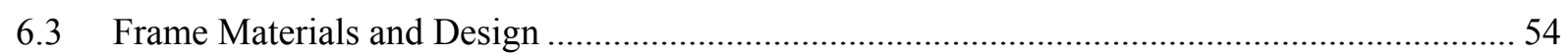

6.4 Window Frame Research and Development Aims ................................................................... 56

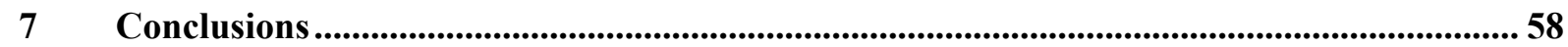

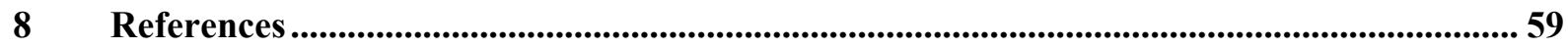

Appendix - List of Highly Thermal Insulating Window Frames.......................................... A-1 


\section{Introduction}

\subsection{Background}

In northern climates the construction of well-insulated buildings is important for reducing the energy use for heating, especially in small residential buildings. Even in larger commercial buildings where internal gains may exceed the transmission losses, well-insulated buildings are desirable. This is because well-insulated buildings have less transmission losses and because thermal discomfort due to badly insulated constructions can be avoided. Because of this, focus has been put on the insulating capabilities of building sections for years. In Norway, for instance, the requirements for the thermal transmittance (U-value) of new building sections like roofs, external walls and windows were last restricted in 2007 (NBC 2007). Table 1 shows the U-value requirements and also the evolution of the U-value requirements for different building sections according to the Norwegian building code. From 1969 to 2007 the thermal transmittance requirements of new outer walls were reduced from 0.46 $\mathrm{W} / \mathrm{m}^{2} \mathrm{~K}$ to $0.18 \mathrm{~W} / \mathrm{m}^{2} \mathrm{~K}$. For windows the reduction has been from 3.14 to $1.2 \mathrm{~W} / \mathrm{m}^{2} \mathrm{~K}$. Even though there have been a reduction for all building envelope parts it is evident that the $U$-value requirement for windows and doors is very different that the requirements for the other envelope parts. The reason for this is of course that windows are built from other materials than the opaque materials used in typical roofs, walls and floors.

Because of the large difference in U-value between windows and other building constructions, the energy losses through windows will contribute to a large part of the transmission losses for a building. For a two-story residential house with base area of $8 \times 10 \mathrm{~m}^{2}$, height of $2 \times 2.5 \mathrm{~m}$ and with $30 \%$ of the walls covered by windows about $60 \%$ of the total energy loss through the building envelope of that building will be through the windows, if the building envelope sections of the building comply with the U-value requirements of NBC (2007). If the window area is reduced to $20 \%$ the corresponding percentage is about $45 \%$. Thus, decreasing the U-value of windows can be an important factor in reducing the energy use for heating in residential buildings. However, it should not be forgotten that windows also allows for solar energy to enter the building.

The window frame is an important part of a fenestration product. Looking at a window with a total area of $1.2 \times 1.2 \mathrm{~m}^{2}$ and a frame with a width of $10 \mathrm{~cm}$, the area occupied by the frame is $30 \%$ of the total. If the total area of the window is increased to $2.0 \times 2.0 \mathrm{~m}^{2}$ the percentage is $19 \%$ (still using the same frame). That is, a substantial part of the heat loss will be attributed to the frame, especially if the frame has an U-value that is higher than the glazing U-value. 
In rating fenestration products engineers area weight the thermal performance of the different parts to find one number describing the entire product. Thus, to get a window with a low U-value, both the glazing and the frame need to have a low thermal transmittance (in addition to the edge part of the window). Below, typical glazing and frame types will be presented as an introduction to the window frame research and market state-of-the-art.

Table 1. Thermal transmittance $\left(W / m^{2} K\right)$ requirements according to Norwegian building codes ${ }^{a)}$.

\begin{tabular}{lcccc}
\hline Building Sections & $\begin{array}{c}\text { Norwegian building } \\
\text { code 1969 } \\
\text { (NBC 1969) }\end{array}$ & $\begin{array}{c}\text { Norwegian building } \\
\text { code 1987 } \\
\text { (NBC 1987) }\end{array}$ & $\begin{array}{c}\text { Norwegian building } \\
\text { code 1997 } \\
\text { (NBC 1997) }\end{array}$ & $\begin{array}{c}\text { Norwegian building } \\
\text { code 2007 } \\
\text { (NBC 2007) }\end{array}$ \\
\hline Temperature & & $>18^{\circ} \mathrm{C}$ & $\geq 20^{\circ} \mathrm{C}$ & \\
\hline Outer Wall & 0.46 & 0.3 & 0.22 & 0.18 \\
Window & 3.14 & 2.4 & 1.6 & 1.2 \\
Door & 3.14 & 2.0 & 1.6 & 1.2 \\
Roof & 0.41 & 0.2 & 0.15 & 0.13 \\
Floor & 0.46 & 0.3 & 0.15 & 0.15 \\
\hline
\end{tabular}

a) This table simplifies the U-value requirements for some building sections and building codes. Please refer to the different building codes for detailed information.

\subsection{Report Outline}

The focus in this report lies on window frames with a high thermal performance; that is on frames with a significantly lower U-value than traditional frames, and frames for which special actions have been taken to reduce the heat loss or in other regards increase the thermal performance. Because the thermal transmittance of window frames is coupled to the glazing spacer (according to some calculation procedures), information related to typical glazing spacers is also included. The main part of the work in this report relates to the research review (Chapter 4) and the market review presented in Chapter 5. The following division in chapters is selected:

- Chapter 1 gives a short background for this report.

- Chapter 2 explains typical thermal performance rating procedure for windows and window frames.

- Chapter 3 explains the typical parts that a window is made of, and typical ways of classification.

- Chapter 4 presents frame related research found in scientific journals and reports. Modeling issues has got the most attention, but new frame designs are also presented.

- Chapter 5 presents the most interesting results from the market review. A separate list is given in the Appendix.

- In Chapter 6 the findings of the previous two chapters are summarized and discussed.

- Chapter 7 concludes the report. 


\section{Thermal Performance Rating}

The most common way of rating fenestration products is by the U-value and the g-value (solar factor). The U-value is the thermal transmittance and the g-value is the total solar energy transmittance (denoted with a number between 0 and 1). In addition the air leakage will have an influence on the energy performance of the various products. The visible transmittance and condensation resistance are also important factors that may be noted. All these parameters can be found by performing measurements or simulations according to documents published by ISO, CEN and NFRC. These documents will not be further described here. Instead issues related to various window and frame Uvalue calculation procedures and other rating procedures, important for understanding some of the topics in later chapters, will be described.

\subsection{Thermal Transmittance (U-value)}

First, the authors note that people should be aware of two different ways of calculating the thermal transmittance (U-value) of windows and window frames, in particular. These are often referred to as the ASHRAE procedure (based on ASHRAE SPC 142P) and the ISO procedures (described in ISO 10077-2). (The two procedures are also described in ISO 15099.) The two approaches are different in the way they treat the effect of the glazing spacer on the heat transfer through the frame and the glazing unit near the frame. The ASHRAE method assumes that the spacer influences both the heat transfer through the frame and the heat transfer through the glazing in an "edge-of glass" region. The edge-of-glass region is set equal to a $63.5 \mathrm{~mm}$ ( $2.5 \mathrm{inch})$ wide area, measured from the glazing/frame sight line. To find the frame and edge-of-glass thermal transmittances the frame is simulated with the glazing/spacer inserted. The total window U-value is calculated according to

$$
U_{w, A S H R A E}=\frac{U_{c g} A_{c}+\sum U_{f r} A_{f}+\sum U_{e g} A_{e}}{A_{t}}
$$

where $U_{c g}$ is the center-of-glass U-value and where $A_{c}, A_{f}, A_{e}$ and $A_{t}$ denote the center-of-glass area, the frame area, the edge-of-glass area, and the total window area, respectively. $U_{f r}$ and $U_{e g}$ are determined from the following equations:

$$
\begin{aligned}
& U_{f r}=\frac{\Phi_{f r}}{l_{f}\left(T_{n i}-T_{n e}\right)} \\
& U_{e g}=\frac{\Phi_{e g}}{l_{e g}\left(T_{n i}-T_{n e}\right)}
\end{aligned}
$$


where $l_{f}$ is the projected length of frame area and $l_{e g}$ is the length of the edge-of-glass area, which is equal to $63.5 \mathrm{~mm}$. These lengths are measured on the internal side. $\Phi_{f r}$ and $\Phi_{e g}$ are heat flow rates through frame and edge-glass areas (internal surfaces), respectively, including the effect of glass and spacer. Both $\Phi_{f r}$ and $\Phi_{e g}$ are expressed per length of frame or edge-glass areas. The summations in Eq. (1) are used to account for the various sections of one particular component type; e.g. several values of the projected frame area, $A_{f}$, are needed in order to sum the contributions of different values of $U_{f r}$ corresponding to sill, head and side jambs. $T_{n i}$ and $T_{n e}$ denote the interior and exterior temperature, respectively.

To follow the ISO method the frame has to be simulated both with an insulation panel and with the glazing/spacer. A linear thermal transmittance that depends on the spacer/glazing configuration can then be calculated. The additional heat transfer due to the existence of the spacer is then assumed to be proportional to the glazing/frame sightline distance that is also proportional to the total glazing spacer length. Thus, the total window U-value is calculated according to

$$
U_{w, I S O}=\frac{U_{g} A_{g}+\sum U_{f} A_{f}+\sum l_{\Psi} \Psi}{A_{t}}
$$

where $U_{g}$ is the center-of-glass U-value and where $A_{g}$ and $A_{f}$, denote projected vision and frame area. $A_{t}$ is the total window area. To find the frame U-value the frame is simulated with an insulation panel instead of the real glazing and spacer. $\Psi$ and $U_{f}$ are then determined from the following equations:

$$
\begin{aligned}
& \Psi=L^{2 D}-U_{f} l_{f}-U_{g} l_{g} \\
& U_{f}=\frac{L_{p}^{2 D}-U_{p} l_{p}}{l_{f}}
\end{aligned}
$$

$L^{2 \mathrm{D}}$ is the thermal coupling coefficient determined from the actual fenestration system (frame, glazing and spacer) and $L_{p}{ }^{2 \mathrm{D}}$ is the coupling coefficient determined from the frame/panel insert system. Further, $U_{p}$ is the thermal transmittance of the foam insert, $l_{p}$ is the internal side exposed length of foam insert, $l_{f}$ is the internal side projected length for frame section, and $l_{g}$ is the internal side projected length of the glass section.

Note that the two ways of calculating the frame U-value in Eq. (2) and Eq. (6) give different frame Uvalues. The reason for this difference is that one of the $U$-values is found by simulating the frame with the actual glazing system, while in the other method the frame is simulated with an insulation panel. The frame U-values presented in this report are based on Eq. (6), that is ISO 10077-2. 
Blanusa et al. (2007) compare the ISO and ASHRAE procedures and find that the two procedures give U-values that differ both for the frame and the entire window product. The difference is largest for small windows. A maximum difference of $3 \%$ is found for entire windows. The difference was explained by the way the corner regions of the window frame and glazing are treated by the assembly of the overall thermal transmittance for a three-dimensional window from the two-dimensional calculations. It is therefore important, if products are compared, that the procedures used to find the Uvalue are noted.

\subsection{Energy Gain}

Nielsen et al. (2000) introduces a method to rate and select windows for new buildings or buildings that are going to be retrofitted. The method considers Net Energy Gain for the windows in question; that is, a net energy gain is calculated by subtracting the transmission losses through the windows from the solar energy passing through the windows,

$$
E=I \cdot g-U \cdot D \quad\left[\mathrm{kWh} / \mathrm{m}^{2}\right]
$$

$I\left(\mathrm{kWh} / \mathrm{m}^{2}\right)$ is the solar gain during the heating season corrected for the g-value's dependency on the incidence angle. $D(\mathrm{kKh})$ is the degree hour during the heating season. The heating season is in this study set to 24/9-13/5. $I$ and $D$ are dependent on the climate and $I$ also depends on the orientation of the windows. A negative net energy gain indicates that the heat loss is larger than the solar gain. Nielsen et al. (2000) only consider the net energy gain for the windows, and not other losses and gains. The net energy gain calculations are based on the temperature and solar radiation conditions of a Design Reference Year (hourly values), and in their study $D=90.36 \mathrm{kKh}$. Using this method it is possible to produce diagrams that show the net energy gain as a function of the U-value, g-value, orientation, and tilt of the glazing or windows, see Figure 1. The method can take into account shading and utilization degree of the heat transmitted into the building. The authors note that the method should only be used in heating dominated buildings. The method is further elaborated on in Lautsen and Svendsen (2005) and Svendsen et al. (2005).

It is noted that similar methods also have been suggested by others, e.g. for rating fenestration products in Canada. There, thermal transmittance losses (using the U-value), solar heat gain and air infiltration losses are counted for. Arasteh et al. (2007) also presents similar plots as Nielsen et al. (2000), and use these to define the performance criteria for residential Zero Energy Windows. Through the use of whole house energy modeling, typical efficient products are evaluated in five US climates and compared against the requirements for Zero Energy Homes. The performance threshold at which a window provides net energy gain for the building rather than net energy loss is determined 
by simulating the building in question with no heat flow through the windows, i.e., the g-value and Uvalue properties of the windows were set to zero, representing perfect thermal resistance, with no solar transmittance. Both cooling and heating is accounted for, with thermostat set points being $21.1{ }^{\circ} \mathrm{C}$ for heating and $25.6{ }^{\circ} \mathrm{C}$ for cooling.

There also exist software tools that are especially designed to evaluate the thermal performance of windows. An example is RESFEN (Mitchell et al. 2005), which calculates heating and cooling energy use and associated costs as well as peak heating and cooling demand for specific window products (http://windows.lbl.gov/software/resfen/resfen.html). Users define a specific "scenario" by specifying house type (single-story or two-story), geographic location, orientation, electricity and gas cost, and building configuration details (such as wall, floor, and HVAC system type). Users also specify size, shading, and thermal properties of the window they wish to investigate. The thermal properties that RESFEN requires are: U-value, solar heat gain coefficient, and air leakage rate. RESFEN calculates the energy and cost implications of the window compared to an insulated wall. The relative energy and cost impacts of two different windows can be compared.

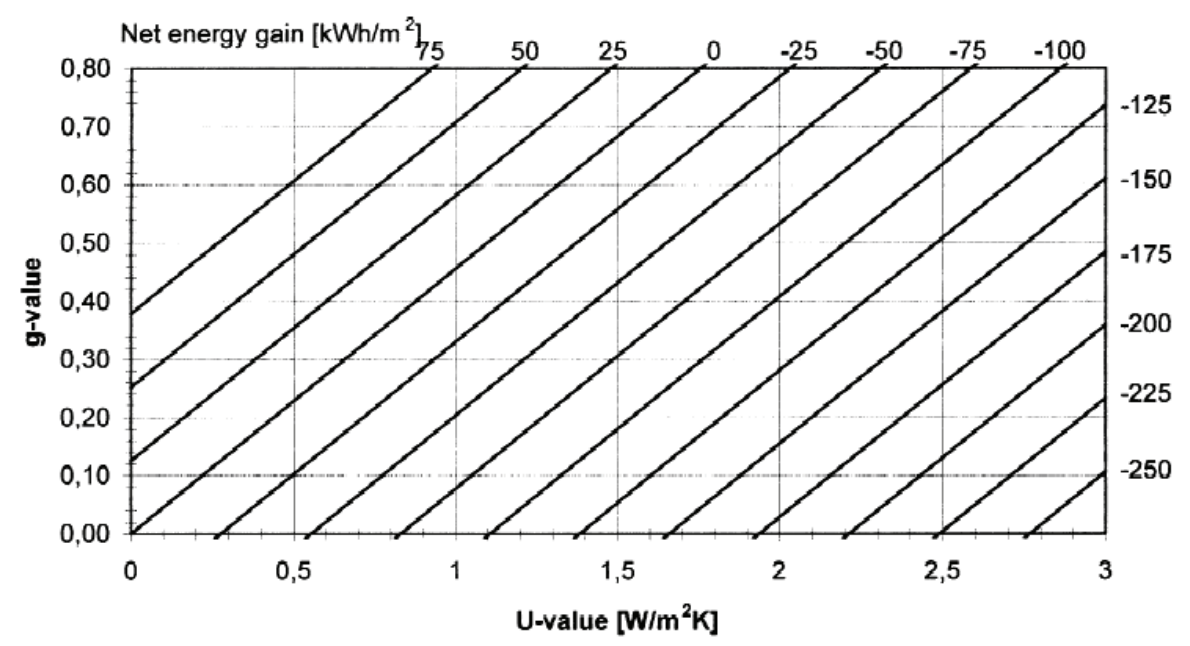

Figure 1. Example of net energy gain diagram for a one-family house in Danish climate during the period 24/913/5 (heating season). The net energy gain is determined taking into account the orientation of the windows in the building and a shading factor of $F=0.7$ (Nielsen et al. 2000).

\subsection{Classification Schemes}

There exist several certification schemes that producers can try to fulfill in order to say that their product is energy efficient. One of the most strict one (in regard to requirements of a low U-value), is the one specified by the Passivhaus Institute in Germany (www.passiv.de). To fulfill the Passivhaus requirements (www.passiv.de) the following demands have to be reached for the glazing, window and frame: 
- $U_{g} \leq 0.80 \mathrm{~W} / \mathrm{m}^{2} \mathrm{~K}$ (window glazing)

- $U_{w} \leq 0.80 \mathrm{~W} / \mathrm{m}^{2} \mathrm{~K}$ (window as a whole)

- $U_{f}$ so that $U_{w} \leq 0.80 \mathrm{~W} / \mathrm{m}^{2} \mathrm{~K}$ (window frame)

If a glazing with a $\mathrm{U}_{\mathrm{g}}$-value equal to $0.80 \mathrm{~W} / \mathrm{m}^{2} \mathrm{~K}$ are to be used in a window where the $\mathrm{U}_{\mathrm{w}}$-value have to be $0.80 \mathrm{~W} / \mathrm{m}^{2} \mathrm{~K}$, the frame U-value must be smaller than $0.80 \mathrm{~W} / \mathrm{m}^{2} \mathrm{~K}$, because of the edge of glass region where the spacer is situated (see Eqs. 3 and 5). If for example the glazing has a $U_{g}$-value considerable below $0.80 \mathrm{~W} / \mathrm{m}^{2} \mathrm{~K}$ the frame U-value may be somewhat above $0.80 \mathrm{~W} / \mathrm{m}^{2} \mathrm{~K}$ and still be able to fulfill the window $U_{w} \leq 0.80 \mathrm{~W} / \mathrm{m}^{2} \mathrm{~K}$ requirement. The exact value has to be calculated for the different windows configurations.

The majority of the windows and frames reported below comply with the Passivhaus requirements. The standard ISO 10077-2 is used to calculate the frame U-value. That is, an insulation panel is used instead of the actual glazing, see also Chapter 2.1. 


\section{What Makes a Window?}

\subsection{Window}

According to Wikipedia (2007) and Encyclopædia Britannica (2007) a window is an opening in an otherwise solid and opaque surface that allows the passage of light and air. Encyclopædia Britannica (2007) further notes that windows often are arranged for the purposes of architectural decoration. Since early times, the openings have been filled with stone, wooden, or iron grilles or lights (panes) of glass or other translucent material such as mica or, in the Far East, paper. Modern windows are almost always filled with glass, though a few use transparent plastic. A window in a vertically sliding frame is called a sash window: a single-hung sash has only one half that moves; in a double-hung sash, both parts slide. A casement window opens sideward on a hinge.

Within this report a window is defined as consisting of:

- Window glazing

○ Glass (single, double, triple, etc.)

- Spacer (Al, Swisspacer, Thermix, etc.)

○ Cavity gas (air, argon, krypton, xenon)

- Glass coating (low emissivity coatings, solar control coatings, etc.)

- Window frame

○ Various frame/casing structures, fixed/opening windows, etc.

- Structural frame materials

○ Highly thermal insulating materials

Windows may be classified into various types, e.g. according to their operating system. One example is depicted in Figure 2. Figure 3 shows properties which have to be addressed in order to make a high-performance window with respect to thermal insulating properties.

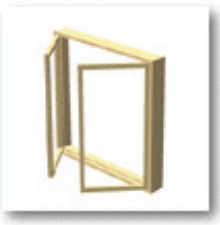

Casement

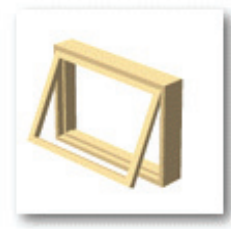

Awning

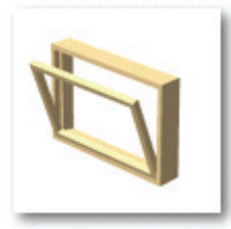

Hopper

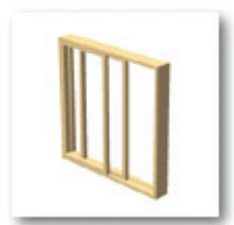

Slider

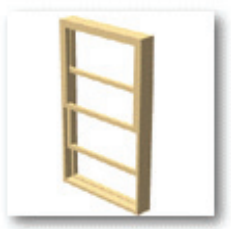

Double Hung

Figure 2. Figures showing classification of windows according to their operating system. From http://www.efficientwindows.org/otypes.cfm. 


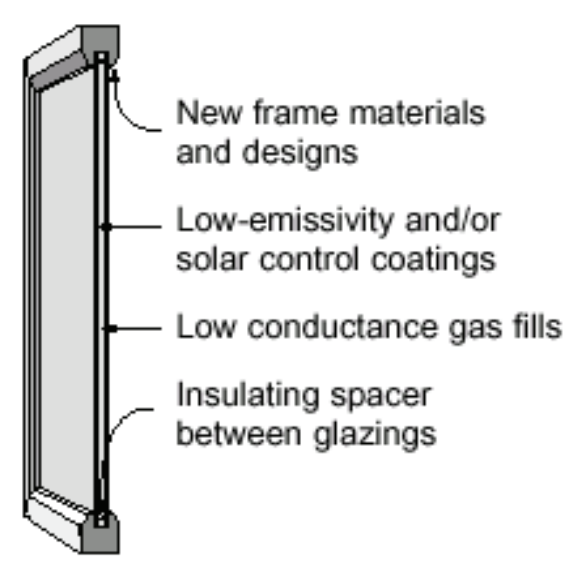

Figure 3. Properties making up a high-performance window (http://www.buildcentral.com/windows/about.asp).

The U-value of the window glazing have been decreased throughout the years, e.g. from $3.0 \mathrm{~W} / \mathrm{m}^{2} \mathrm{~K}$ to $1.6 \mathrm{~W} / \mathrm{m}^{2} \mathrm{~K}$ and further down to $1.2 \mathrm{~W} / \mathrm{m}^{2} \mathrm{~K}$ for double glazing. By applying triple glass panes and low emissivity coatings on two glasses, the $\mathrm{U}_{\mathrm{g}}$-value has been further decreased down to $0.7 \mathrm{~W} / \mathrm{m}^{2} \mathrm{~K}$ (argon filled cavities) and $0.5 \mathrm{~W} / \mathrm{m}^{2} \mathrm{~K}$ (krypton filled cavities). Window frame U-values above $1.0 \mathrm{~W} / \mathrm{m}^{2} \mathrm{~K}$ for traditional window frames are therefore becoming a minimum factor in the window design of today, which may hamper the goal of reduced heat loss through the windows. In order to reduce the heat loss from buildings in general and windows in particular, it is therefore crucial to develop highly thermal insulating window frames.

\subsection{Window Glazing}

The glazing is usually the larger part of a window. Various classification systems of glazing types or window glass panes may be found in the literature, where one example is shown in Figure 4.

Typical window glazing U-values depending on number of glasses, thickness of cavity, choice of cavity gas and number of low emissivity coatings are given in Table 2. Increasing number of glasses, increasing number of low emissivity coatings and application of argon or krypton instead of air, decreases the $U_{g}$-value substantially. The lowest $U_{g}$-value of $0.5 \mathrm{~W} / \mathrm{m}^{2} \mathrm{~K}$ is found for a glazing with three layers of glass, two low emissivity coatings and krypton in the cavities for a normal 4E-12-4-12E4 configuration ( $\mathrm{E}=$ low emissivity coating, each cavity $12 \mathrm{~mm}, 4 \mathrm{~mm}$ thick glasses). 


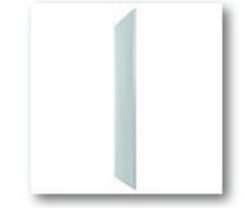

Sinqle-qlazed Clear

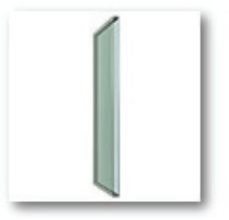

Double-qlazed with High Performance Tint

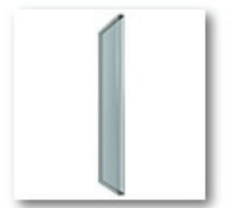

Triple-qlazed with Moderate-Solar-Gain Low-E, Arqon/Krypton Gas

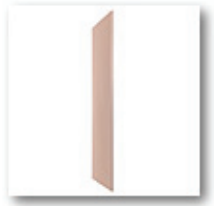

Sinqle-qlazed with Bronze/Gray Tint

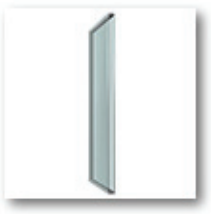

Double-glazed with HiqhSolar-Gain Low-E. Arqon/Krypton Gas

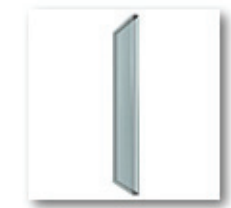

Triple-qlazed with Low-

Solar-Gain Low-E,

Arqon/Krypton Gas

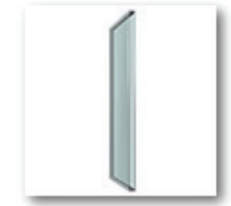

Double-qlazed Clear

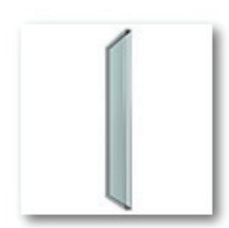

Double-qlazed with Moderate-Solar-Gain LowE. Arqon/Krypton Gas

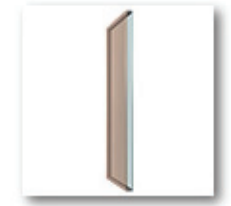

Double-qlazed with Bronze/Gray Tint

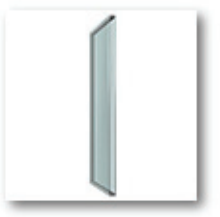

Double-qlazed with LowSolar-Gain Low-E. Arqon/Krypton Gas

Figure 4. Classification of glazing types/window glass panes (http://www.efficientwindows.org/gtypes.cfm).

Table 2. Typical $U_{g}$-values for window glazings depending on number of glasses, choice of cavity gas and number of low emissivity coatings ( $E=$ low emissivity coating, each cavity $12 \mathrm{~mm}, 4 \mathrm{~mm}$ thick glasses).

\begin{tabular}{|c|c|c|c|c|}
\hline \multicolumn{5}{|c|}{ Glazing U-value $\left(\mathbf{W} /\left(\mathbf{m}^{2} \mathbf{K}\right)\right)$} \\
\hline \multirow{2}{*}{$\begin{array}{c}\text { Glazing Configuration } \\
(\mathbf{m m})\end{array}$} & \multicolumn{3}{c|}{ Cavity Gas } \\
\cline { 2 - 5 } & 4 & Air & Argon & Krypton \\
\hline \multirow{2}{*}{$\begin{array}{c}\text { No low } \\
\text { emissivity } \\
\text { coating }\end{array}$} & $4-12-4$ & 5.8 & - & - \\
\cline { 2 - 5 } & $4-12-4-12-4$ & 2.0 & 1.9 & 1.7 \\
\hline \multirow{2}{*}{$\begin{array}{c}\text { Low } \\
\text { emissivity } \\
\text { coating }\end{array}$} & $4-12-E 4$ & 1.6 & 1.3 & 1.1 \\
\cline { 2 - 5 } & $4-12-4-12-E 4$ & 1.3 & 1.0 & 0.8 \\
\cline { 2 - 5 } & $4 \mathrm{E}-12-4-12-\mathrm{E} 4$ & 1.0 & 0.7 & 0.5 \\
\hline
\end{tabular}




\subsection{Window Frame Types}

The various window frame types are at this stage divided into the groups listed below. This division is based on the actual frames found in the market review (see Chapter 5). Other window frame classification systems may also be found, e.g. the one given in http://www.efficientwindows.org/ftypes.cfm. In this report, the subdivisions are made according to the structural load carrying element for the opening windows (a fixed frame group and a glass facade system group have also been specified - for further details see Chapter 5.1):

- Wood frame

- Wood frame with insulation-filled Al cladding

- $\quad$ PVC frame

- $\quad$ PVC frame with insulation filled Al cladding

- $\mathrm{Al}$ frame

- Fixed wood and Al frame

- Glass facade system

All these frames include insulating materials in addition to the structural materials.

As noted above typical window frames seldom reach $\mathrm{U}_{\mathrm{f}}$-values below $1 \mathrm{~W} / \mathrm{m}^{2} \mathrm{~K}$. They normally have $\mathrm{U}_{\mathrm{f}}$-values quite a bit larger than $1 \mathrm{~W} / \mathrm{m}^{2} \mathrm{~K}$. The $\mathrm{U}_{\mathrm{f}}$-value for wood frames is mainly decided by the thickness of casement and frame in the heat flow direction. Typical thicknesses are between 80 and $100 \mathrm{~mm}$ for the casement and between 60 and 70 for the frame. This results in a mean $\mathrm{U}_{\mathrm{f}}$-value for casement and frame of 1.5 to $1.7 \mathrm{~W} / \mathrm{m}^{2} \mathrm{~K}$. For plastic frames the $\mathrm{U}_{\mathrm{f}}$-value is between 1.6 and $2.8 \mathrm{~W} / \mathrm{m}^{2} \mathrm{~K}$, and is mainly dependent on the number of air cavities and the location of the load carrying element which usually is of metal. Window frames constructed of metal, usually aluminum, should be constructed of one outer and one inner profile and separated by an insulating material (a thermal break), i.e. polyamide. The thermal break is necessary to meet low U-value requirements and also to achieve acceptable surface temperatures. Traditionally metal frames have had a high $\mathrm{U}_{\mathrm{f}}$-value, but new aluminum frames with a thermal break may have $\mathrm{U}_{\mathrm{f}}$-values varying from about 1.4 to 2.8 $\mathrm{W} / \mathrm{m}^{2} \mathrm{~K}$. 


\section{Window Frames Research}

This chapter presents various topics related to the thermal performance of window frames found in research papers and reports. The main focus has been on reports and papers that only study the window frame. But because the frame usually is a part of a complete window, research on topics related to windows in general is also presented. For these reports and papers the issues related to the frame and focusing on energy rating topics have been selected. Research focusing on the glazing and glazing topics are not referred in detail.

\subsection{Effect of Frame and Spacer on Window U-Value}

The thermal performance of the window frame has an effect on the thermal performance of the entire window, because the U-value of the entire window is an area-weighted average of the individual components (glazing, edge and frame). A good window frame will therefore influence the total window U-value positively compared to a poor window frame.

Carpenter and McGowan (1989) studied the effect of various frames and spacers on the thermal performance of the entire window. They found that double-glazed windows with insulation spacers have a $6 \%$ lower U-value than those with aluminum spacers. Furthermore, insulating spacers can reduce the total window $\mathrm{U}$-value by as much as $12 \%$ in high-performance windows (three glass panes), as compared with aluminum spacers. (Further, they also found that the U-value of aluminum frames is $39 \%$ higher than wood frames for standard double-glazed windows and up to $52 \%$ higher for high-performance glazings. The frame U-values ranged from $11.2 \mathrm{~W} / \mathrm{m}^{2} \mathrm{~K}$ for aluminum frames and $2.1 \mathrm{~W} / \mathrm{m}^{2} \mathrm{~K}$ for wood frames. They used a method similar to the alternate method in ISO 15099 to calculate the frame U-value. That is, the frames were simulated with glazing and spacer, not with an insulation panel to find the frame U-value.)

\subsection{Thermal Performance Improving Measures}

There are several ways of improving the thermal performance of windows and frames in particular. There are also several ways of assessing if one product has a better performance than another product. With regard to window frames the thermal transmittance (U-value) seems the most appropriate way of assessing the thermal performance. But when the ultimate goal is a complete window (glazing and frame) with a good thermal performance, other measures may also be useful, like the Net energy gain method presented above. Using the latter method may show that a window with a U-value of 0.97 $\mathrm{W} / \mathrm{m}^{2} \mathrm{~K}$ (frame $\mathrm{U}$-value equal to $1.49 \mathrm{~W} / \mathrm{m}^{2} \mathrm{~K}$ ) have a higher net energy gain than window with a Uvalue of $0.79 \mathrm{~W} / \mathrm{m}^{2} \mathrm{~K}$ (frame U-value equal to $0.75 \mathrm{~W} / \mathrm{m}^{2} \mathrm{~K}$ ), Lautsen and Svendsen (2005). The reason for this is that the former window has a larger glazing area than the latter window. 
With regard to frame U-value, one may look at changing the geometry as an option to modify the thermal transmittance. Replacing high-conductivity materials with low-conductivity materials is another way to reduce the thermal transmittance of frames. Here we present measures that various researchers have investigated in order to improve the frame's or the window's thermal performance.

In 1992 Byars and Arasteh examined various design options for reducing the frame U-value. They studied the effect of substituting wood (conductivity equal to $0.1159 \mathrm{~W} / \mathrm{mK}$ ) with an insulating material and also substituting the glazing spacer with an insulating material (conductivity equal to $0.0294 \mathrm{~W} / \mathrm{mK}$ ). The insulating material for the frame was not a real material with the structural properties needed for a window frames, but rather a material with the wanted thermal properties (reported in percentages of the conductivity of wood). The authors found that reducing the thermal conductivity of the jamb and sash from $100 \%$ of the conductivity of wood to $50 \%$ and $10 \%$ of the conductivity of wood for the sash and jamb, respectively, resulted in a U-value decrease from 1.48 to $0.57 \mathrm{~W} / \mathrm{m}^{2} \mathrm{~K}$ (with an insulated spacer). The authors also investigated the effects of varying cladding thickness and fill materials on "clad frame" frame U-values. They found that changing the fill material from wood to an insulating material was more important than changing the clad thickness (i.e. from 2 $\mathrm{mm}$ to $1 \mathrm{~mm}$ ). Once the fill was insulated the, the cladding thickness and conductivity became important.

Two papers, Noyé and Svendsen (2002) and Lautsen and Svendsen (2005), describe how the Net Energy Gain method can be used to find better window designs. As explained above, this method takes both the thermal losses and the gains into consideration. The window with the largest net energy gain does therefore not necessarily have the lowest frame U-value. Lautsen and Svendsen (2005) examine 7 different window designs. The design of the two windows having the largest net energy gain is presented below.

The window with the largest net energy gain $\left(18 \mathrm{kWh} / \mathrm{m}^{2}\right.$ for Danish climate) is shown in Figure 5. It is a proposal, and the frame construction is made of fiber glass reinforced polyester, which is both very slim and deep. There is room for three glass panes with an unusually large gap, which has the effect that the depth of the frame is as much as $150 \mathrm{~mm}$. The frame can be made even deeper for walls with more thermal insulation. The total area of the window is $1.23 \mathrm{~m} \times 1.48 \mathrm{~m}$ and the frame width is $25 \mathrm{~mm}$. Thus, the glass percentage is $93 \%$. The frame U-value is $1.49 \mathrm{~W} / \mathrm{m}^{2} \mathrm{~K}$, the centre U-value of the glazing is $0.93 \mathrm{~W} / \mathrm{m}^{2} \mathrm{~K}$, and the g-value is 0.58 . A version of this window with shutters on the outside was also tested, and this window produced even a larger net energy gain. The main idea behind this design, besides increasing the overall solar energy transmittance from the window, is that it should not be necessary to reduce the insulation thickness in the wall where the window is mounted (Schultz and Svendsen, 2000, and Schultz, 2002). A traditional and the new design are shown in 
Figure 6. For the new design the thermal bridge effects in the wall can be minimized or eliminated. The thermal bridge effect by the frame itself is also minimized. The inner and outer pane of the window has a hard coat low emissivity layer. Another advantage with this design is that it does not have a sealed glazing unit. This should increase the life time of the product (Schultz, 2002).

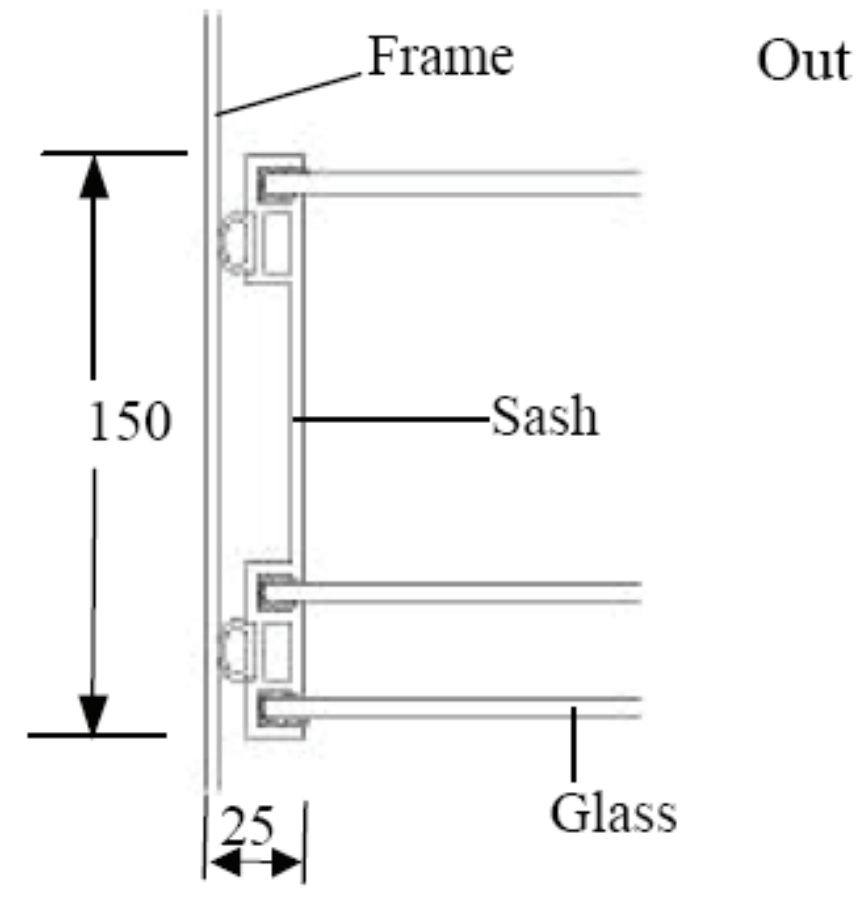

Figure 5. Frame profile made from fiber glass reinforced polyester with three layers of glass (Lautsen and Svendsen, 2005). The frame $U$-value is $1.33 \mathrm{~W} / \mathrm{m}^{2} \mathrm{~K}$.
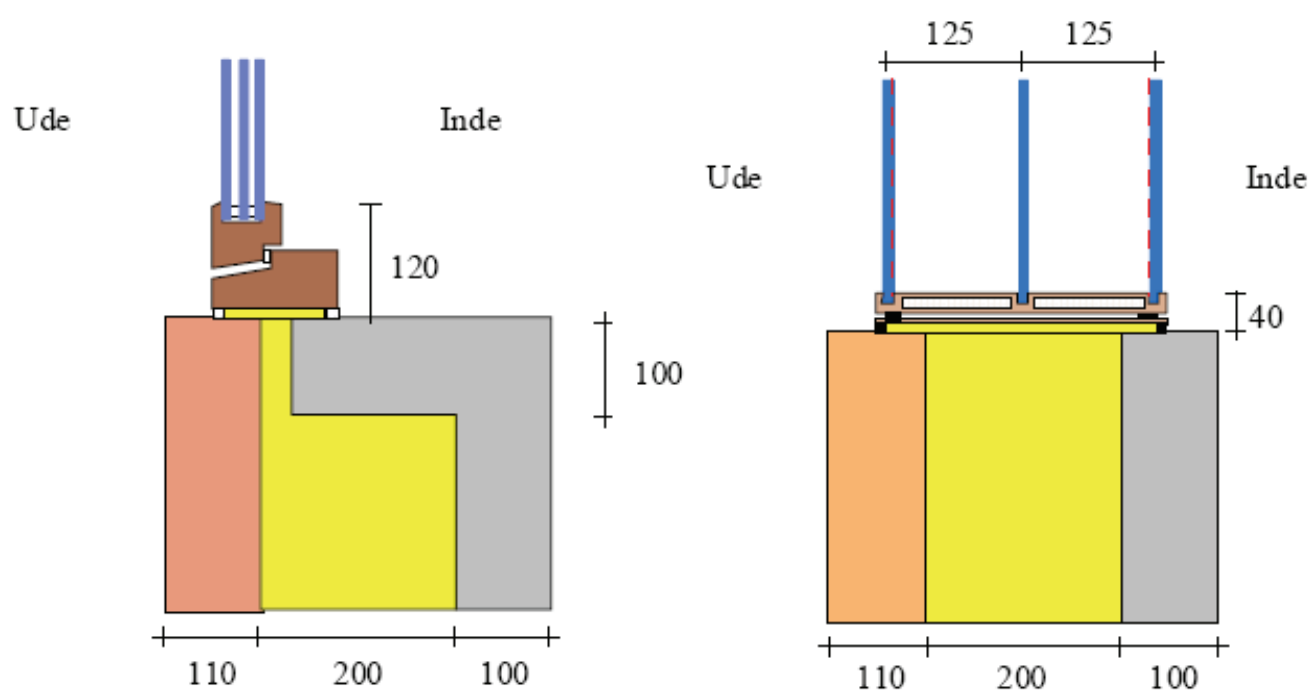

Figure 6. Traditional and new window designs illustrating how thermal bridges in the wall around the windows can be reduced by using a wide window. (Schultz, 2002). 
The window with the second largest net energy gain $\left(-2 \mathrm{kWh} / \mathrm{m}^{2}\right.$ for Danish climate) has a frame profile that is made of wood covered with aluminum, see Figure 7. The glazing has a double layer low energy glazing 4-15-4 mm with 90\% argon filling and a low-emissivity coating on the inner pane on the surface facing the gap. In order to achieve a high g-value the outer pane is made of float glass with low iron content. The spacer is made of plastic with a very thin stainless steel film. The height of the frame is reduced by about $5 \mathrm{~cm}$ compared to a traditional wood frames by moving the sash out in front of the outer frame. The glazing area is therefore increased by $15 \%$ compared to a similar window of wood where the frame width is $10 \mathrm{~cm}$ (window dimensions: $1.48 \times 1.23 \mathrm{~m}$ ). A large width is selected to reduce the thermal bridge between the window and the wall.

A Passivhouse window was also simulated. This frame gave a net energy gain slightly smaller (more heat loss) than the second best frame. This window had a U-value of $0.77 \mathrm{~W} / \mathrm{m}^{2} \mathrm{~K}$, with a frame having a U-value of $0.75 \mathrm{~W} / \mathrm{m}^{2} \mathrm{~K}$. This frame is shown in Figure 8.

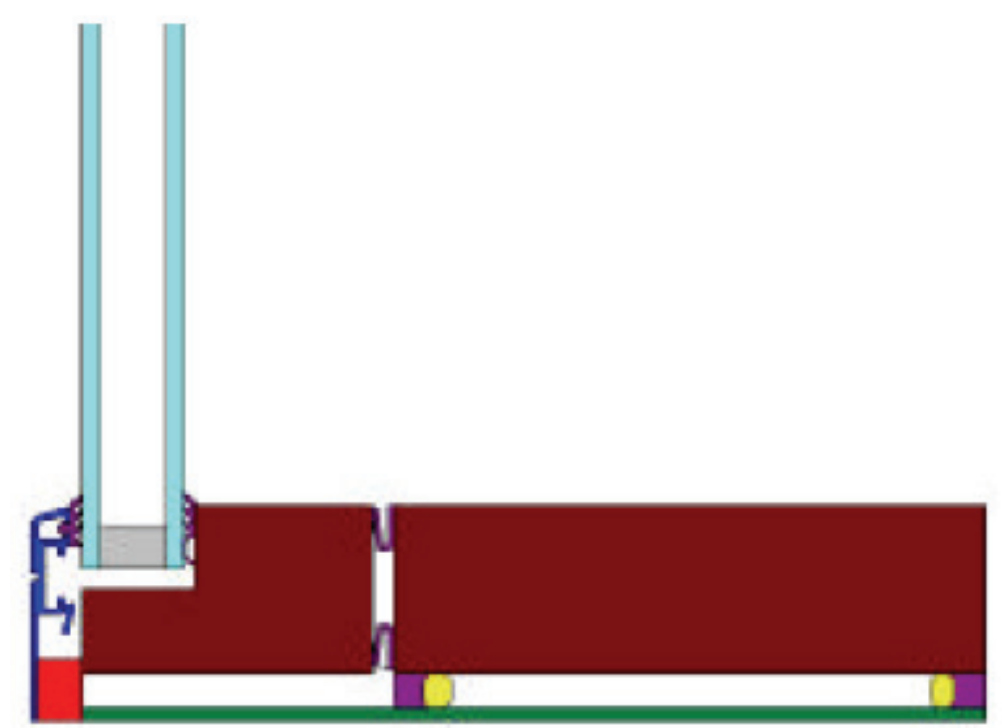

Figure 7. Slim frame profile $(5 \mathrm{~cm})$ made from wood covered with aluminum (Lautsen and Svendsen, 2005). The frame $U$-value is $1.33 \mathrm{~W} / \mathrm{m}^{2} \mathrm{~K}$. 


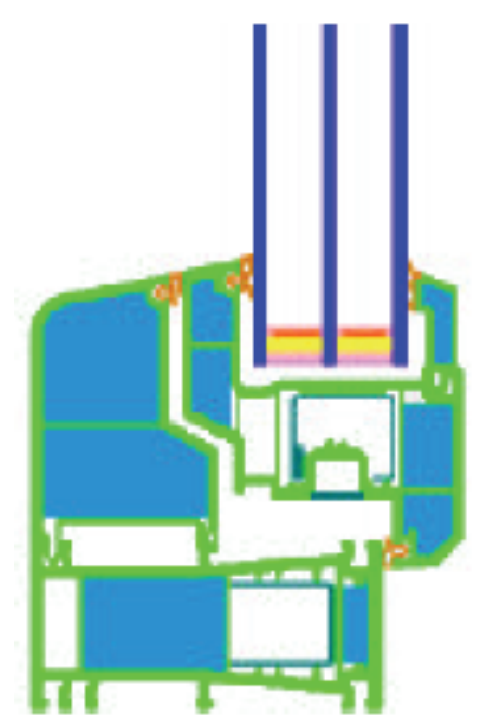

Figure 8. A window satisfying the PassivHaus requirements. The frame is made of a PVC frame profile with $P U$ foam in the cavities (Lautsen and Svendsen, 2005).

Some authors have also investigated the effect of frame geometry on new and emerging technologies, such as an electrochromic vacuum glazed window. Fang and Eames (2006) found that the frame rebate depth had a significant influence on the window U-value. Calculations of the thermal performance of a vacuum glazing (two glass panes) in a solid wood frame with rebate depths of 0 to $22.4 \mathrm{~mm}$ have been carried out (see Figure 9). The emissivity of the coatings on the two glass surfaces within the evacuated gap was 0.18 . Over the depth of rebates considered, the U-value of the total window area (glazing had a size of 0.4 by $0.4 \mathrm{~m}^{2}$ ) decreased from 1.4 to $0.83 \mathrm{~W} / \mathrm{m}^{2} \mathrm{~K}$. The U-value of the center glazing area decreased from 1.04 to $0.82 \mathrm{~W} / \mathrm{m}^{2} \mathrm{~K}$. The authors also examined the effect of rebate depth on an electrochromic vacuum glazed window. The construction was similar to the one shown in Figure 9 , but with the glass pane to the left replaced with an electrochromic glazing system. Thus, the total width of the entire glazing system was wider than for the vacuum window alone. For this construction the total window U-value decreased from 1.48 to $1.13 \mathrm{~W} / \mathrm{m}^{2} \mathrm{~K}$ when the rebate depth increased from 0 to $22.4 \mathrm{~mm}$. The center $\mathrm{U}$-value changed from 0.98 to $0.80 \mathrm{~W} / \mathrm{m}^{2} \mathrm{~K}$. 


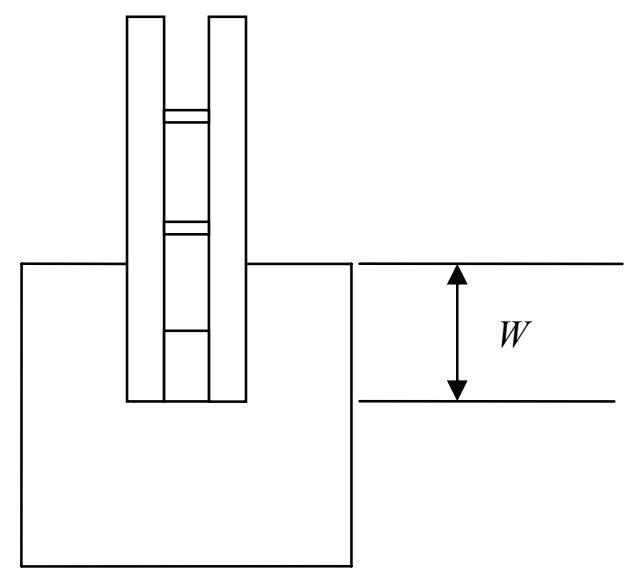

Figure 9. Schematic showing of a vacuum glazing with a wood frame. $W$ is the rebate depth. The size of the pillars separating the glass panes in the figure is not comparable to a real vacuum window.

\subsection{D and Other Effects on Thermal Performance}

Griffith et al. (1998b) and Carpenter and McGowan (1998) studied heat transfer in curtain-wall aluminum frames and focused on the effect of the bolts on the heat flow and the temperature distribution on the warm side surface of the specimens. Both studies conclude that it is important to include the bolts when the thermal performance of the frames is found. They also found that twodimensional program gives accurate results when appropriate calculation procedures are applied.

Hallé et al. 1998 studied the effect of air leakage on the heat transfer in window frames with internal cavities. They used computational fluid dynamic (CFD) techniques to simulate air leakage effects. The frame cavities were treated as solids. Two window frames (an aluminum frame with a PVC thermal break and a PVC frame) were examined with air leakage rates of 1.65 and $0.55 \mathrm{~m}^{3} / \mathrm{h}$ per meter crack length. For the infiltration case the authors found that the air-frame interaction caused the air to be preheated by the frame. This decreased the apparent thermal transmittance of the frame. For the exfiltration case, air increases the frame temperature, which increases heat losses and the apparent thermal transmittance of the frame.

\subsection{Heat Transfer Modeling of Window Frame Cavities}

A large part of the work related to heat transfer issues in fenestration cavities has focused on the glazing cavity. The goal has mostly been to develop accurate correlations for natural convection effects inside multiple pane windows (see e.g. Batchelor 1954, Eckert and Carlson 1961, Hollands et al. 1976, Raithby et al. 1977, Berkovsky and Polevikov, 1977, Yin et al. 1978, ElSherbiny et al. 1982a, Shewen et al. 1996, Wright 1996, or Zhao 1998). Most of these papers study natural convection between two high vertical isothermal walls separated by two horizontal adiabatic or 
perfectly conducting walls (a two-dimensional cavity). Some of these studies are also relevant for frame cavities. The natural convection correlation used to find the effective conductivity for certain frame cavities are from some of these studies.

Studies of heat transfer in multiple pane windows also include findings of which Rayleigh numbers there will be secondary (or multicellular) flow (see e.g. Korpela et al. 1982, Lee and Korpela 1983, Zhao et al. 1997, Lartigue et al. 2000). Secondary flow enhances heat transfer through glazing cavities, and may also take part in frame cavities of a certain shape, see Gustavsen and Thue (2007).

In solid window frames the heat flow is carried out by conduction, which can be simulated with standard conduction simulation software. In window frames with internal cavities the heat transfer process is more complex, involving combined conduction, convection and radiation. Ideally, to fully describe heat transfer through such window frames there is a need to simulate fluid flow to find the convection effects and to use either view-factors or ray-tracing techniques to find the radiation effects inside the cavities. But because of computational resources and the additional modeling efforts these simulations often require, such simulations still are rare. Instead air cavities are transformed into solid materials with an effective conductivity; that is, the conduction, convection and radiation effects are combined into an effective conductivity. Then, like for solid window frames without internal cavities, standard conduction simulation software can be used to find how well such sections insulate, or the Uvalue. Some computer packages (like e.g. Blomberg 2000, Enermodal 2001 or Finlayson et al. 1998) do find the effective conductivity automatically, by applying procedures specified in international standards (ISO 15099 or ISO 10077-2). In some computer programs it is also possible to use viewfactors to calculate the radiation heat transfer effects (Finlayson et al. 1998).

Some studies have been performed with focus on heat transfer effects in window frames, and with focus on window frames with internal cavities. Standaert (1984) studied the U-value of an aluminum frame with internal cavities. The cavities were treated as solids and effective conductivities were assigned to each cavity. The effective conductivities of cavities not completely surrounded by aluminum were calculated from a fixed thermal resistance of $R=0.37 \mathrm{~m}^{2} \mathrm{~K} / \mathrm{W}\left(\lambda_{e q}=L / R\right.$ where $\lambda_{e q}$ is the equivalent conductivity and $L$ is the length of the cavity in the heat flow direction). Cavities completely surrounded by aluminum were assigned an effective conductivity of $0.1 \mathrm{~W} / \mathrm{mK}$. The thermal transmittance of the frame studied was $5.9 \mathrm{~W} / \mathrm{m}^{2} \mathrm{~K}$. Jonsson (1985) and Carpenter and McGowan (1989) also treated air in window frame cavities as solids and used equivalent conductivities to calculate heat flow. In their studies the effective conductivity concept was formulated as, 


$$
\lambda_{e q}=\lambda_{\text {air }} \times N u+\frac{h_{R} \times L}{\left[1 / \varepsilon_{H}+1 / \varepsilon_{C}-1\right]}
$$

where $\lambda_{e q}$ is the equivalent conductivity, $\lambda_{\text {air }}$ is the conductivity of air, $N u$ is the Nusselt number, $L$ is the length of the air cavity, $\varepsilon_{H}$ and $\varepsilon_{C}$ and are the emissivities of the warm and cold sides of the cavity walls, respectively. $h_{R}$ is the black-body radiative heat transfer coefficient, which depends on temperatures of the interior walls of the cavity and also on cavity geometry. Jonsson (1985) used $h_{R}=$ $3.3 \mathrm{~W} / \mathrm{m}^{2} \mathrm{~K}$ for different cavity geometries while Carpenter and McGowan (1989) report different $h_{R}$ values, depending on cavity height to length aspect ratios. The frames studied by Carpenter and McGowan (1989) had U-values between 2.1 and $11.2 \mathrm{~W} / \mathrm{m}^{2} \mathrm{~K}$. The former value is for a wooden frame and the latter value for an aluminum frame. Jonsson (1985) examined windows with U-values between 2.79 and $4.23 \mathrm{~W} / \mathrm{m}^{2} \mathrm{~K}$.

Svendsen et al. (2000) and Noyé et al. (2001) examined the accuracy of the radiation procedures prescribed in EN ISO 10077-2 and found that using view-factors to account for radiation instead of the simplified correlation in EN ISO 10077-2, results in U-values that compare better with measured results. The natural convection correlations of EN ISO 10077-2 were used. Two frames were examined, one thermally broken aluminum frame and one frame made of PVC. Svendsen et al. (2000) found that division of air cavities also affects the U-value, but not as much as the change of radiation model.

Gustavsen (2001) studied heat transfer in window frames with internal cavities, and focused mainly on convections effects. Most of the results were published in papers and are reported below. Some results are however only available in the introduction part of the thesis; these will be reported here. Gustavsen (2001) compares the frame cavity convection correlations from various standards to relevant correlations found in the literature. He found that the Nusselt number correlations that are to be used for horizontal window frames according to ISO 15099 not necessarily is accurate for frame cavities with a height to length aspect ratio between 0.5 and 5, because ISO 15099 prescribes that interpolation have to be used for these geometries. (The correlation for cavities with an aspect ration smaller than 0.5 is based on analytical consideration, while the correlation for high aspect ratio cavities, $H / L>5$, is based on experiments for typical glazing enclosures.) For some geometries and Rayleigh numbers the correlation works but for others the correlation predicts Nusselt numbers that are not correct. Further, the author found that the convection correlation prescribed for frame cavities in ISO 10077-2 only is valid for vertical frame cavities. 
Gustavsen and coauthors have studied several aspect of heat transfer in window frames with internal cavities. In Gustavsen et al. (2001a), they used infrared thermography to verify that a CFD code was capable of simulating the natural convection effects taking place in window frames with internal cavities. In a follow-up study the authors (Gustavsen et al. 2001b) examined three-dimensional convection effects in simple window frames with internal cavities and concluded that it appears that the thermal transmittance (U-value) of a four-sided section sections (with one open internal cavity) can be found by calculating the area weighted average of the thermal transmittance of the respective single horizontal and vertical sections. However, precise surface temperature predictions require threedimensional simulations, especially for the corners of the frames (see Figure 10). In addition, the authors concluded that two-dimensional heat transfer simulation software agrees well with CFD simulations, with regard to heat transfer rates for the simple square-shaped frames simulated, if the natural convection correlations used for the internal cavities were correct.

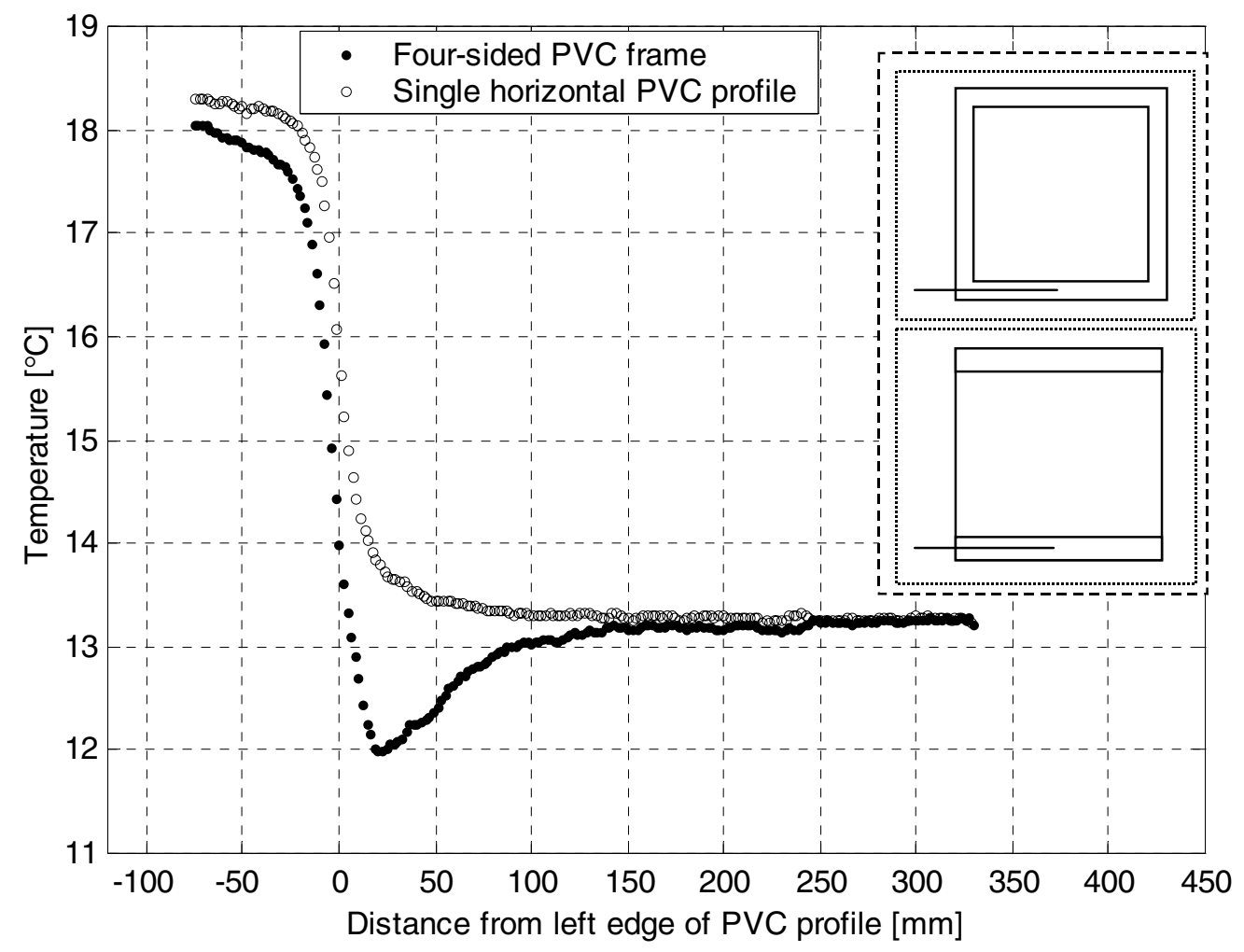

Figure 10. Temperatures along the left lower horizontal part of the four-sided two-inch PVC frame compared to the surface temperatures along the middle of the lowest two-inch profile in the configuration made up of two separate horizontal profiles (Gustavsen et al. 2001b).

Gustavsen et al. (2005) used computational fluid dynamics (CFD) modeling to assess the accuracy of the simplified frame cavity conduction/convection models presented in ISO 15099 and used in software for rating and labeling window products. Three (horizontal) representative complex cavity cross-section profiles with varying dimensions and aspect ratios were examined, see Figure 11. Stream 
contour plots, Figure 12, and heat transfer rates were presented. The results supported the ISO 15099 rule that complex cavities with small throats should be subdivided; however, the authors suggest that cavities with throats smaller than $7 \mathrm{~mm}$ should be subdivided, in contrast to the ISO 15099 rule, which places the break point at $5 \mathrm{~mm}$. Further, the authors found that the agreement between CFD modeling results and the results of the simplified models was moderate for the heat transfer rates through the cavities. This was explained by inaccuracies in the underlying ISO 15099 Nusselt number correlations being based on studies where cavity height/length aspect ratios were smaller than 0.5 and greater than 5 (with linear interpolation assumed in between).
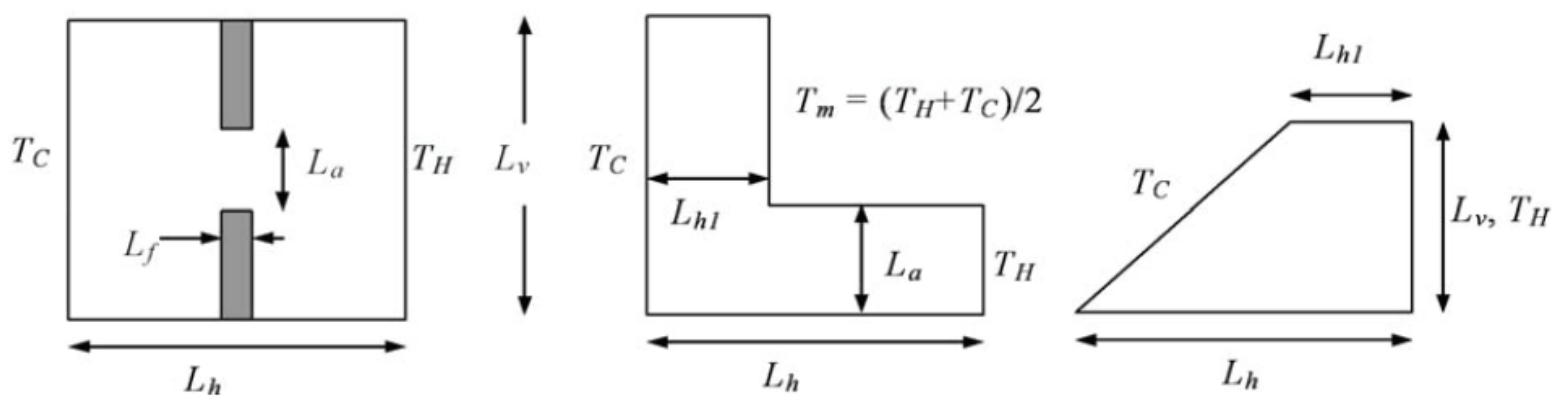

Figure 11. Schematics of cavities studied by Gustavsen et al. (2005). The height and the width of the two cavities to the left were $30 \mathrm{~mm}$. The right cavity had a width of $30 \mathrm{~mm}$ and the height was $10 \mathrm{~mm}$ and $20 \mathrm{~mm}$. $L_{a}$ was varied to between 0 and $30 \mathrm{~mm}$ for the cavity to the left and 3 and $15 \mathrm{~mm}$ for the cavity in the middle.

Gustavsen et al. (2007) used two-dimensional computational fluid dynamics (CFD) and conduction simulations to study heat transfer in horizontal window frames with internal cavities (the above mentioned paper studied only cavities). Temperatures and U-values for typical horizontal window frames with internal cavities are compared; results from CFD simulations with detailed radiation modeling are used as a reference. Four different frames were studied. Two were made of polyvinyl chloride (PVC) and two of aluminum. For each frame, six different simulations were performed, two with a CFD code and four with a building-component thermal-simulation tool using the Finite Element Method (FEM). The FEM tool addresses convection using correlations from ISO 15099; it addressed radiation with either correlations from ISO 15099 or with a detailed, view-factor-based radiation model. The practice of subdividing small frame cavities was examined, in some cases not subdividing, in some cases subdividing cavities with interconnections smaller than five $\mathrm{mm}$ (according to ISO 15099) and in some cases subdividing cavities with interconnections smaller than seven mm. For the various frames studied (two were made of aluminum and two of PVC), the calculated U-values were found to be quite comparable (the maximum difference between the reference CFD simulation and the other simulations was found to be 13.2 percent). A maximum difference of 8.5 percent was found between the CFD simulation and the FEM simulation using ISO 15099 procedures. The ISO 15099 correlation works best for frames with high U-factors. For more efficient frames, the relative 
differences among various simulations are larger. Finally, the effectiveness of the ISO cavity radiation algorithms was examined by comparing results from these algorithms to detailed radiation calculations (from both programs). The author conclude that improvements in cavity heat transfer calculations can be obtained by using detailed radiation modeling (i.e. view-factor or ray-tracing models), and that incorporation of these strategies may be more important for improving the accuracy of results than the use of CFD modeling for horizontal cavities. Figure 13 shows a stream contour plot for one of the PVC frames studied.

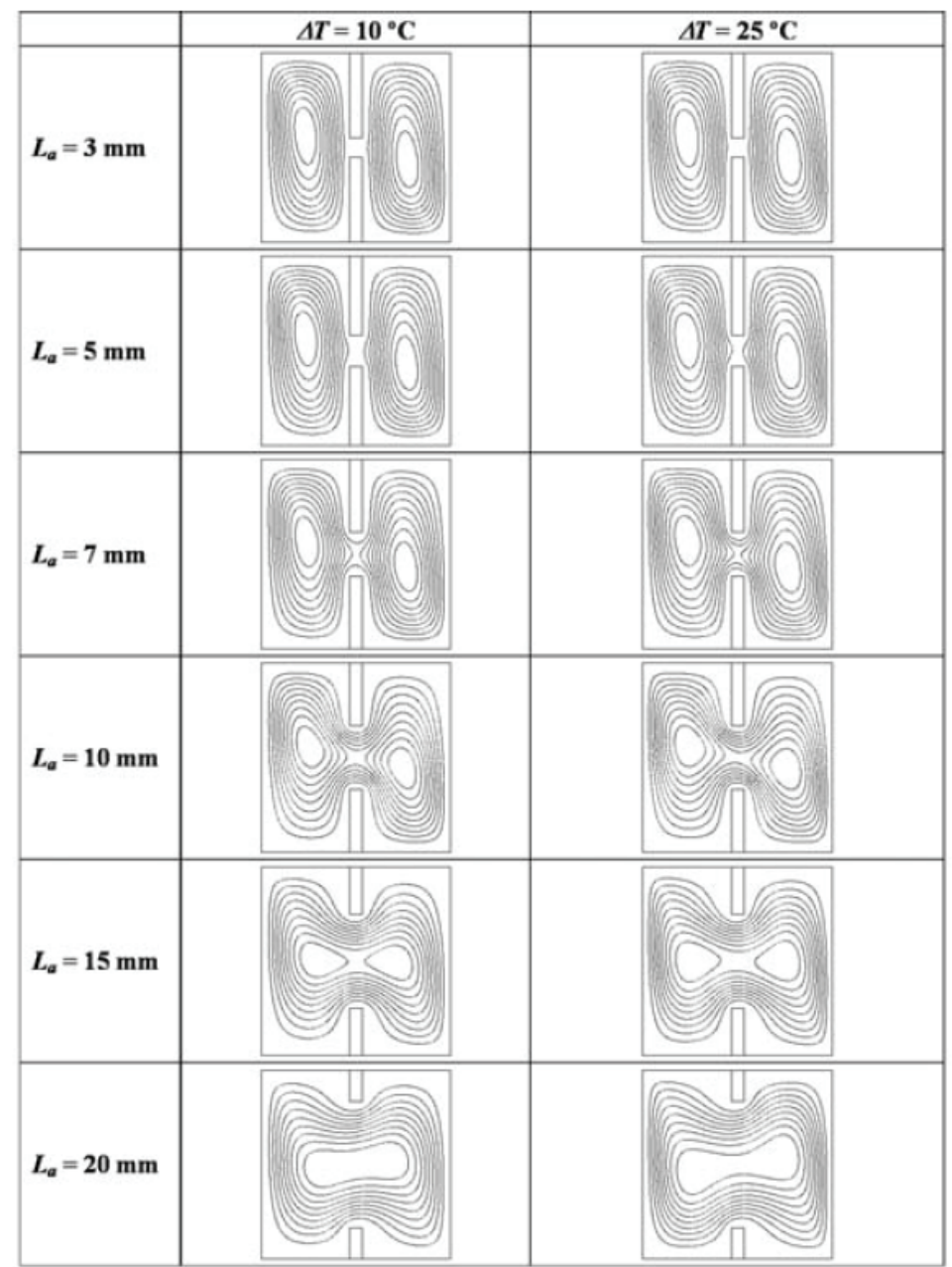

Figure 12. Stream contours for the cavity to the left in Figure 11 (named the $\mathrm{H}$-cavity). $\mathrm{L}_{a}$ is the size of the gap opening, and $\Delta T$ is the difference between the hot and cold wall temperatures, reported in ${ }^{\circ} \mathrm{C}$. 


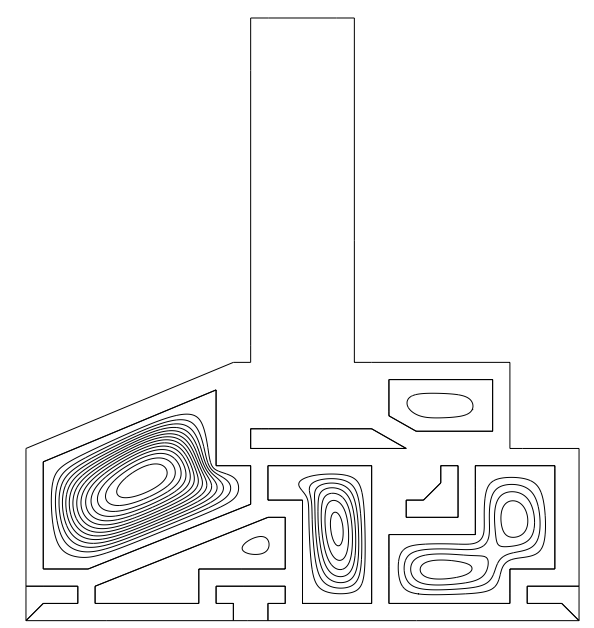

Figure 13. Stream contours for one of the PVC frames studied by Gustavsen et al. (2007).

Gustavsen and Thue (2007) used a commercial computational fluid dynamic program to study the effect of the horizontal aspect ratio $(W / L)$ on heat flow through three-dimensional cavities with a high vertical aspect ratio $(H / L)$. These are the kind of cavities that can be found in vertical window frames, see Figure 14. The cavities studied have two opposite isothermal vertical walls separated by four adiabatic walls. The vertical aspect ratios are 20,40, and 80 and the horizontal aspect ratios range from 0.2 to 5 . Simulations of two-dimensional cavities are also included. The simulations show that three-dimensional cavities with a horizontal aspect ratio larger than five can be considered as being two-dimensional cavities to within $4 \%$ when considering heat transfer rates. A complex flow was also found, for several of the cavities; one example is shown in Figure 15. Nusselt number correlations for the different horizontal aspect ratios are presented.
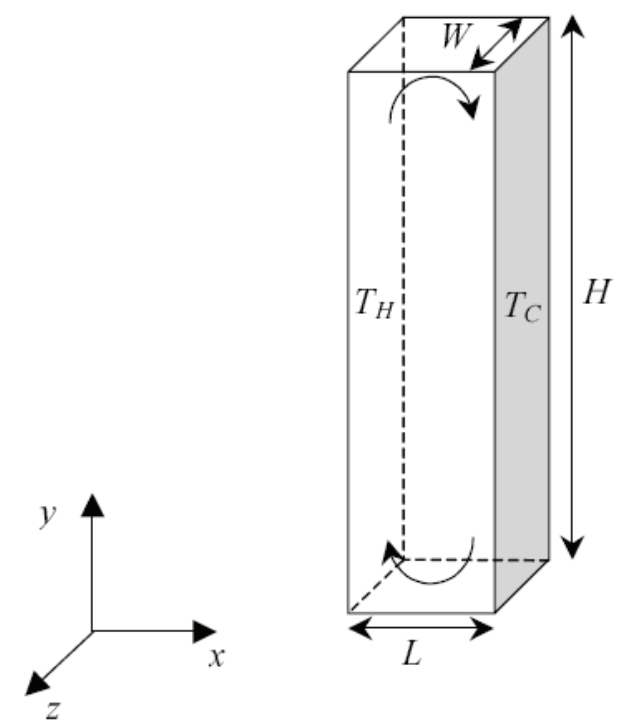

Figure 14. Geometry studied by Gustavsen and Thue (2007). The vertical aspect ratios, $H / L$, were 20, 40, and 80 and the horizontal aspect ratios, $W / L$, ranged from 0.2 to 5 . 

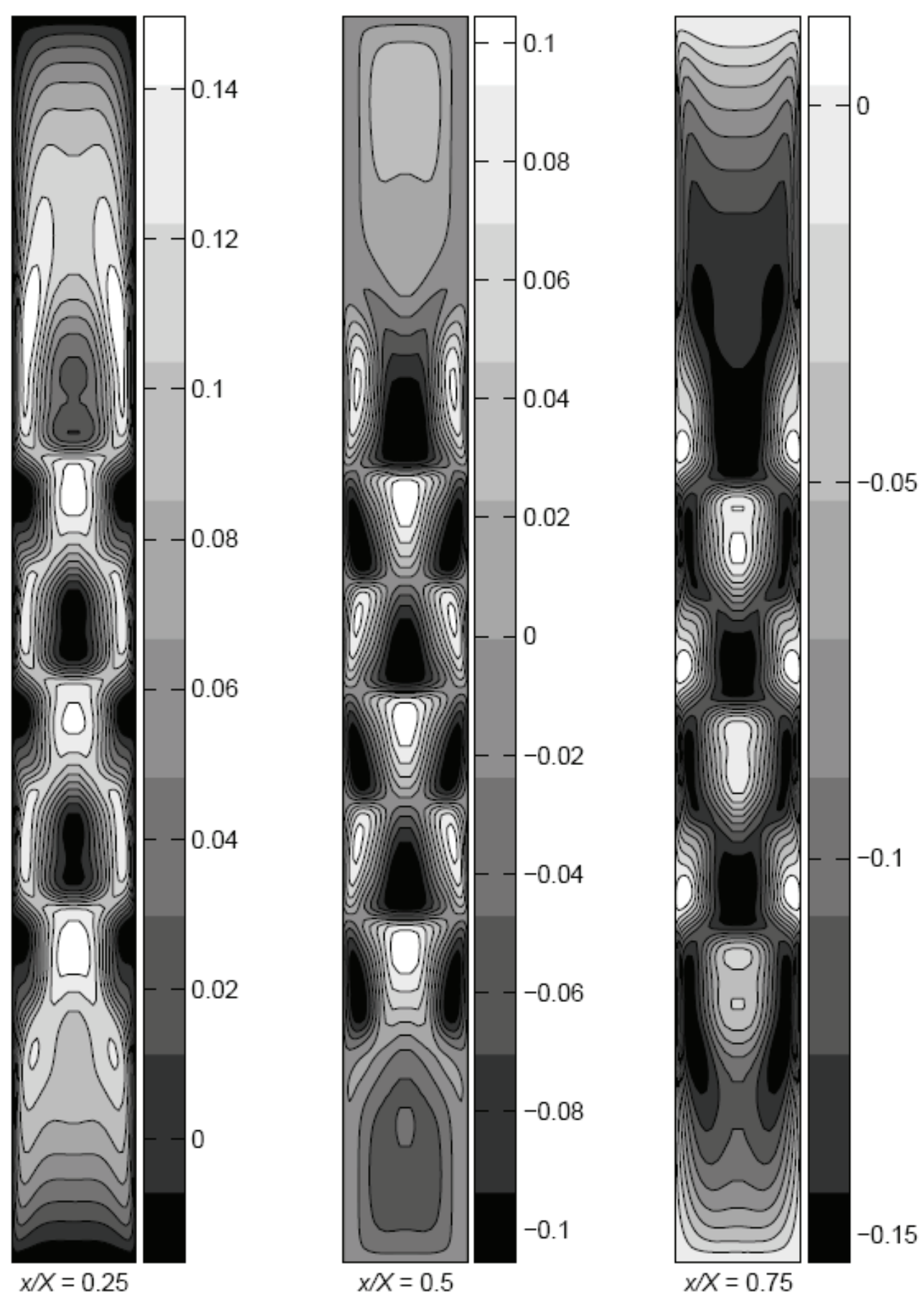

Figure 15. $y$-velocity contours $(\mathrm{m} / \mathrm{s})$ at different planes in a cavity where $(H / L, W / L)=(40,2)$. The Rayleigh number was equal to $2 \times 10^{4}$. Each plane is parallel to the $y$-z-plane in Figure 14. $X$ is the total length of the cavity. The $x$-vector is pointing into the page, the $y$-vector is pointing from bottom to top, and the $z$ vector is pointing from left to right. The figures are not in the correct scale (Gustavsen and Thue, 2007).

Fomichev and co-workers have also studied heat transfer effects in the kind of cavities that can be found in horizontal and vertical frame cavities (Fomichev et al. 2007). They used both experimental and numerical techniques (two- and three-dimensional CFD simulations) and studied the effect of the aspect ratios (horizontal and vertical) as well as tilt angle on the heat transfer rates. They concluded 
that two-dimensional modeling is appropriate to predict natural convection heat transfer in horizontal frame cavities (such as the ones found in frame head and sill) tilted around the long axis. They further concluded that three-dimensional simulations is needed to predict natural convection heat transfer in frame cavities tilted around the short axes, such as the ones found in vertical frame sections (jambs, and vertical meeting rail and mullion cross-sections). Fomichev et al. (2007) also note that the frame cavity correlation equations suggested by ISO 15099 for vertical frame cavities do not correlate well with their three-dimensional CFD simulation results. The authors suggest new correlations for both horizontal frame sections (vertical aspect ratios between 0.5 and 5) and vertical frame sections (vertical aspect ratios between 20 and 40, and horizontal aspect ratios between 0.5 and 2). The correlations depend on both Rayleigh number and tilt angle (in addition to the aspect ratios). Fomichev et al. (2007) in addition did some studies of the convection heat transfer effects for ventilated frame cavities.

\subsection{Exterior and Interior Surface Modeling}

When the thermal performance of fenestration products is found, through the calculation of the Uvalue, surface conditions (surface resistances) are among the properties. And like for modeling of internal frame cavities, these properties will pay a more important part for high performance frames than for frames with a poorer performance. Accurate treatment of the surface conditions is therefore important, to be able to accurately predict the thermal transmittance and also to distinguish between various designs with regard to obtaining desired glass/frame surface temperatures.

Curcija and Goss (1993) used a finite element method to study two-dimensional, laminar convection over an isothermal indoor fenestration surface (glazing/frame assembly). Results were reported for three typical configurations: glazing with no frame, a single-step frame and a double-step frame. The authors present local indoor surface convective heat transfer coefficient to be used in two- and threedimensional heat transfer analysis of fenestration systems (valid both for the glazing and the frame part of the product).

Carpenter and Elmahdy (1994) examined the thermal performance for four complex fenestration systems (flat glazed skylight, a domed skylight, a greenhouse window and a curtain wall) using computer simulation tools and guarded hot box testing. They found discrepancies of up to $16 \%$ between the simulated and measured cases, and explain the difference by uncertainties in the warm and cold side film coefficients and lower warm-side air temperatures because of stagnant airflow. They also found that that the thermal simulations must account for thermal bridges like bolts in curtain walls and curbs in skylights. 
In 1994 Curcija and Goss investigated three different ways of modeling heat transfer boundary conditions for complete (two-dimensional) fenestration systems (with wood frame). A computation fluid dynamics (CFD) program was used in order to allow for fluid flow in the glazing cavity. Two of the surface models incorporated fixed indoor and outdoor coefficients and one incorporated variable (position dependent) coefficients. Component and overall U-factors were compared. The authors found that the U-values from using variable boundary conditions generally were lower than the ones calculated using constant surface heat transfer coefficients. The average difference was approximately $15 \%$. Curcija and Goss (1994) further noted that the effects of variable boundary conditions, which more accurately model local heat transfer on the indoor and outdoor fenestration surfaces, create "insulated" zones in the vicinity of the edge-of-glass region, which can significantly change the local heat transfer and temperature distribution when compared to constant-boundary-condition situations. This effect of lower heat transfer in these "insulated" zones could be used in the design process, so that altering the frame design on either side of the frame could create more pronounced outdoor insulated zones and less pronounced indoor insulated zones, therefore improving the condensation resistance of the fenestration system. The results also showed that the edge-of-glass area used when simulating frame and edge of glass (with spacer) should not be defined as $63.5 \mathrm{~mm}$ (2.5 in) from the sight line, since $102 \mathrm{~mm}$ (4 in) is a more realistic measure.

In 1998 Griffith et al (1998a) and Arasteh et al (1998) examined how improved radiation modeling (using view-factor models instead of fix coefficients) could improve the prediction of surface temperatures when modeling projecting fenestration products. Griffith et al (1998a) found that using view-factor modeling could improve the accuracy of the models for predicting surface temperature and lower the results for U-values for projecting windows (skylights, greenhouse windows).

Branchaud and co-workers examined the local heat transfer taking place in open frame cavities (open to the exterior environment) in 1998. The study shows that there can be a significant variation of the local convective heat transfer coefficient on the outdoor surface of a fenestration system. The variation is mainly a result of the products geometry. Based on the CFD simulations carried out, the authors find that significant convective heat transfer effects extend only up to one times the width of the cavity opening, for the cavities studied.

Schrey et al. (1998) studied the local heat transfer coefficient for two flush-mounted glazing units. One of the glazings had a foam spacer while the other one had an aluminum spacer. No window frame was included in the studies. Wright and Sullivan (1994) used a two-dimensional CFD code to study the natural convection effects in a vertical rectangular window cavity, but did not consider frame heat transfer. Secondary flow was also reported. 


\subsection{Spacer Research}

The glazing spacer and the location of the spacer in the frame may influence the thermal performance of the window, as seen in some of the reported work above. We therefore also include the result from some papers related to spacer research, although the focus in this report is on the window frame.

Elmahdy and Frank (1993) studied the effect of various spacers on the surface temperature of double pane glazings, without frame. Hot box measurements and finite-difference modeling were performed. Four different spacers were considered: Aluminum spacer, silicone foam spacer, a corrugated metal spacer and a thermally broken metal spacer. As expected, as the thermal resistance of the spacer bar increases, the glass surface temperature on the warm side of the spacer bar increases and the glass surface temperature on the cold side decreases. They also modeled the various glazing/spacer configurations inserted in a simple wood sash, and found that the difference in the glass surface temperatures between the various configurations was smaller as a result of the added sash. Elmahdy and Frank (1993) expect the differences to get even smaller for thicker frame profiles.

Löffler (1997) and Löffler and Buck, (1997) presents foamglass as a possible spacer material, and investigates the possibility for windows without a frame. The authors claim windows without a frame will have a transparent area which is 10 to $15 \mathrm{~cm}$ larger at each edge. This will increase the solar gain and at the same time reduce the heat loss from window (if the frame has a lower heat resistance than the glazing).

Elmahdy (2003) describes several different spacer types, see Figure 16, and examines the thermal performance of various spacers by experiments. The spacers were mounted between two clear glass panes, and with air in the glazing cavity. The size of the specimens was $152 \mathrm{~mm}$ by $1200 \mathrm{~mm}$. The specimens were tested without and with frames.

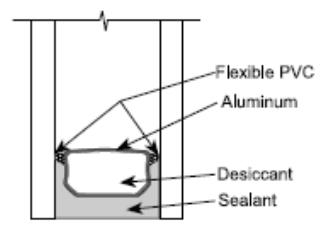

IG1

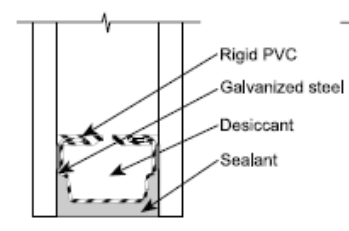

IG6

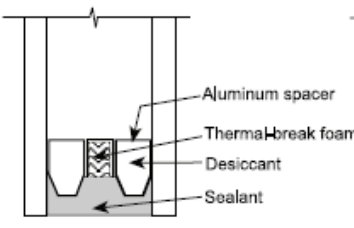

IG2

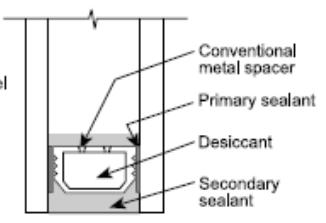

IG7

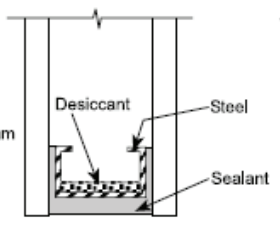

IG3

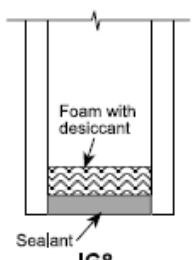

IG8

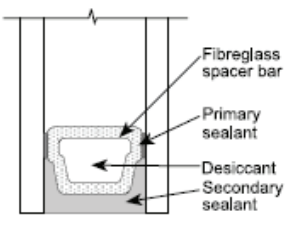

IG4

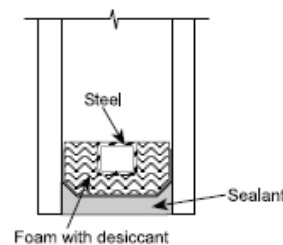

IG5

Figure 16. Spacer bar assemblies studied by Elmahdy (2003). 
By examining warm-side glass surface temperature of the various glazing units, Elmahdy (2003) found that IG8 had the highest temperature. Units IG 4 and IG9, which almost experienced the same temperatures, had the second highest temperatures. Thus, these units are therefore best suited for reducing warm-side surface condensation. Unit IG7 had the lowest surface temperature while unit IG5 had the second lowest temperature. The temperature difference between the best and the poorestperforming units was $6 \mathrm{~K}$. The temperatures on the warm and cold sides of the specimens were 21 and $-18{ }^{\circ} \mathrm{C}$, respectively. The experiments showed that the warm-side surface temperature for all specimens were almost the same when moving away from the edge-of-glass region (about $60 \mathrm{~mm}$ from the spacer). Glazing units $(1000 \mathrm{~mm}$ by $1000 \mathrm{~mm})$ were also tested as part of a complete window. The frames were made of various materials (redwood, vinyl, thermally broken aluminum and foam-filled fiberglass). The foam-filled fiberglass frame combined with glazing unit IG8 offered the warmest glass surface temperature (measured $10 \mathrm{~mm}$ from the lower sight line). The thermal resistance of each configuration (glazing/spacer/frame) was also tested, and it was found that the wood frame windows performed the best, regardless of spacer configuration. The only exceptions were for spacer bars IG4 and IG6, for which the thermal resistance values for the vinyl frame and the wood frame performed almost the same.

\subsection{Evaluation of Condensation Risk}

Several studies have been performed on evaluation of condensation risk in fenestration products. But, for high-performance products internal condensation should not be a problem. On the other side, external condensation may be a problem for the exterior pane of the glazing system. Still this is a problem for the glazing and not for opaque frames. This topic is therefore not covered in more detail here. Interested readers may are referred to e.g. Moshfegh et al. (1989), Carpenter and Hanam (2001), and Kohler et al. (2003).

\subsection{Other Topics (Material Properties, etc)}

In this chapter we present research that could not be sorted under the headings above. Most of the data are related to the material properties of typical and unusual frame materials.

Erten et al. (1996) investigated reinforced mosaic door and window frames as an alternative to wood frames to be used mainly in housing in the Eastern Black Sea region. These frames have been applied increasingly by the regional people in their houses. The paper deals with the production, application, details and failures of reinforced mosaic frames, but does not address the thermal properties of the frames, which probably is rather poor.

Jakubowicz and Möller (1992) examined a PVC window frame that had been naturally aged for 20 years. One of the main findings was that the heaviest degradation, detectable by IR spectroscopy, had 
occurred in a relatively thin surface layer of about $100 \mu \mathrm{m}$. The surface degradation effects were also confirmed by impact strength measurements. Still, after removing the surface layer the impact strength was rather low compared with expected values for undegraded PVC. They therefore concluded that some kind of degradation also had occurred in the bulk material. Still, the PVC frame investigated would probably fulfill the requirements for approval according to most national standards.

Gustavsen and Berdahl (2003) studied the normal spectral emissivity of an anodized aluminum window frame profile, and an untreated aluminum profile. The normal spectral emissivity was measured in the wavelength interval from 4.5 to $40 \mu \mathrm{m}$ (wavenumbers $2222 \mathrm{~cm}^{-1}$ to $250 \mathrm{~cm}^{-1}$ ). Total emissivity values were also reported. Specimens were cut from the edge and from the middle of the six-meter long anodized aluminum profile. Specimens facing the internal cavities (thermal break cavity and all aluminum cavity) were measured. The authors found that the normal total emissivity is fairly constant (between 0.834 and 0.856 ) for exterior parts of the anodized profile and for surfaces facing the thermal break cavity. The normal total emissivity of the all-aluminum internal cavities was found to vary between 0.055 and 0.82 , with the smallest value close to the middle of the profile.

Larsson et al. (1999) studied a super insulated window experimentally and numerically. The test was performed in steady state. A three pane glazing and wood frame was investigated. Fluid flow was simulated inside the internal cavities of the glazing while fixed film coefficients were used for the boundaries. A special test room was used for the experimental part of the work. The authors compared measured and calculated temperatures, and found good agreement between numerical and experimental results. 


\section{Market Review of Window Frames}

Highly thermal insulating window frames found in the market are presented, where the U-values for the frames are given $\left(U_{f}\right)$. The $\mathrm{U}_{\mathrm{f}}$-values are calculated according to Eq. (6); that is, an insulation panel is used instead of the actual glazing system, according to ISO 10077-2. The frame configurations with the various materials used are given together with some drawings, photos and temperature profiles. In addition, some other properties are given, e.g. window glazing $\mathrm{U}$-value $\left(U_{g}\right)$, total window $\mathrm{U}$-value $\left(U_{w}\right)$, linear thermal transmittance $(\Psi)$, window glass pane spacer used and physical dimensions $(\mathrm{w} \times \mathrm{h})$. This report gives a selection of the window frames found. The Appendix contains a more complete list.

In this report the authors wanted to collect and present the best window frames available, with their respective frame U-value. In the search for such frames the authors quickly found out that some of the best available frames on the market were the ones presented and rated by the Passivhaus Institute in Germany. To fulfill the Passivhaus requirements the window frames need to have $U_{f}$ values (window frame) so that $U_{w} \leq 0.80 \mathrm{~W} / \mathrm{m}^{2} \mathrm{~K}$ (window as a whole) (see Chapter 2.3). Since the frames complying with the Passivhaus Institute requirement seem to be the best ones out there (when the U-value is used as rating parameter), it was decided to focus on these frames. That is; in order for a window frame to be of interest, it had to comply with the requirement of the Passivhaus Institute. Most of the frames presented below and in the appendix are therefore rated by the Passivhaus Institute, and/or comply by their requirements. However, an extensive separate web-search was also performed, aiming at finding window frames with a low $U$-value. However, this search did not result in very many frames different from the frames rated by the Passivhaus Institute. A problem with some of the frames found was a lacking frame U-value. Sometimes the total window U-value was presented, but not always. The authors decided to present only frames with a known U-value. Some exceptions were however allowed, in order to allow for some frames made of a specific material or frames having a specific geometry.

Because of the above, and because the search was performed through Internet search engines with English and German search terms, the list will not be a complete one, including all window frames complying by the above mentioned criteria. However, the authors expect that the list presented in the Appendix, and the examples below, include most of the materials used, and give an overview over some of the best window frames (lowest $\mathrm{U}_{\mathrm{f}}$-value) available.

\subsection{Various Window Frame Examples}

Various window frame examples are given, where the main focus is to achieve as high thermal insulation properties (U-value) as possible. Both traditional window frame/casing systems and glass 
facade systems are shown. For simplicity reasons the various window frames are (at this stage) divided into the following groups:

- Wood frame

- Wood frame with insulation filled Al cladding

- $\quad$ PVC frame

- $\quad$ PVC frame with insulation filled Al cladding

- $\mathrm{Al}$ frame

- Fixed wood and $\mathrm{Al}$ frame

- Glass facade system

- Window frame examples with higher $U$ values than the Passivhaus requirement

The above frame subdivisions are made according to the structural load carrying element for the opening windows. In addition, a fixed frame group and a glass facade system group are also specified. With the wood, PVC, $\mathrm{Al}$ and wood/Al window groups it is implicitly meant (without stating it) that these frames incorporates larger volumes of a highly thermal insulating material (or several) in order to obtain a window $\mathrm{U}$-value below $0.80 \mathrm{~W} / \mathrm{m}^{2} \mathrm{~K}$, which is the requirement for a Passivhaus window. Normal window frames consisting of only wood, $\mathrm{PVC}, \mathrm{Al}$ or wood/Al, and thereby with higher frame $\mathrm{U}_{\mathrm{f}}$-values resulting in window $\mathrm{U}_{\mathrm{w}}$-values larger than $0.80 \mathrm{~W} / \mathrm{m}^{2} \mathrm{~K}$, are not dealt with in this context. As Al claddings may or may not be thermal insulated, and managing the Passivhaus requirement, it is added one wood and one PVC window frame group with insulation filled Al claddings.

\subsubsection{Wood Frame}

Examples of three wood window frames are given in Figure 17-Figure 19, where further details may be found in appendix. In these examples PUR is applied as a highly thermally insulating material inside the structural wood frame construction. Typically, as is also the case in these examples, the PUR elements are placed more or less in the middle of the frame. 

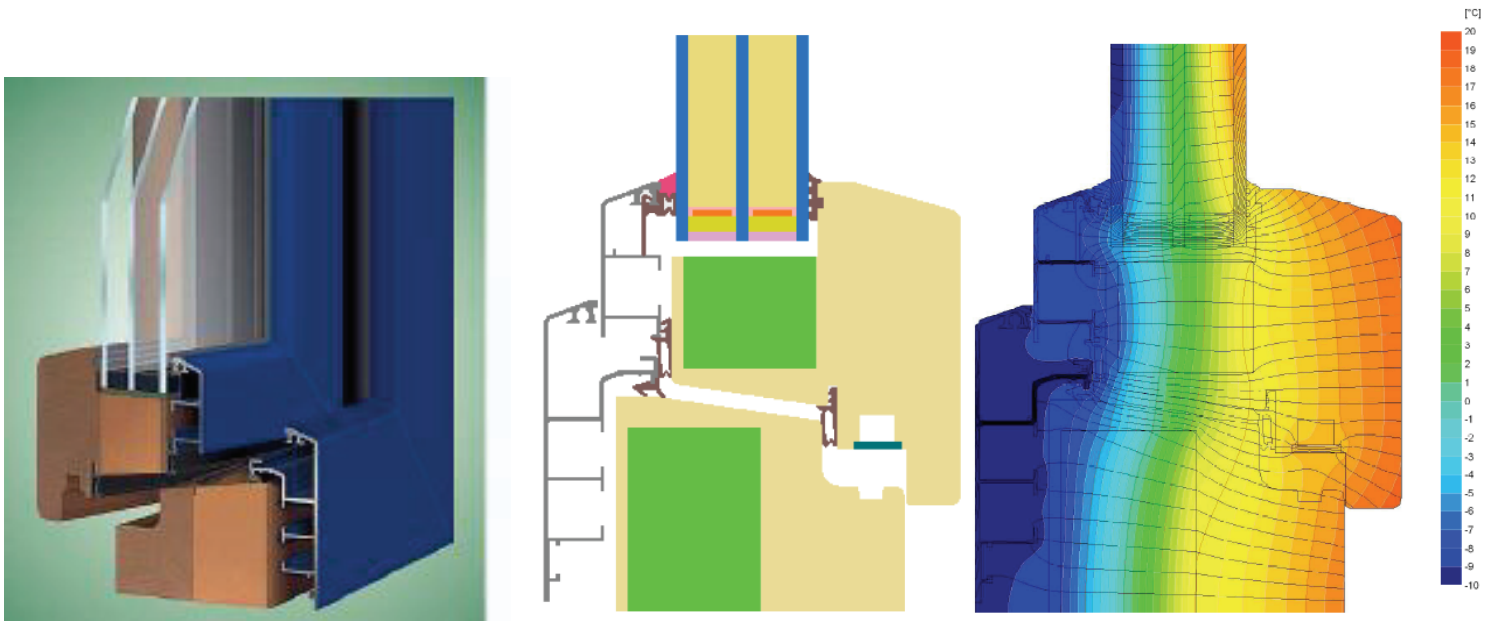

Figure 17. Example of a wood window frame with low U-value - Super-Warmfenster U 07 Serie HF 8120 by HEUSER Türen + Fenster-Metalbau GmbH. One photo to the left, one schematic drawing in the middle and one temperature profile to the right. Wood frame with PUR. Frame U-value $U_{f}=0.65 \mathrm{~W} / \mathrm{m}^{2} \mathrm{~K}$. From http://www.passiv.de and www.heuser-tueren-fenster.de.
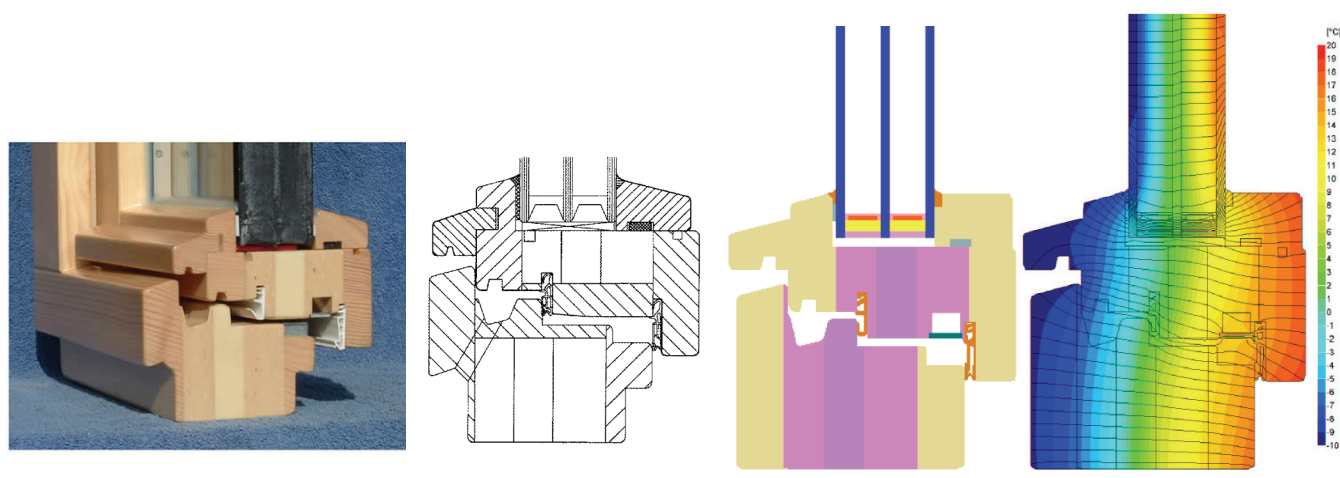

Figure 18. Example of a wood window frame with low U-value - VÖRDE-Passivhausfenster by H. Buck GmbH Fenster und Türen. Photos with corresponding drawing to the left, thereafter one schematic drawing and one temperature profile to the right. Wood frame with PUR and PUR recycled material (purenit). Frame $U$-value $U_{f}=0.72 \mathrm{~W} / \mathrm{m}^{2} \mathrm{~K}$. This frame may be bought with and without Al cladding. From http://www.passiv.de and www.fenster-buck.de.

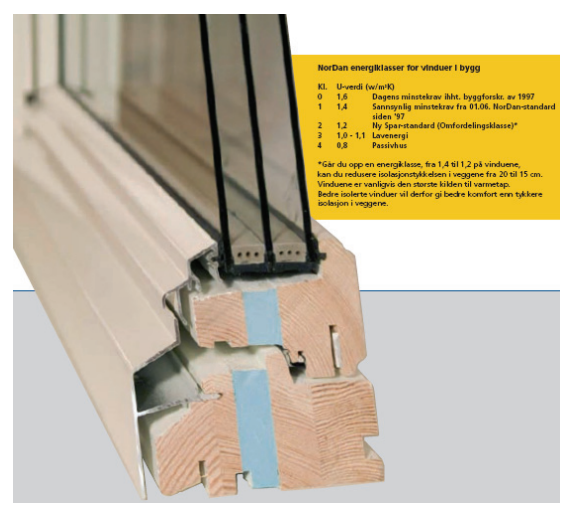

Figure 19. Example of a wood window frame with low $U$ value - N Tech Passiv Superspacer by NorDan AS. Wood frame with PUR. The frame U-value is not stated, whereas the total window U-value is reported to be $U_{w}=0.7 \mathrm{~W} / \mathrm{m}^{2} \mathrm{~K}$. From http://www.nordan.no. 


\subsubsection{Wood Frame with Insulation Filled Al Cladding}

Examples of three wood window frames with insulation filled Al claddings are given in Figure 20-Figure 22, where further details may be found in appendix. In these examples PUR is applied as a highly thermally insulating material inside the structural wood frame construction and in the $\mathrm{Al}$ claddings. In addition, as seen for the frame in Figure 21, XPS may also be utilized. Typically, as is also the case in these examples, the PUR elements are placed more or less in the middle of the frame.

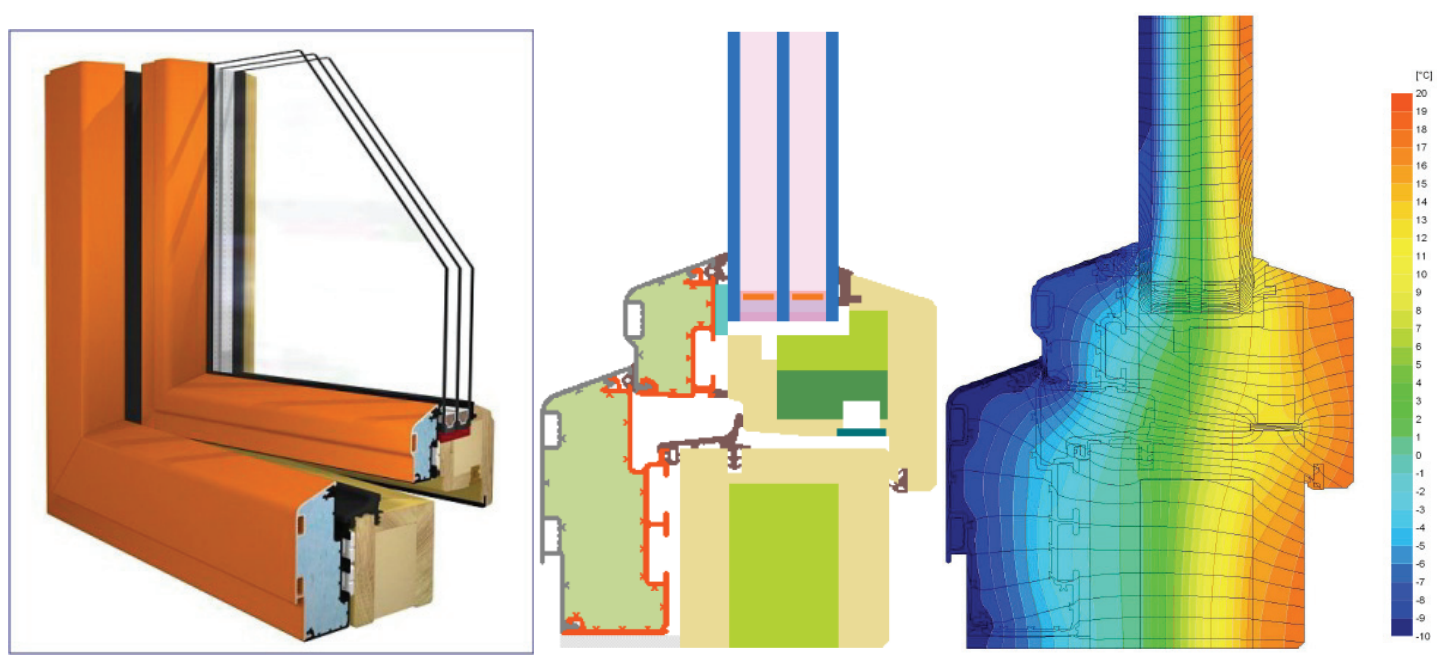

Figure 20. Example of a wood window frame with insulation filled Al cladding with low U-value - EGE-THERM PLUS by EGE Holzbau GmbH \& Co. KG. One photo/drawing to the left, one schematic drawing in the middle and one temperature profile to the right. Wood frame with PUR, PUR recycled material and PUR filled Al cladding. Frame U-value $U_{f}=0.77 \mathrm{~W} / \mathrm{m}^{2} \mathrm{~K}$. From http://www.passiv.de and www.ege.de.
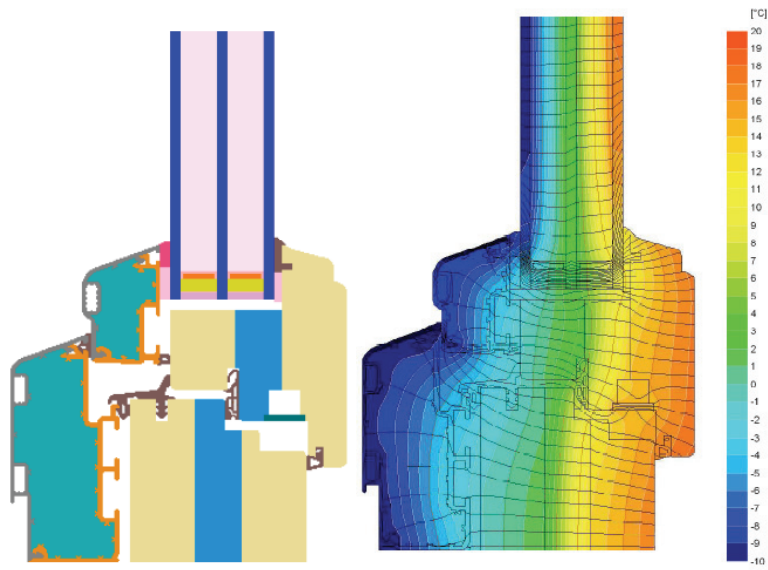

Figure 21. Example of a wood window frame with insulation filled Al cladding with low U-value - KombiRoyal Plus $\mathrm{PH}$ by NIVEAU Fenster Westerburg $\mathrm{GmbH}$. One schematic drawing to the left and one temperature profile to the right. Wood frame with PUR and XPS filled Al cladding. Frame U-value $U_{f}=0.68 W / \mathrm{m}^{2} \mathrm{~K}$. From http://www.passiv.de and www.niveau.de. 

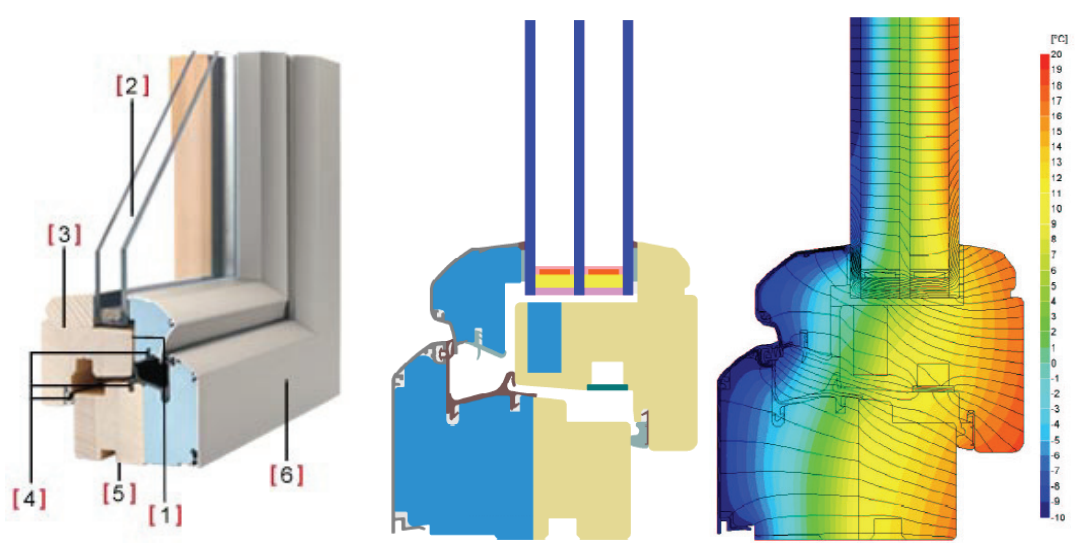

Figure 22. Example of a wood window frame with insulation filled Al cladding with low U-value - ed[it]ion passiv by Internorm International $\mathrm{GmbH}$. One photo/drawing to the left, one schematic drawing in the middle and one temperature profile to the right. Wood frame with PUR and PUR filled Al cladding. Frame $U$-value $U_{f}=0.73 \mathrm{~W} / \mathrm{m}^{2} \mathrm{~K}$. Compare with fixed window in Figure 27. From http://www.passiv.de and www.internorm.com.

\subsubsection{PVC Frame}

Examples of two PVC window frames are given in Figure 23-Figure 24, where further details may be found in appendix. In these two examples PUR is applied as a highly thermally insulating material inside the structural PVC frame construction. The placement of the PUR elements are varying from the frame edges to the middle of the frame.
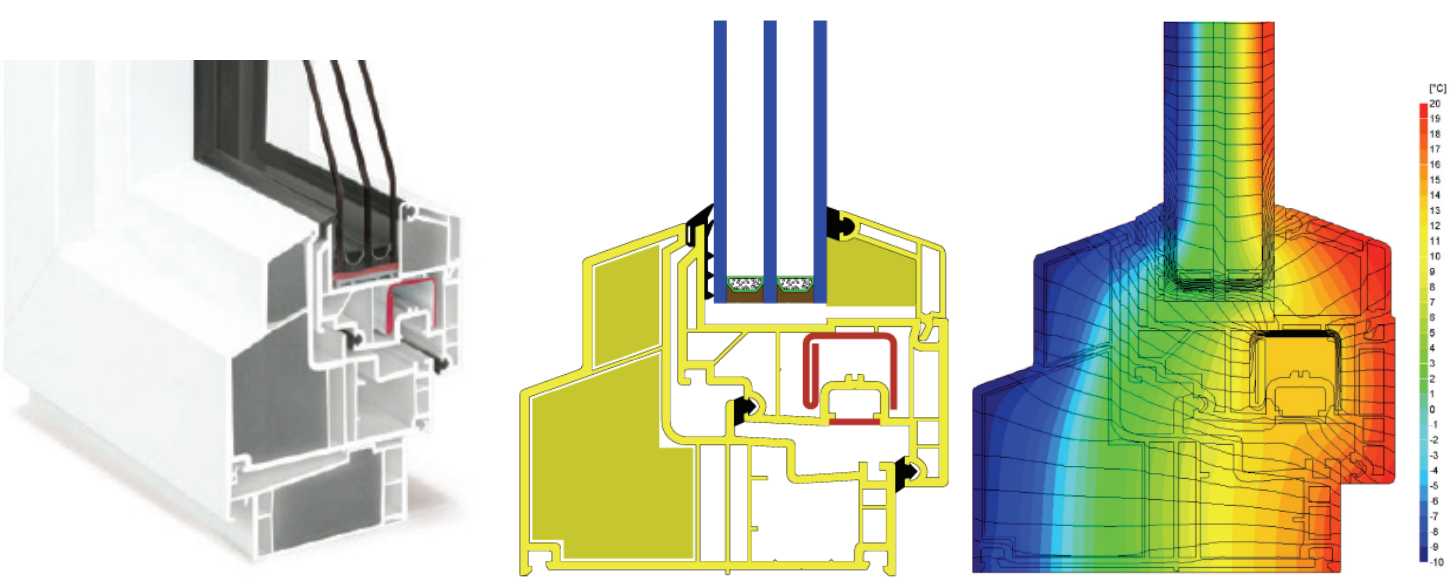

Figure 23. Example of a PVC window frame with low U-value - REHAU Clima Design by REHAU AG + Co, Hochbau. One photo/drawing to the left, one schematic drawing in the middle and one temperature profile to the right. PVC profile with PUR. Frame U-value $U_{f}=0.71 \mathrm{~W} / \mathrm{m}^{2} \mathrm{~K}$. From http://www.passiv.de and www.rehau.de. 

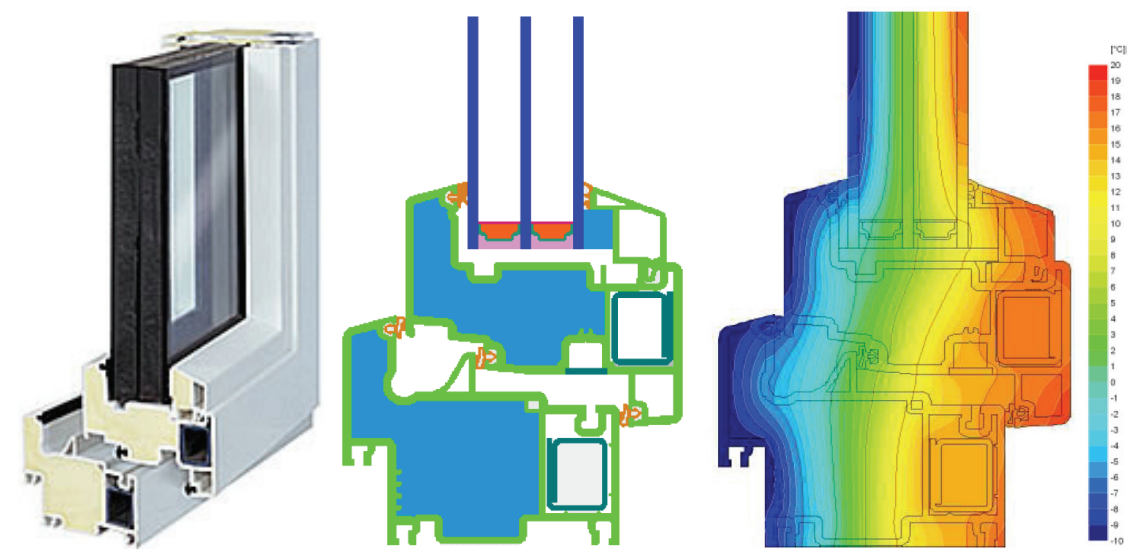

Figure 24. Example of a PVC window frame with low $\mathrm{U}$-value $-\mathrm{eCO}_{2}$ by Kochs $\mathrm{GmbH}$. One photo/drawing to the left, one schematic drawing in the middle and one temperature profile to the right. PVC profile with PUR $(\lambda=0.030 \mathrm{~W} /(\mathrm{mK}))$. Frame U-value $U_{f}=0.74 \mathrm{~W} / \mathrm{m}^{2} \mathrm{~K}$. From http://www.passiv.de and www.kochs.de.

\subsubsection{PVC Frame with Insulation Filled Al Cladding}

Example of one PVC window frame with insulation filled Al cladding is given in Figure 25, where further details may be found in appendix. In this example PUR is applied as a highly thermally insulating material inside the Al cladding, while there is no insulation material inside the PVC frame.
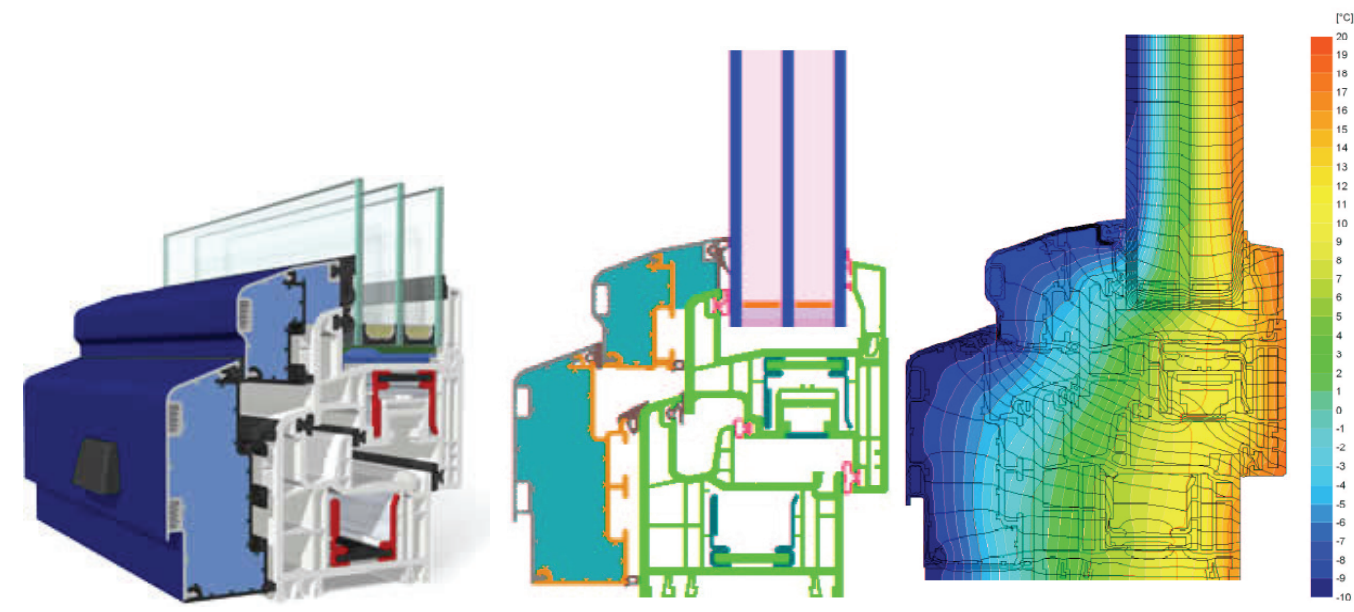

Figure 25. Example of a PVC window frame with insulation filled Al cladding with low U-value - GEALAN S 7000 IQ Passivhaus by GEALAN WERK Fickenscher $\mathrm{GmbH}$. One drawing to the left, one schematic drawing in the middle and one temperature profile to the right. PUR filled Al cladding. Frame U-value $U_{f}=0.82 W / m^{2} K$. From http://www.passiv.de and www.gealan.de.

\subsubsection{Al Frame}

Example of one Al window frame is given in Figure 26, where further details may be found in appendix. In this example PUR is applied as a highly thermally insulating material inside the structural $\mathrm{Al}$ frame construction. The whole Al profile is filled with the PUR elements. 


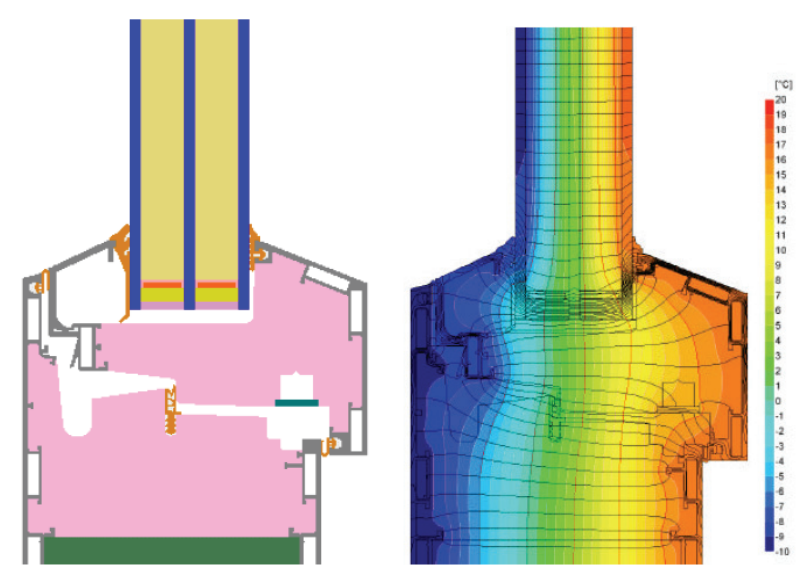

Figure 26. Example of an Al window frame with low U-value - RP-ISO-PURAL BP by Pural Profilwerk GmbH \& Co. KG. One schematic drawing to the left and one temperature profile to the right. Al frame filled with PUR. Frame U-value $U_{f}=0.71 \mathrm{~W} / \mathrm{m}^{2} \mathrm{~K}$. From http://www.passiv.de and www.pural-profile.de.

\subsubsection{Fixed Wood and Al Frame}

Example of one fixed wood and $\mathrm{Al}$ window frame is given in Figure 27, where further details may be found in appendix. In this example PUR is applied as a highly thermally insulating material inside the structural wood and Al frame construction. About half of the frame, towards the outer side, is filled with the PUR elements.
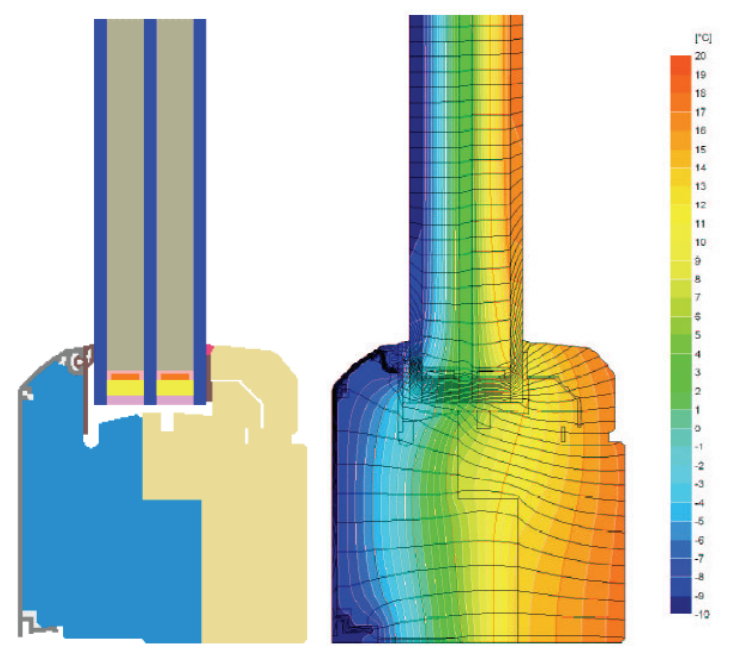

Figure 27. Example of a fixed wood and Al window frame with low U-value - ed[it]ion passiv, Fixverglasung by Internorm International $\mathrm{GmbH}$. One schematic drawing to the left and one temperature profile to the right. Wood and Al frame filled with PUR. Frame U-value $U_{f}=0.63 \mathrm{~W} / \mathrm{m}^{2} \mathrm{~K}$. Compare with opening window in Figure 22. From http://www.passiv.de and www.internorm.com. 


\subsubsection{Glass Facade System}

Examples of two glass facade systems are given in Figure 28-Figure 29, where further details may be found in appendix.
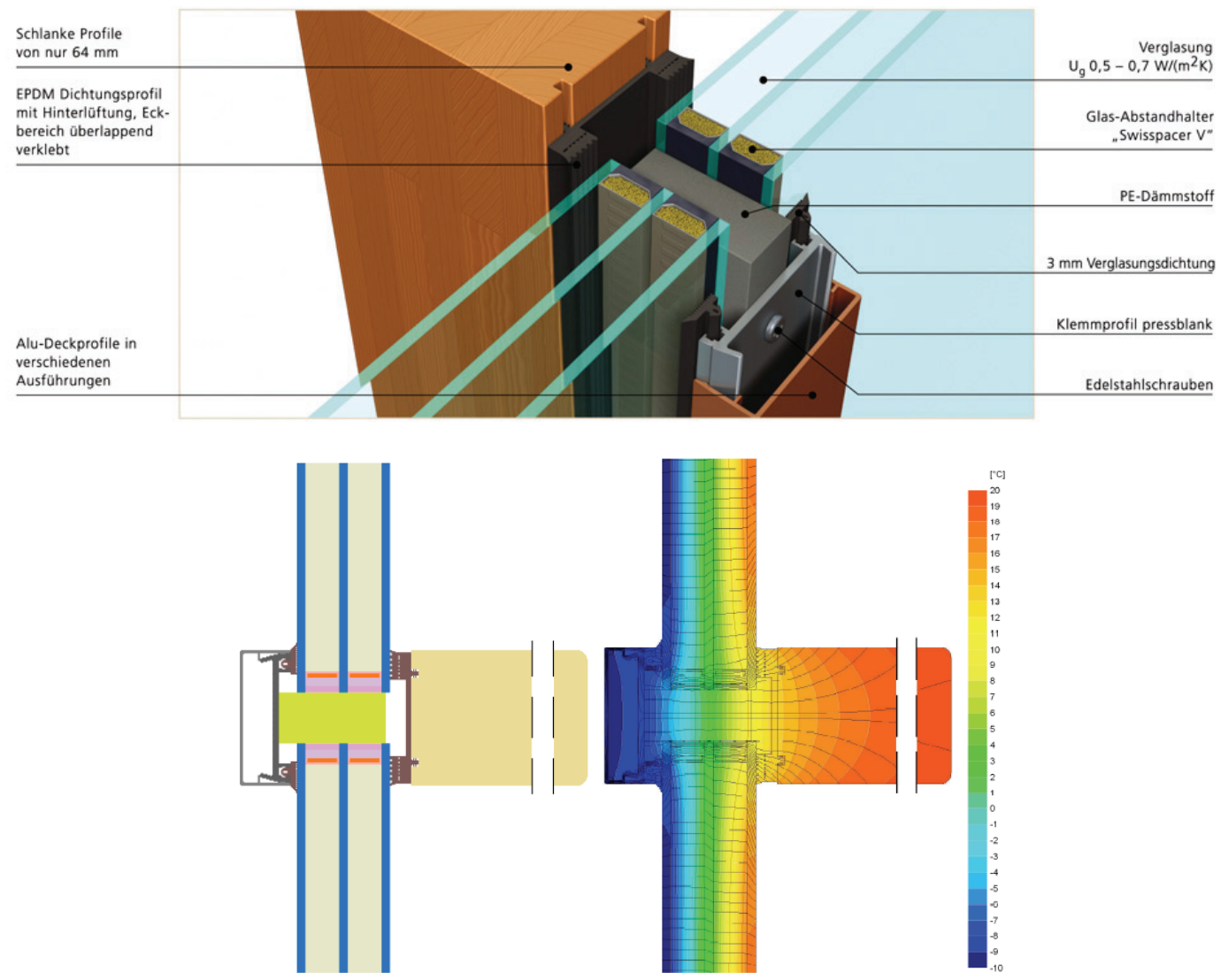

Figure 28. Example of a glass facade system with low U-value - ON TOP PLUS by Endl-Wagner GmbH.Picture on the top, one schematic drawing to the left and one temperature profile to the right. Wood-Al profile. Frame U-value $U_{f}=0.65 \mathrm{~W} / \mathrm{m}^{2} K$. From http://www.passiv.de and www.endl.at.

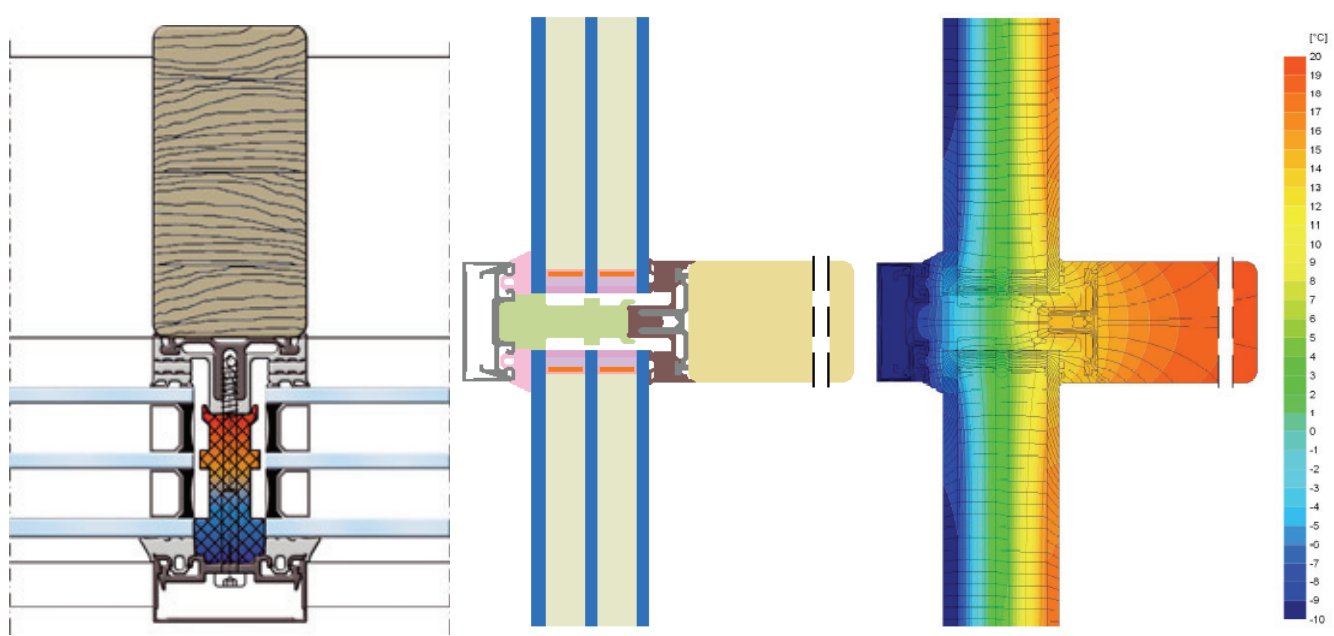

Figure 29. Example of a glass facade system with low U-value - FWT 50-1 HA E-plus by esco Metallbausysteme $\mathrm{GmbH}$. Two schematic drawings to the left and in the middle, and one temperature profile to the right. Wood-Al profile. Frame U-value $U_{f}=0.73 \mathrm{~W} / \mathrm{m}^{2} \mathrm{~K}$. From http://www.passiv.de and www.escoonline.de. 


\subsubsection{Window Frame Examples with Higher U-Values than the Passivhaus Requirement}

Figure 30 shows a wood window with PUR and two layer window glazing from NorDan with a window $\mathrm{U}_{\mathrm{w}}$-value of $1.2 \mathrm{~W} / \mathrm{m}^{2} \mathrm{~K}$. Figure 31 shows a wood window (without any highly thermal insulation materials) and three layer window glazing from Elitfönster with a window $U$-value of $U_{w}=0.9 \mathrm{~W} / \mathrm{m}^{2} \mathrm{~K}$. Figure 32 shows a fiberglass window from Thermotech with window $U$-values of $U_{w}=1.0 \mathrm{~W} / \mathrm{m}^{2} \mathrm{~K}$ and $U_{w}=1.6 \mathrm{~W} / \mathrm{m}^{2} \mathrm{~K}$ for a three-layer and two-layer window glazing, respectively. These window $U$-values are higher than the Passivhaus requirement of $U_{w} \leq 0.80 \mathrm{~W} / \mathrm{m}^{2} \mathrm{~K}$.

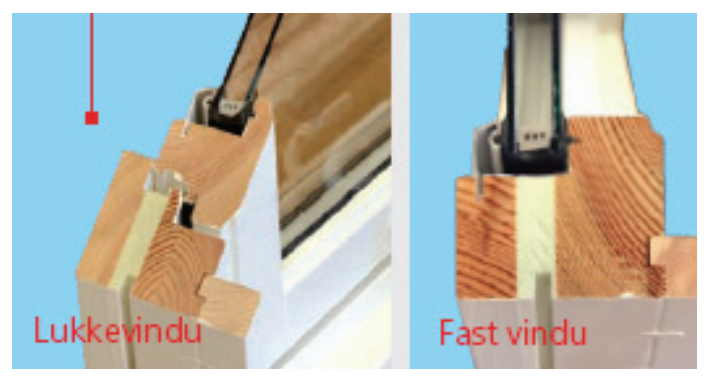

Figure 30. Example of a wood window frame with a relatively low U-value - N-Tech Lavenergi Superspacer by NorDan AS. Wood frame with PUR. The frame U-value is not stated, whereas the total window Uvalue is reported to be $U_{w}=1.2 \mathrm{~W} / \mathrm{m}^{2} \mathrm{~K}$. Note that a two-layer window pane is employed in this case (not three-layer). From http://www.nordan.no.
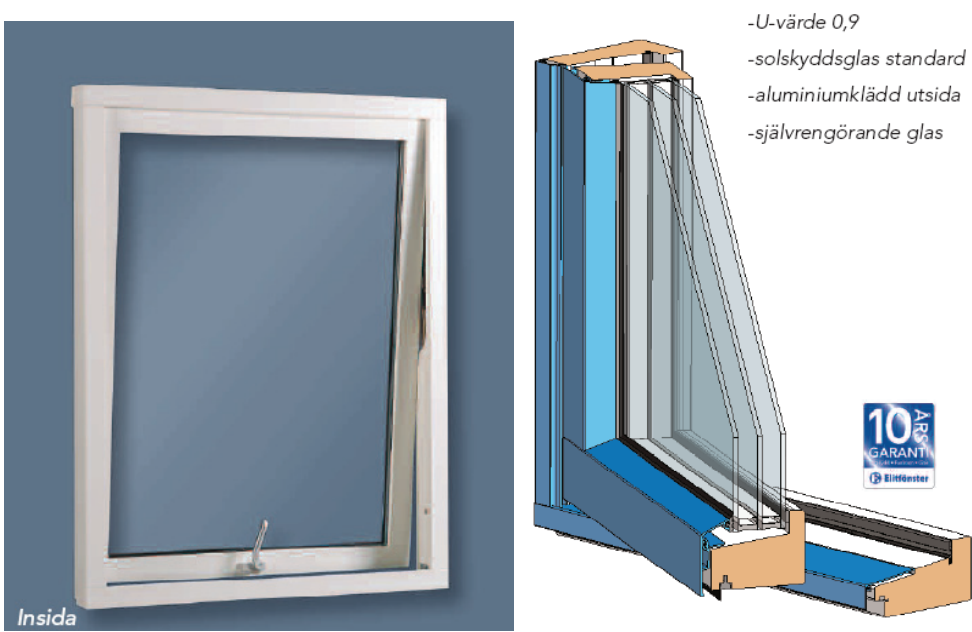

Figure 31. Example of a wood window frame with a relatively low U-value - Elit Extreme 0,9 Fönster, AXH by Elitfönster $A B$. The frame $U$-value is not stated, whereas the total window $U$-value is reported to be $U_{w}=0.9 \mathrm{~W} / \mathrm{m}^{2} \mathrm{~K}$. A three-layer window pane is employed in this case with a window glazing U-value of $U_{g}=0.6 \mathrm{~W} / \mathrm{m}^{2} \mathrm{~K}$. From http://www.elitfonster.se. 

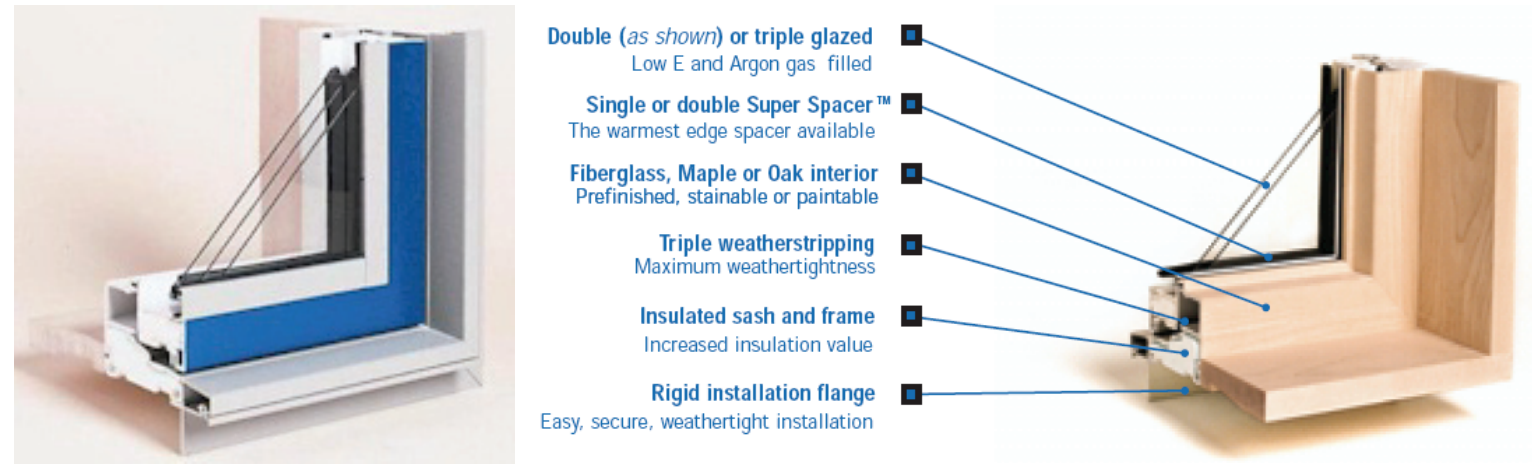

Figure 32. Example of a fiberglass window frame with a relatively low U-value - Thermotech windows by Thermotech Windows Ltd. The frame $U$-value is not stated, whereas one specific total window U-value is reported to be $U_{w}=1.0 \mathrm{~W} / \mathrm{m}^{2} \mathrm{~K}$ with a window glazing $U$-value of $U_{g}=0.7 \mathrm{~W} / \mathrm{m}^{2} \mathrm{~K}$ for a three-layer window pane (322 AFG TiR, \#2,\#5). The corresponding $U$-values for a two-layer window pane (211 AFG TiR, \#3) system is $U_{w}=1.6 \mathrm{~W} /\left(\mathrm{m}^{2} \mathrm{~K}\right)$ and $U_{g}=1.4 \mathrm{~W} / \mathrm{m}^{2} \mathrm{~K}$. From http://www.thermotechfiberglass.com.

\subsection{U-Value Comparison for Various Window Frame Types}

An $\mathrm{U}_{\mathrm{f}}$-value comparison of the various window frame types are given in Table 3. The $\mathrm{U}$-values (calculated according to the procedures in ISO 10077-2, with an isolation panel instead of the actual glazing) are examples and are not meant to be representative values for the different frame categories. From Table 3 it is seen that a specific wood frame (opening window) has a low frame $U_{\mathrm{f}}$-value of $0.65 \mathrm{~W} / \mathrm{m}^{2} \mathrm{~K}$, whereas a fixed wood and $\mathrm{Al}$ frame has as low $\mathrm{U}_{\mathrm{f}}$-value as $0.63 \mathrm{~W} / \mathrm{m}^{2} \mathrm{~K}$. Note also that the PVC frame with insulation filled Al cladding has a frame $\mathrm{U}_{\mathrm{f}}$-value of $0.82 \mathrm{~W} / \mathrm{m}^{2} \mathrm{~K}$, and may still fulfill the Passivhaus requirements of a window $U_{w}$-value $\leq 0.80 \mathrm{~W} / \mathrm{m}^{2} \mathrm{~K}$ provided that the window glazing U-value is less than $0.80 \mathrm{~W} / \mathrm{m}^{2} \mathrm{~K}$. For this specific PVC frame (Figure 25) the window $\mathrm{U}_{\mathrm{w}}$-value $=0.80 \mathrm{~W} / \mathrm{m}^{2} \mathrm{~K}$ and glazing $\mathrm{U}_{\mathrm{g}}$-value $=0.70 \mathrm{~W} / \mathrm{m}^{2} \mathrm{~K}$.

With window glazing $\mathrm{U}_{\mathrm{g}}$-values as low as $0.7 \mathrm{~W} / \mathrm{m}^{2} \mathrm{~K}$ and even $0.5 \mathrm{~W} / \mathrm{m}^{2} \mathrm{~K}$ (triple glass, two low emissivity coatings, argon and krypton filled cavities, respectively), it is seen that the frame $\mathrm{U}_{\mathrm{f}}$-value is becoming the minimum factor.

\subsection{Materials Applied in Window Frames}

Table 4 gives the thermal conductivity for various window frame materials. Other properties, e.g. mechanical properties like the tensile strength, elasticity modulus and as impact hardness, are also important when materials are selected. Some materials which may be the best ones with respect to obtaining a very low thermal conductivity, exhibit usually not the required mechanical strength. In addition, other properties than the mechanical and thermal properties will also be important, e.g. 
durability and climate exposure resistance are of outmost importance. Waste treatment, recycling and environmental impact of the various frame materials should also be considered.

Some materials may also represent a health hazard even if they are safe in their intended use. Polyurethane (PUR) is an example of this. During a fire PUR will when burning release hydrogen cyanide $(\mathrm{HCN})$, which is very poisonous. The toxicity stems from the cyanide anion $\left(\mathrm{CN}^{-}\right)$which prevents cellular respiration. Generally, hydrogen cyanide may be found in the smoke from nitrogen (N) containing plastics. From the frame table in appendix, it is observed that PUR is definitively the most widespread applied highly thermal insulating material in the various window frames. This fact may be doubtful with respect to the above discussion concerning $\mathrm{HCN}$ poisonous release during a fire. Note that some low-conducting polymer foams like polyethylene (PE) and polypropylene (PP) with no additives do only contain carbon and hydrogen, and will therefore release only $\mathrm{CO}_{2}$ (and maybe some $\mathrm{CO})$ during a fire, i.e. no nitrogen or chlorine compounds. PE and PP foams may therefore represent possible substitutes for todays large use of PUR in highly insulating window frames. Advantages and disadvantages of using various structural window materials may be found at http://www.greenspec.co.uk/html/materials/windowframes.html, where the pro and cons do not necessarily present the whole and fully truth, but rather a specific point of view.

Table 3. Window frame types with examples of their corresponding $U_{t}$-values*.

\begin{tabular}{|c|c|c|c|c|}
\hline Window Frame Type & $\begin{array}{c}\text { Schematic } \\
\text { Drawing }\end{array}$ & $\begin{array}{c}\text { Thermal } \\
\text { Insulation } \\
\text { Fill } \\
\text { Material }\end{array}$ & $\begin{array}{c}\text { Figure } \\
\text { Reference }\end{array}$ & $\begin{array}{l}U_{\text {f-value* }} \\
\left(W / \mathbf{m}^{2} \mathbf{K}\right)\end{array}$ \\
\hline Wood frame & & PUR & Figure 17 & 0.65 \\
\hline Wood frame with insulation filled Al cladding & & $\begin{array}{c}\text { PUR and } \\
\text { XPS }\end{array}$ & Figure 21 & 0.68 \\
\hline PVC frame & & PUR & Figure 23 & 0.71 \\
\hline PVC frame with insulation filled Al cladding & & PUR & Figure 25 & 0.82 \\
\hline Al frame & & PUR & Figure 26 & 0.71 \\
\hline Fixed wood and Al frame & & PUR & Figure 27 & 0.63 \\
\hline Glass facade system & & $\begin{array}{c}\text { PE and } \\
\text { EPDM } \\
\text { (support) }\end{array}$ & Figure 28 & 0.65 \\
\hline
\end{tabular}

\footnotetext{
${ }^{*} \mathrm{U}_{\mathrm{f}}$-values are calculated according to the procedures in ISO 10077-2, with an isolation panel instead of the actual glazing system.
} 
Table 4. Thermal conductivity values for various window frame materials. Note that the tabulated values are from specific sources and that variations exist. Specific correct values need to be determined for each product and from each producer. Naturally, the thermal properties are influenced by the mass density of each material.

\begin{tabular}{|c|c|c|}
\hline Window Frame Materials & $\begin{array}{c}\text { Thermal } \\
\text { Conductivity } \\
(\mathrm{W} / \mathrm{mK})\end{array}$ & References \\
\hline \multicolumn{3}{|c|}{ Highly Thermal Insulating Materials } \\
\hline Polyurethane (PUR) foam & $0.021-0.050$ & $1,2,3,4,5$ \\
\hline Polyurethane (PUR) recycled material (e.g. Purenit) & $0.06-0.1$ & 2 \\
\hline Polyethylene (PE) foam & $0.034-0.067$ & $5,6,7,8,9$ \\
\hline Polypropylene (PP) foam & $0.034-0.067$ & 9 \\
\hline Polyvinylchloride (PVC) foam & 0.035 & 4 \\
\hline Polyetherimide (PEI) foam & 0.025 & 9 \\
\hline Polystyrene (PS) foam (e.g. extruded/expanded, XPS/EPS) & $0.027-0.057$ & $3,4,9$ \\
\hline Fiberglass matting & $0.033-0.044$ & 3 \\
\hline Cork & $0.039-0.052$ & 3,5 \\
\hline \multicolumn{3}{|c|}{ Materials Utilized Partly as Thermal Insulation and Various Joint Materials } \\
\hline Polyethylene (PE) (in glass facade systems) (HDPE) & $0.33-0.50$ & 10 \\
\hline Ethylene-propylene-diene-monomer (EPDM) rubber & 0.25 & 10 \\
\hline Polyamide (Nylon) & $0.25-0.30$ & 10 \\
\hline \multicolumn{3}{|c|}{ Common Structural Frame Materials } \\
\hline Wood (pine/spruce) & $0.11-0.17$ & 11 \\
\hline Aluminium alloy $6061(\mathrm{Al})$ & 160 & 10 \\
\hline Polyvinylchloride (PVC) & 0.17 & 4,10 \\
\hline Fiberglass composite & 0.30 & 13 \\
\hline Wood composite material (e.g. Fibrex) & 0.22 & 12 \\
\hline Glass & 1.00 & 10 \\
\hline 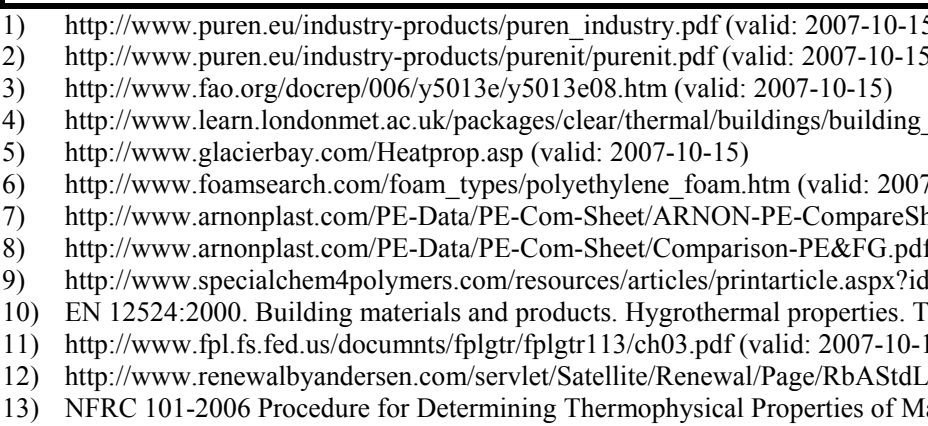 & $\begin{array}{l}\text { valid: } 2007-10-15 \text { ) } \\
\text { 07-10-15) } \\
\text { id: } 2007-10-15 \text { ) } \\
\text { lesign values } \\
4649805005 \text { (valid: } 2 \\
\text { r Use in NFRC-Appr }\end{array}$ & $\begin{array}{l}\text { 10-15) } \\
\text { Software Programs }\end{array}$ \\
\hline
\end{tabular}


As a digression it may be mentioned that in February 2007 NORDAM announced that they would use composite materials to build window frames for the Boing 787 Dreamliner (NORDAM, 2007). NORDAM will use HexMC®, which is a high performance carbon molding composite, specifically designed for compression molding. The epoxy matrix and high carbon fiber volume content enable components to be molded for a wide range of applications (HEXCEL, 2007). The thermal properties of the window, window frame or materials applied were not noted. Use of such materials in high performance window frames for buildings have however not been found.

\subsection{Spacers}

\subsubsection{Spacers in General}

Spacers for application in window panes represent an important component in the overall window design with respect to thermal properties. As this report focuses on window frames, spacers will not be dealt with exclusively in detail here. Some examples will be shown, though.

Shortly, as an excerpt from the table of frames in appendix concerning spacers, it is found that the spacers applied in these window panes in order to achieve/satisfy the PassivHaus window requirement is mainly one of the following two types:

- Swisspacer

- Thermix

or different variations of one of these two, e.g. Swisspacer V, Swisspacer with Al foil, Thermix TX.N, etc. In addition, some other spacers are also used:

- Refined/stainless steel

- TGI

- $\quad$ TPS

Refined or stainless steel is used as spacer bars in windows because it has a lower conductivity than the more common material aluminum. Stainless steel has a conductivity of about $17 \mathrm{~W} / \mathrm{mK}$ while aluminum has a conductivity of about $200 \mathrm{~W} / \mathrm{mK}$. TGI-spacers are manufactured of stainless steel combined with a high quality plastic polypropylene as a strengthening and insulating material due to its low heat conductivity (http://www.glassinsulation.de/english/products.cfm). TPS stands for Thermo Plastic Spacer system, and is a butyl-based sealant, in an insulated glass unit. More details about Swisspacer and Thermix are given below. 


\subsubsection{Swisspacer}

From the website http://www.designbuild-network.com/contractors/joinery/giesbrecht/ the following excerpt concerning Swisspacer is made (see also Table 5):

"Swisspacer is a thermally-improved, or warm-edge, spacer bar for insulating glazing. It is manufactured from special fibreglass, composite material. Swisspacer is available in two versions:

- Swisspacer - the composite material is covered by an ultra thin foil of aluminium

- Swisspacer $V$ - with an extremely thin stainless steel foil for maximal possible insulation.

These metallic foils guarantee the gas tightness and excellent sealant adhesion."

Table 5. Thermal performance data ${ }^{+)}$for Swisspacer. From the website http://www.designbuildnetwork.com/contractors/joinery/giesbrecht/.

\begin{tabular}{|c|c|c|c|c|}
\hline Spacer system & Aluminum & High grade steel & Swisspacer & Swisspacer V \\
\hline \multicolumn{5}{|c|}{ Wood window - Frame U-value $U_{f}=1.3 \mathrm{~W} / \mathrm{m}^{2} \mathrm{~K}$ e.g. } \\
\hline$\Psi(\mathrm{W} / \mathrm{mK}) *)$ & 0.074 & 0.053 & 0.044 & 0.033 \\
\hline $\begin{array}{c}\text { Window U-value, } U_{w}, 1- \\
\text { wing }\left(\mathrm{W} / \mathrm{m}^{2} \mathrm{~K}\right)\end{array}$ & 1.3 & 1.3 & 1.3 & 1.2 \\
\hline $\begin{array}{l}\text { Window U-value, } U_{w}, 2- \\
\text { wing }\left(\mathrm{W} / \mathrm{m}^{2} \mathrm{~K}\right)\end{array}$ & 1.5 & 1.4 & 1.3 & 1.3 \\
\hline $\begin{array}{l}\text { Min glass surface temp. } \\
\text { at }-10,+20\left({ }^{\circ} \mathrm{C}\right)\end{array}$ & 5.3 & 7.4 & 8.0 & 9.2 \\
\hline \multicolumn{5}{|c|}{ PVC window - Frame U-value $U_{f}=1.9 \mathrm{~W} / \mathrm{m}^{2} \mathrm{~K}$ e.g } \\
\hline$\Psi(\mathrm{W} / \mathrm{mK})$ & 0.070 & 0.052 & 0.043 & 0.034 \\
\hline $\begin{array}{c}\text { Window U-value, } U_{w}, 1- \\
\text { wing }\left(\mathrm{W} / \mathrm{m}^{2} \mathrm{~K}\right)\end{array}$ & 1.5 & 1.5 & 1.4 & 1.4 \\
\hline $\begin{array}{l}\text { Window U-value, } U_{w}, 2- \\
\text { wing }\left(\mathrm{W} / \mathrm{m}^{2} \mathrm{~K}\right)\end{array}$ & 1.7 & 1.6 & 1.6 & 1.5 \\
\hline $\begin{array}{c}\text { Min glass surface temp. } \\
\text { at }-10,+20\left({ }^{\circ} \mathrm{C}\right)\end{array}$ & 6.8 & 8.6 & 9.2 & 10.1 \\
\hline \multicolumn{5}{|c|}{ Aluminum window - Frame U-value $U_{f}=2.0 \mathrm{~W} / \mathrm{m}^{2} \mathrm{~K} \mathrm{e.g}$} \\
\hline$\Psi(\mathrm{W} / \mathrm{mK})$ & 0.115 & 0.072 & 0.060 & 0.041 \\
\hline $\begin{array}{c}\text { Window U-value, } U_{w}, 1 \text { - } \\
\text { wing }\left(\mathrm{W} / \mathrm{m}^{2} \mathrm{~K}\right)\end{array}$ & 1.7 & 1.6 & 1.5 & 1.5 \\
\hline $\begin{array}{c}\text { Window U-value, } U_{w}, 2- \\
\text { wing }\left(\mathrm{W} / \mathrm{m}^{2} \mathrm{~K}\right)\end{array}$ & 1.9 & 1.7 & 1.7 & 1.6 \\
\hline $\begin{array}{l}\text { Min glass surface temp. } \\
\text { at }-10,+20\left({ }^{\circ} \mathrm{C}\right)\end{array}$ & 6.5 & 8.9 & 9.5 & 10.7 \\
\hline
\end{tabular}

*) $\Psi$ is the linear thermal transmittance at the glass edge (W/mK) according to EN ISO 10077-2.

${ }^{+)}$All window U-values are based on a window area of $1.23 \mathrm{~m} \times 1.48 \mathrm{~m}$ and glazing $\mathrm{U}$-value of $1.1 \mathrm{~W} / \mathrm{m}^{2} \mathrm{~K}$. 
Furthermore, some additional information is given about Swisspacer and comparisons with other spacer materials in Figure 33 and Figure 34. Note the large thermal conductivity difference between Swisspacer $(0.19 \mathrm{~W} / \mathrm{mK})$ and for example aluminum $(200 \mathrm{~W} / \mathrm{mK})$.
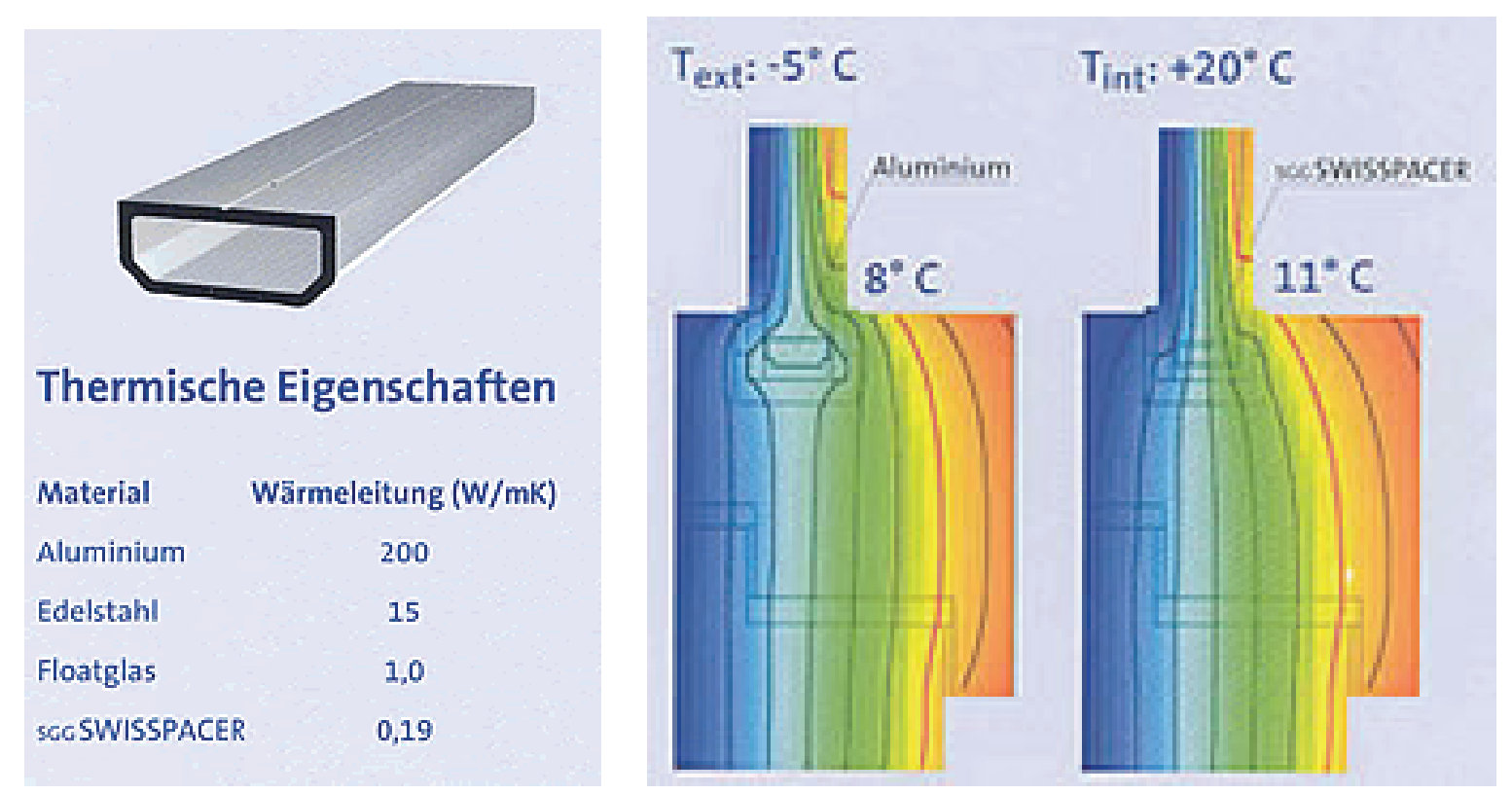

Figure 33. Selected Swisspacer information comparing thermal conductivity values with other materials (left) and temperature distribution in frame and lower glazing for Al and Swisspacer (right). From http://www.pewo-fenster.ch/isolierglas.htm.

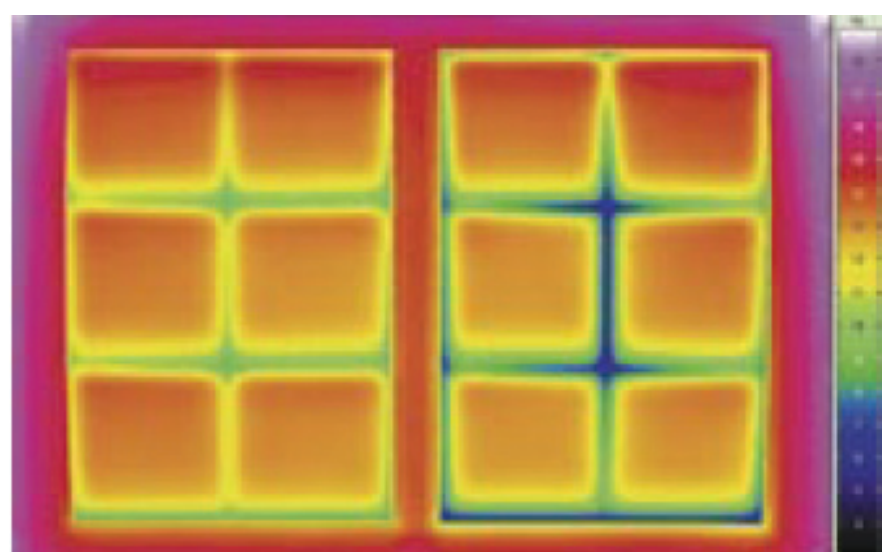

Figure 34. Infrared photo of two windows with Swisspacer to the left and normal Al profile to the right. From www.scanglas.dk/servlet/RichTextHandler?name=swisspacer.pdf.

\subsubsection{Thermix}

From the website http://www.das-passivhaus.de/gb-fenster.html the following excerpt concerning the Thermix spacer is made: 
"More intelligently is the "Thermix"-sealant, constructed from PVC and high grade steel: High grade steel has a conduction rate of only $26 \mathrm{~W} / \mathrm{mK}$ and the used PVC a rate of just $0.21 \mathrm{~W} / \mathrm{mK}$."

Furthermore, from http://www.thermix.de/t-en/presse/2005/messe-bau-intelligenter-isolieren.php:

"Thermix ${ }^{\circledR}$ bars are made of glass-fibre reinforced plastics. The water vapour and gas tightness of the Thermix ${ }^{\circledR}$ edge bond has been demonstrated on the basis of valid norms."

Miscellaneous information about the Thermix spacer and comparisons with other spacer materials are given in Table 6 and in Figure 35 and Figure 36.

Table 6. Comparison of Thermix TX.N (noted as Thermix in the table below) with Al spacers ${ }^{\star}$. From the website http://www.insulbar.de/i-it/pdf/Thermix TXN flyer E 0307.pdf.

\begin{tabular}{|c|c|c|c|c|c|c|}
\hline Type of window & \multicolumn{2}{|c|}{ Wood window } & \multicolumn{2}{|c|}{ Plastic window } & \multicolumn{2}{|c|}{$\begin{array}{l}\text { Thermally broken } \\
\text { metal window }\end{array}$} \\
\hline $\begin{array}{l}\text { Glazing } U_{g}\left(\mathrm{~W} / \mathbf{m}^{2} \mathbf{K}\right) \\
\text { Frame } U_{f}\left(W / \mathbf{m}^{2} \mathbf{K}\right) \\
\end{array}$ & \multicolumn{2}{|c|}{$\begin{array}{l}1.2 \\
1.4\end{array}$} & \multicolumn{2}{|c|}{$\begin{array}{l}1.2 \\
1.9\end{array}$} & \multicolumn{2}{|c|}{$\begin{array}{l}1.2 \\
2.0\end{array}$} \\
\hline Spacer & Aluminum & Thermix & Aluminum & Thermix & Aluminum & Thermix \\
\hline$\Psi$-value $(\mathrm{W} / \mathrm{mK})$ & 0.08 & 0.040 & 0.08 & 0.036 & 0.11 & 0.053 \\
\hline $\begin{array}{c}\text { Improvement in } \Psi \\
\text { by Thermix }(\%)\end{array}$ & \multicolumn{2}{|c|}{50} & \multicolumn{2}{|c|}{55} & \multicolumn{2}{|c|}{52} \\
\hline Window $U_{w}\left(W / m^{2} K\right)$ & 1.46 & 1.36 & 1.61 & 1.50 & 1.72 & 1.57 \\
\hline
\end{tabular}

*) Values for aluminum spacers are from prEN ISO 10077-1:2004/8.

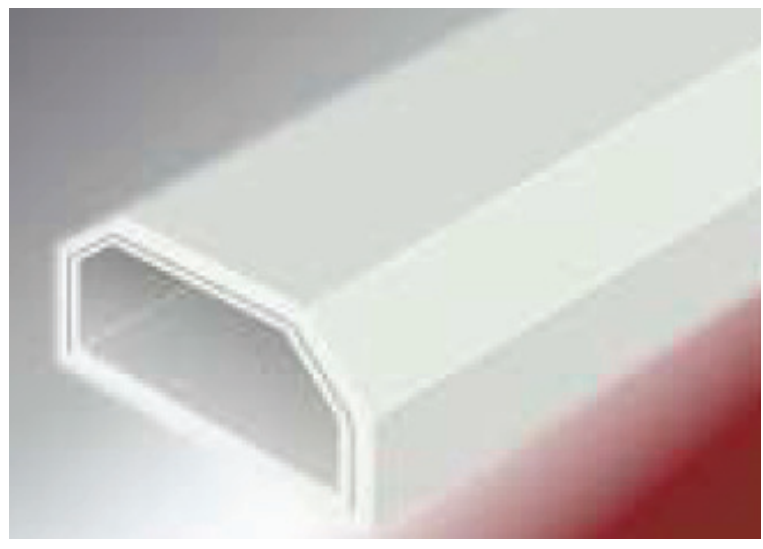

Figure 35. Drawings of the Thermix spacer. online.com/prospekte/pdfdownload.php?ID $=54$

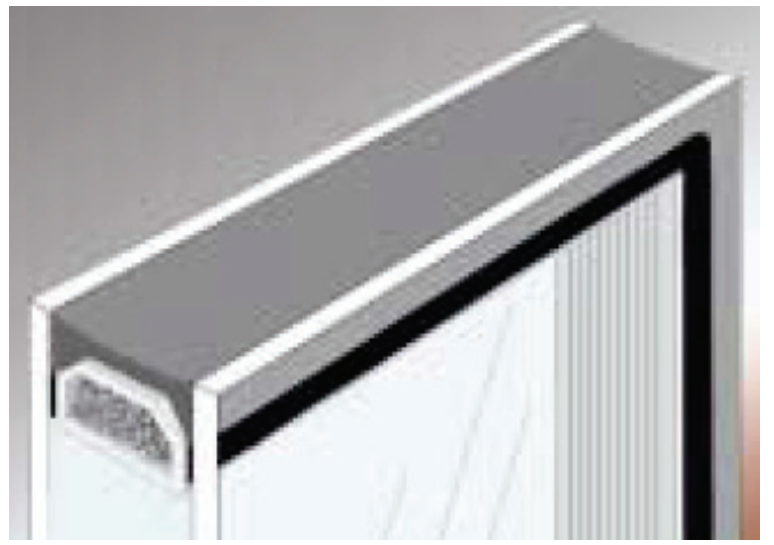

From the website http://www.ensinger- 


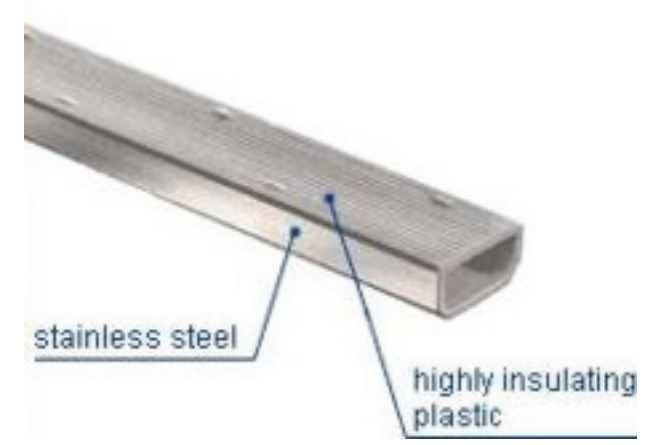

Figure 36. Thermix TX.N spcer. From http://www.fenestration-uk.com/News/News/temRSS. aspx?id=1885. 


\section{Discussion}

When future window frames are going to be developed and future window frame research is to be carried out, it is necessary to know what the current status is. This report makes an attempt to establish this. At the same time it is also important to know what the aims of the research and product development should be, and what criteria should be used to evaluate the window and the frame. In this chapter a summary of the state of the art is presented in Chapters 6.2 and 6.3, with a discussion about the future development aims found in Chapter 6.4. Chapter 6.1 discusses briefly the frame rating procedures.

\subsection{Frame Thermal Performance Rating}

In Chapter 2, two different window rating procedures have been pointed out, the $U$-factor and the Net Energy Gain. For heating dominated climates the latter may be to be the way to go, although very different windows may be the optimum solution for different buildings (dwellings, office buildings, factories etc.). It might therefore be "dangerous" or misleading to look at one parameter, being either the Net Energy Gain or the U-value, for selecting windows. What is wanted is an optimum indoor climate for the users of the building. A window that has optimum properties for capturing energy might not be optimum with respect to giving satisfactory temperature, light and glare conditions for the users of the buildings. A window that works very well during winter conditions may make the building unhabitable in the summer season. It is therefore recommended that whole building energy simulation programs are used to assess the indoor climate of the building. Several windows configurations (e.g. thermal properties including shading, window areas, and façade distribution) may be considered.

Still, when rating individual building components like walls, windows and doors, simple parameters may be wanted. In national codes, for instance, the U-value is the parameter that attracts the most attention, for all kinds of building elements. For opaque building sections like walls and window frames the U-value might also be the most appropriate parameter. But, for windows with a solarenergy transparent glazing, what really is of interest is the right combination of parameters, e.g. light transmittance, solar or near infrared reflectance, $\mathrm{U}$ - and g-value, for the building in question, i.e. building type and climate. A window's solar transmittance and reflectance properties may be divided into several parameters depending on the part of the solar spectrum of interest (i.e. ultraviolet, visible and near infrared radiation). For one building one type of window (frame, glazing and shading accessories) might be the right choice, but for another building a different window might be the appropriate one. 
For the frame alone the $\mathrm{U}$-value seems to be the right parameter if individual frames are being compared.

\subsection{Heat Transfer Modeling}

Based on the literature review the following summary related to heat transfer modeling of window frames may be presented. This summary relates mostly to the standard ISO 15099. This standard seems to be the most up to date and accurate standard, e.g. the standard differentiates between vertical and horizontal frames. The standard also refers to scientific reports and papers where it prescribes certain procedures or correlations.

- Conduction in solid materials can be accurately modeled with most simulation codes, provided that an appropriate mesh is used for the geometry in question, although it may be questioned whether today's treatment of hardware penetrating parts of the frame (i.e. hinge) is sufficiently accurately treated. Hardware effects will be more important for high-performance frames than for frames with a high U-value.

- International standards prescribe that natural convection correlations shall be used for air cavities in window frames. For horizontal frames (sill and head) the correlations in ISO 15099 are not necessarily accurate for vertical aspect ratios between 0.5 and 5, because they are based on interpolation between other correlations. The frame cavity correlations supposed to be used in vertical frame cavities according to ISO 15099 are developed for glazing cavities. Correlations for vertical jambs exist; see Gustavsen and Thue (2007). Fomichev et al. 2007 has recently also developed correlations for tilted frame cavities, both for horizontal (sill, head sections) and vertical frame (jamb) sections. These new correlations might be more accurate than the currently used correlations.

- Frame cavities should be divided for interconnections smaller than $7 \mathrm{~mm}$; ISO 15099 sets the break point at $5 \mathrm{~mm}$. Division of frame cavities should also be considered for cavities having sharp angels, because little convection takes place there.

- According to ISO 15099 a radiation correlation is used to account for frame cavity radiation heat transfer. Research has shown that using a view-factor based method instead of this correlation improves the accuracy.

- There exist variable surface coefficient equations that can be used to resemble the heat transfer effects at the frame surfaces (i.e. in corners).

- CFD simulation of heat transfer in window frames (with and without frame cavities), has shown that CFD tools can be used to predict the thermal transmittance and surface temperature with good accuracy. 
The summary shows that there is still room for improvement in the international standards used for calculation of the thermal performance for window frames. Some of the improvement can easily be incarcerated because new correlations and calculation procedure already exits (i.e. improved radiation modeling). Within other areas, more research is needed to improve the calculation procedures.

A question that may be raised is; why not use CFD tools instead of conduction tools and natural convection correlations to capture the convection effects that occur at external and internal surfaces and in frame cavities? With CFD tools heat transfer at the internal and external surfaces and in the cavities will be a part of the solution process. Before a decision about moving to CFD can be made, one should be aware of that vertical window frames (jambs) require three-dimensional geometries to be simulated in order to reproduce the convection effects taking place. Therefore it seems like user friendly three-dimensional conduction calculation tools (with correlations for natural convection) should be the first target. When these are available, one may consider including fluid flow equations.

CFD simulations will take more time to do than conduction simulations. There are two reasons for this: 1) there are more equations to solve for CFD problems, and 2) simulating vertical sections require three-dimensional geometries to be simulated. If practitioners should move to CFD, the added simulation time should not be very large, especially taking into account that many frame designers simulate many frame geometries to find the one with the best thermal performance.

One problem that may arise when solving the full CFD problem of heat transfer in window frames and windows in general, is that some cases do not necessarily have a stationary solution. Procedures for how to find and report the thermal transmittance (which is a stationary quantity) will then be needed.

\subsection{Frame Materials and Design}

Based on the literature and market review in Chapters 4 and 5, it seems like there exists two different tracks for finding better windows and window frames in particular:

1. Based on the current typical frame geometry (frame with a height of typically $10 \mathrm{~cm}$ ), reduce the $\mathrm{U}$-value as much as possible. The various strategies may then be sought:

a. New Materials. Apply or invent new novel thermally low conducting materials which satisfy the requirements for being used in window frames.

b. New Constructions/Solutions. Apply or invent new novel thermally low conducting constructions/solutions which satisfy the requirements for being used in window frames.

c. Substitution Strategy. Substitute large parts of the existing window frame with known thermally low conducting materials, which alone can not constitute the whole frame (due to mechanical strength, stability etc.), e.g. polyurethane (PU) in a wood frame. 
2. Develop new window designs where the main aim is to make windows with a very slim frame, or no frame at all.

The first point seems to be a result of the focus on the U-value (transmission losses) by itself. Then the aim is to have a window with a low $\mathrm{U}$-value, and since the frame is an important part of a window, the frame U-value should be minimized. The size of the frame is not that important, as long as the frame $\mathrm{U}$-value is lower than the glazing U-value (which usually not is the case today).

The second item is a result of using the Net Energy Gain (see Chapter 2) to rate windows. Then the (solar) energy gain through windows also plays an important part, in addition to the transmission losses. The focus is at maximizing the energy gain through the window (at least when only the heating season is considered). This again leads to maximizing the glazing area (in addition to increasing the g-value and reducing the U-value), which again results in slim frame profiles. Ultimately, the best window frame might be no frame at all.

The market review seems to depict that the substitution strategy is the most applied one so far.

As seen in earlier chapters and in the table in appendix, polyurethane (PUR) is clearly the most widespread applied highly thermal insulating material in the PassivHaus window frames, e.g. within wood frames. Certain variations of the PUR material (foam etc.) have very low thermal conductivities, e.g. $0.023 \mathrm{~W} / \mathrm{mK}$. This widespread use of PUR may give rise to a concern as when PUR is burning during a fire, hydrogen cyanide ( $\mathrm{HCN})$, which is very poisonous, will be released. A search for other highly thermal insulating frame materials, which are at least as good as PUR for frame applications, especially with respect to thermal properties, may/will therefore be important.

The following options should be explored in order to improve the thermal performance of frames even more:

- The slim wood frame suggested by Lautsen and Svendsen (2005) may be improved by replacing some of the wood in the frame with thermal insulation materials. Then the slim frame is retained (allowing a high net energy gain) but with a frame that has a lower U-value.

- New insulation materials should be investigated, aiming at finding the best thermal insulating materials suitable for application in window frames.

- Development or invention of new novel thermally low-conducting frame constructions/solutions might also be a possibility. 


\subsection{Window Frame Research and Development Aims}

The thermal performance of the window frame has undoubtedly an effect on the thermal performance of the entire window, because the U-value of the entire window is an area-weighted average of the individual components (glazing, edge and frame). Therefore, a frame with a lower U-value than the glazing will have a good effect on the total window U-value, and vice versa. When the thermal performance of the glazing is improving, it will therefore also be important to have window frames that can match or be better than the U-value of the glazing. If this becomes a problem, the focus will be on reducing the frame area.

So far the best available glazing systems have a $\mathrm{U}_{\mathrm{g}}$-value of about $0.5 \mathrm{~W} / \mathrm{m}^{2} \mathrm{~K}$ ( 3 panes of glass with 2 layers of low emissivity coatings and krypton filling). A design target for frames therefore seems to be a $\mathrm{U}_{\mathrm{f}}$-value of about $0.5 \mathrm{~W} / \mathrm{m}^{2} \mathrm{~K}$ or better. On the other hand, if window frames are compared to other opaque building elements, like walls, one should look at the code requirements. In Norway for instance, the current U-value requirement for walls is $0.18 \mathrm{~W} / \mathrm{m}^{2} \mathrm{~K}$. Other countries have similar requirements. Using other parameters than the U-value (i.e. net energy gain, or performing whole building simulations) to find a performance target may lead to other research and development aims. Both Nielsen et al. (2000) and Arasteh et al. (2007) have shown that windows with a $U_{w}$-value larger or equal to about $1.0 \mathrm{~W} / \mathrm{m}^{2} \mathrm{~K}$ can provide a net energy gain to a building, while a window with a lower $\mathrm{U}_{\mathrm{w}}$-value may not. This depends on the window properties and the climate (outdoor temperature and solar radiation).

One window may be optimized either with summer or winter conditions in mind, or by doing a whole year energy simulation. The optimum building is a building in which a heating system and a cooling system is redundant. With respect to this, a good window will help a building designer in building such a building. Thus, an optimum window is a window that minimizes the need for a heating (it should have small transmission losses and admit heat into the building when needed) and a cooling system (it keeps solar radiation out of the building, or lets heat out, when needed). A good window also minimizes the need for artificial lighting. Since, for most climates, the need for heating and cooling varies during the year the window needs to be dynamic.

So far only the glazing part of a window has been considered dynamic. It is through this part of the window that heat can enter directly into the building (and be blocked if necessary). The frame on the other hand stops the sunlight from entering the building. For the frame this leads to the following conclusions: Either the frame has to be reduced to a minimum, allowing a maximum controllable glazing area. Or the frame itself has to have dynamic properties that can be utilized to fulfill the goal of a building with no heating or cooling system. 
The authors of this report see the following potential technological applications for the frame, involving dynamic utilization of the frame:

- Include phase change materials in the frame, e.g. to store heat until it is needed (although such materials may be better utilized when used inside the building).

- Integrate a shading system with the frame and glazing in a way that also makes it usable for additional night time insulation (external or integrated in the glazing). Sufficient air tightness for the additional air or gas layer(s) is important to make this work.

- PV cells may be integrated in the frames; whereas due to visual considerations, there may be limitations in integrating PV cells in the glazing.

- The frame may be used for storage of smart controlling equipment for shading systems (e.g. external blinds or electrochromics). It should be possible to buy self-contained (wireless, if necessary) units, with electronic components having the same life time as the hardware (insulated glazing unit and frame) of the window itself. Electrochromic windows (ECWs) will be powered from the electrical grid system in buildings, where the solar energy transfer in the ECWs may be controlled automatically by the computer system in an intelligent building system. The automatic control system may receive input from a temperature sensor inside the building and a light sensor outside the building. A manual override system located on the windows themselves may also be desirable from a user's point of view. 


\section{Conclusions}

This report shows that there exist several alternatives to traditional wood, PVC and aluminum window frames. Most of the high performance frames found in this study have a $U_{\mathrm{f}}$-value of about 0.7-0.8 $\mathrm{W} / \mathrm{m}^{2} \mathrm{~K}$. The lowest $\mathrm{U}_{\mathrm{f}}$-value found is $0.63 \mathrm{~W} / \mathrm{m}^{2} \mathrm{~K}$ (for a traditional looking window frame). This frame consists of an inner layer of wood, with an aluminum cladding and polyurethane in between. Still there is a discrepancy between the best standard glazings, having a U-value of $0.5 \mathrm{~W} / \mathrm{m}^{2} \mathrm{~K}$, and the best frame. And the difference is even larger between the thermal performance of typical walls (Uvalues of $0.2-0.3 \mathrm{~W} / \mathrm{m}^{2} \mathrm{~K}$ ) and window frames. It is therefore important to decrease the U-value of window frames even lower than the currently best frames.

This report also reports and discusses heat transfer modeling issues related to window frames. Thermal performance increasing measures, surface modeling, and frame cavity modeling are among the topics discussed. The review shows that the current knowledge gives the basis for improving the calculation standards' calculation procedures. At the same time it is room for improvement within some areas. 


\section{References}

Arasteh, D., Goudey, H., Huang, J., Kohler, C. and Mitchell, R. 2007. Performance Criteria for Residential Zero Energy Windows, ASHRAE Transactions, Vol. 113, pt. 1, pp. 176-185.

Arasteh, D.K., Finlayson, E., Curcija, D., Baker, J., and Huizenga, C. 1998. Guidelines for modeling projecting fenestration products, ASHRAE Transactions, Vol. 104, pp. 856-860.

ASHRAE 1998. Standard Method for Determining and Expressing the Heat Transfer and Total Optical Properties of Fenestration Products, Public Review Draft of Standard 142P, American Society of Heating, Refrigerating and Air Conditioning Engineers, Atlanta.

Batchelor, G.K. 1954. Heat transfer by free convection across a closed cavity between vertical boundaries at different temperatures, Quarterly Applied Mathematics, Vol. 12, pp. 209-233.

Berkovsky, B.M. and V.K. Polevikov. 1977. Numerical study of problems on high-intensive free convection. In: Heat Transfer and Turbulent Buoyant convection (D.B. Spalding and N. Afgan, editors), Vol. II, pp. 443-455. Washington: Hemisphere Publishing Corporation.

Blanusa, P., Goss, W.P., Roth, H., Weitzmannn, P., Jensen, C.F., Svendsen, S., and Elmahdy, H. 2007. Comparison between ASHRAE and ISO thermal transmittance calculation methods, Energy and Buildings, Vol. 39, pp. 374-384.

Blomberg, T. 2000. HEAT2, A PC-program for heat transfer in two dimensions. Manual with brief theory and examples. Version 5.0. Lund: Lund University.

Branchaud, T.R., D. Curcija, and W.P. Goss. 1998. Local heat transfer in open frame cavities of fenestration systems. In: Thermal performance of the exterior envelopes of buildings. Atlanta: American Society of Heating, Refrigeration and Air-Conditioning Engineers.

Byars, N. and Arasteh, D. 1992. Design options for low-conductivity window frames, Solar Energy Materials and Solar Cells, Vol. 25, pp. 143-148.

Carpenter, S.C. and Elmahdy, A.H. 1994. Thermal performance of complex fenestration systems, ASHRAE Transactions, Vol 100, pp. 1179-1186.

Carpenter, S. and Hanam, M. 2001. Rating the Condensation Potential of Windows: Results from Testing and Simulation, ASHRAE Transactions, Vol. 107, pp. 550-558.

Carpenter, S.C. and A.G. McGowan. 1989. Frame and spacer effects on window U-value. ASHRAE Transactions, Vol. 95, pp. 604-608.

Carpenter, S.C. and A. McGowan. 1998. Three-dimensional heat transfer effects in building components. ASHRAE Transactions, Vol. 104, pp. 1070-1076.

Curcija, D. 1992. Three-dimensional finite elements model of overall, night time heat transfer through fenestration products. Ph.D. dissertation. Massachusetts: Department of Mechanical and Industrial Engineering, University of Massachusetts Amherst.

Curcija, D. and W.P. Goss. 1993. Two-dimensional natural convection over the isothermal indoor fenestration surface - finite element numerical solution. ASHRAE Transactions, Vol. 99, pp. 274-287.

Curcija, D. and Goss, W.P. 1994. Two-dimensional finite-element model of heat transfer in complete fenestration systems, ASHRAE Transaction, Vol. 100, pp. 1207-1221. 
Eckert, E.R.G. and W.O. Carlson. 1961. Natural convection in an air layer enclosed between two vertical plates with different temperatures, International Journal of Heat and Mass Transfer, Vol. 2, pp. 106-120.

Elmahdy, A.H. and Frank, T. 1993. Heat transfer at the edge of sealed insulating glass units: Comparison of hot bok measurements with finite-difference modeling, ASHRAEe Transactions, Vol. 99, pp. 915-922.

Elmahdy, A.H. 2003. Effects of improved spacer bar design on Window Performance, Construction Technology Update No. 58. Ottawa, Ontario: Institute for Research in Construction, National Research Council Canada. (http://www.irc.nrc-cnrc.gc.ca).

ElSherbiny, S.M., G.D. Raithby, and K.G.T. Hollands. 1982a. Heat transfer by natural convection across vertical and inclined air layers. - Journal of Heat Transfer. Transactions of the ASME, Vol. 104, pp. 96-102.

Encyclopædia Britannica. 2007. Window, Encyclopædia Britannica Online. 30 July 2007, http://www.britannica.com/eb/article-9077176.

Enermodal 2001. Modelling Windows, Glass Doors and Other Products with FRAMEplus 5. Kitchener, Ontario: Enermodal Engineering.

Erten, E., Kamuran, Ö. and Sümerkan, M.R. 1996. A locally developed reinforced mosaic door and window frame for the Black Sea region of Turkey. Construction and Building Material, Vol. 10, pp. 441-444.

Fang, Y., Eames, P.C. 2006. The effect of glass coating emittance and frame rebate on heat transfer through vacuum and electrochromic vacuum glazed windows, Solar Energy Materials \& Solar Cells, Vol. 90, pp. 2683-2695.

Finlayson, E., R. Mitchell, D. Arasteh, C. Huizenga, and D. Curcija. 1998. THERM 2.0. Program description. A PC program for analyzing the two-dimensional heat transfer trough building products. Berkeley: University of California.

Fomichev, A., Curcija, D.C., Balagurunathan, B., and Stocki, M. 2007. Investigation of heat transfer effects of sloped and ventilated internal cavities of framing systems, Final Report. Amherst: Center for Energy Efficiency and Renewable Energy, University of Massachusetts.

Griffith, B., Curcija, D., Türler, D., and Arasteh, D.K. 1998a. Improving computer simulations of heat transfer for projecting fenestration products: Using Radiation view-factor models, ASHRAE Transactions, Vol. 104, pp. 845-855.

Griffith, B., E. Finlayson, M. Yazdanian, and D. Arasteh. 1998b. The Significance of bolts in the thermal performance of curtain-wall frames for glazed facades. ASHRAE Transactions, Vol. 104, pp. 1063-1069.

Gustavsen, A. 2001. Heat transfer in window frames with internal cavities. PhD Thesis. Department of Building and Construction Engineering, Norwegian University of Science and Technology.

Gustavsen A., Griffith B.T., and Arasteh D. 2001a. Natural convection effects in three-dimensional window frames with internal cavities, ASHRAE Transactions, Vol. 107, pp. 527-537.

Gustavsen A., Griffith B.T., and Arasteh D. 2001b. Three-dimensional conjugate computational fluid dynamics simulations of internal window frame cavities validated using infrared thermography, ASHRAE Transactions, Vol. 107, pp. 538-549. 
Gustavsen, A., Kohler, C., Arasteh, D., and Curcija, D. 2005. Two-Dimensional Conduction and CFD Simulations of Heat Transfer in Horizontal Window Frame Cavities. ASHRAE transactions, Vol. 111, pp. 587-598.

Gustavsen, A., Kohler, C., Arasteh, D., and Dalehaug, A. 2007. Two-dimensional computational fluid dynamics and conduction simulations of heat transfer in horizontal window frames with internal cavities, ASHRAE Transactions, Vol. 113, Pt. 1, pp. 165-175.

Gustavsen, A. and Thue, J.V. 2007. Numerical simulation of natural convection in three-dimensional cavities with a high vertical aspect ratio and a low horizontal aspect ratio, Journal of Building Physics, Vol. 30(3), pp. 217-240. (http://dx.doi.org/10.1177/1744259107071660.)

Hallé, S., M.A. Bernier, A. Patenaude, and R. Jutras. 1998. The combined effect of air leakage and conductive heat transfer in window frames and its impact on the Canadian energy rating procedure. ASHRAE Transactions, Vol. 104, pp. 176-184.

HEXCEL. 2007. HexMC - Sheet-molding compound, http://www.hexcel.com/Products/Matrix+Products/Other+FRM/HexMC/. (Link valid 2007-06-29).

Hollands, K.G.T., T.E. Unny, G.D. Raithby, and L. Konicek. 1976. Free convective heat transfer across inclined air layers. Journal of Heat Transfer. Transactions of the ASME, Vol. 98, pp. 189-193.

ISO 2003. ISO 10077-2, Thermal Performance of Windows, Doors and Shutters-Calculation of Thermal Transmittance-Part 2: Numerical Method for Frames, International Standards Organization, Geneva.

Jakubowicz, I. and Möller, K. 1992. An FTIR, impact strength and thermal analysis investigation of a PVC window frame naturally aged for 20 years, Polymer Degradation and Stability, Vol. 36, pp. 111120.

Jonsson, B. 1985. Heat transfer trough windows. During the hours of darkness with the effect of infiltration ignored. Document D13:1985. Stockholm: Swedish Council for Building Research.

Kohler, C., Arasteh, D. Mitchell, R. 2003. THERM Simulations of Window Indoor Surface Temperatures for Predicting Condensation, ASHRAE Transactions, Vol. 109.

Korpela, S.A., Y. Lee, and J.E. Drummond 1982. Heat transfer through a double pane window, Journal of Heat Transfer. Transactions of the ASME, Vol. 104, pp. 539-544.

Lartigue, B., S. Lorente, and B. Bourret. 2000. Multicellular natural convection in a high aspect ratio cavity: experimental and numerical results, International Journal of Heat and Mass Transfer, Vol. 43, pp. 3157-3170.

Laustsen, J.B and Svendsen, S. 2005. Improved Windows for Cold Climates, Proceedings of the 7th Nordic symposium on building physics.

Lee, Y. and S.A. Korpela. 1983. Multicellular natural convection in a vertical slot. Journal of Fluid Mechanics, Vol. 126, pp. 91-121.

Löffler, M. 1997. Foamglass as spacer in multiple glazing. Detailed study for new design of edge seal in multiple-glazing significantly reduces energy consumption, Building Research and Information, Vol. 25, pp. 107-110. 
Löffler, M. and Buck, D. 1997. Glazing edge-seal using foamglass as spacer and frameless window design, Solar Energy, Vol. 61, 5, pp. 303-312.

Mitchell, R., Huang, J., Arasteh, D., Huizenga, C., and Glendenning, S. 2005. RESFEN5: Program Description. A PC Program for Calculating the Heating and Cooling Energy Use of Windows in Residential Buildings, Lawrence Berkeley National Laboratory.

Moshfegh, B., Loyd, D., and Karlsson, B. 1989. Heat Transfer at modern windows - Risk of condensation, Energy and Buildings, Vol. 13, pp.119-125.

NBC 1969. Norwegian building code (in Norwegian). Forskrifter om bygg av 1. august 1969.

Oslo: GRØNDAHL \& SØN.

NBC 1987. Norwegian building code (in Norwegian). Byggeforskrift av 27. mai 1987 nr. 458 med endringer, sist av 21. desember 1988 nr. 1144. Oslo: GRØNDAHL \& SØN.

NBC 1997. Norwegian building code (in Norwegian). Forskrift om krav til byggverk og produkter til byggverk. Tekniske forskrifter til plan- og bygningsloven av 14. juni 1985 nr.77. Oslo: Statens byggetekniske etat.

NBC 2007. Norwegian building code (in Norwegian). Forskrift om endringer i forskrift 22.1.1997 nr. 33 til plan- og bygningsloven om krav til byggverk og produkter til byggverk (TEK). Oslo: Statens byggetekniske etat.

Nielsen, T.R., Duer, K., and Svendsen, S. 2000. Energy performance of glazings and windows, Solar Energy, Vol. 69, pp. 137-143.

NORDAM 2007. NORDAM pioneers composite window frames for Boing 787 Dreamliner, http://www.nordam.com/news/press_releases/default.aspx?pr=020807-1. (Link valid 2007-06-29).

Noyé, P., Laustsen, J.B. and Svendsen, S. 2002. Windows with improved energy performance, Proceedings of the 6th Nordic Symposium on Building Physics.

Noyé, P.A., Laustsen, J.B. Svendsen, S. 2004. Calculating the heat transfer coefficient of frame profiles with internal cavities, Nordic Journal of Building Physics (Acta physica aedificiorum), Vol. 3, http://www.byv.kth.se/avd/byte/bphys/.

Raithby, G.D., K.G.T. Hollands and T.E. Unny. 1977. Analysis of heat transfer by natural convection across vertical fluid layers. Journal of Heat Transfer. Transactions of the ASME, Vol. 99, pp. 287-293.

Schrey, A.-C., R.A. Fraser, and P.F. de Abreu. 1998. Local heat transfer coefficients for a flushmounted glazing unit. ASHRAE Transactions, Vol. 104, pp. 1207-1221.

Shewen, E., K.G.T. Hollands, and G.D. Raithby. 1996. Heat transfer by natural convection across a vertical air cavity of large aspect ratio. Journal of Heat Transfer. Transactions of the ASME, Vol. 118, pp. 993-995.

Schultz, J. M., and Svendsen, S. 2000. Improved energy performance of windows through an optimization of the combined effect of solar gain and heat loss. In: Proceedings of the EuroSun 2000, Copenhagen, Denmark, June 19-22, 2000.

Schultz, J.M. 2002. Windows with a slim frame construction and a large light and solar transmission (in Danish), Report R-028, Department of Civil Engineering, Technical university of Denmark. 
Standaert P. 1984. Thermal evaluation of window frames by the finite difference method. In: Proceedings of windows in building design and maintenance. Stockholm: Swedish Council for Building Research.

Svendsen, S, Kragh, J., and Laustsen, J.B. 2005. Energy performance of windows based on net energy gain, Proceedings of the 7th Nordic symposium on building physics.

Svendsen, S., K. Duer, and P. Noyé. 2000. Calculating the heat transfer coefficient of frame profiles in aluminium. Report SR-0023 - Revision 1. Lyngby: Department of Buildings and Energy, Technical University of Denmark.

Yin, S.H., T.Y. Wung, and K. Chen. 1978. Natural convection in an air layer enclosed within rectangular cavities, International Journal of Heat and Mass Transfer, Vol. 21, pp. 307-315.

Wright, J.L. and Sullivan, H.F. 1994. A two-dimensional numerical model for natural convection in a vertical, rectangular window cavity, ASHRAE Transactions, Vol. 100, pp. 1193-1206.

Wright, J. 1996. A correlation to quantify convective heat transfer between vertical window glazings. ASHRAE Transactions, Vol. 102, pp. 940-946.

Zhao, Y., D. Curcija, and W.P. Goss. 1997. Prediction of the multicellular flow regime of natural convection in fenestration glazing cavities. ASHRAE Transactions, Vol. 103.

Zhao, Y. 1998. Investigation of heat transfer performance in fenestration system based on finite element method. Ph.D. dissertation. Massachusetts: Department of Mechanical and Industrial Engineering, University of Massachusetts Amherst.

Wikipedia. 2007. Wikipedia, the free encyclopedia, http://en.wikipedia.org/. (Valid 2007-07-04) 


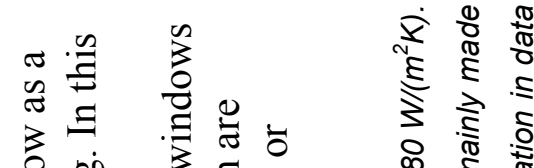

할 일

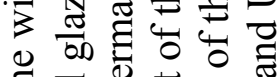

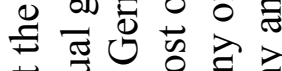

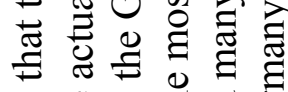

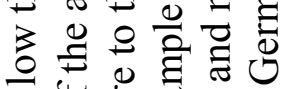

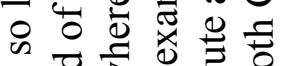

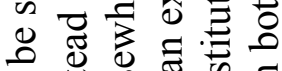

을 응

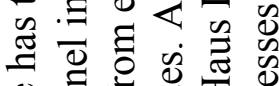

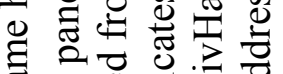

政

策

들 능

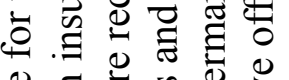

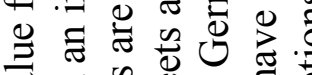

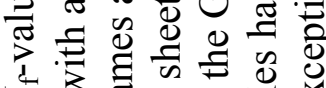

2.

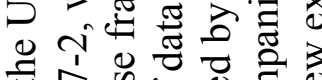

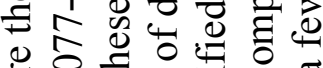
응

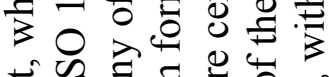

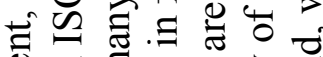

政

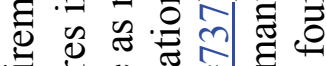

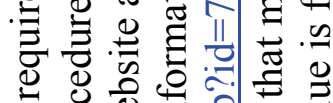

政

돈

我

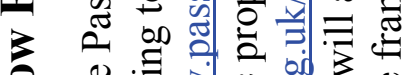

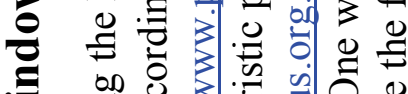

Dof o

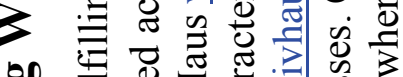

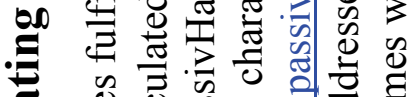

क्ञ

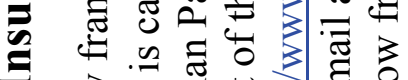

중

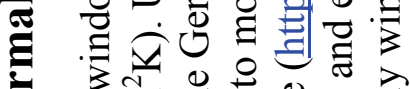

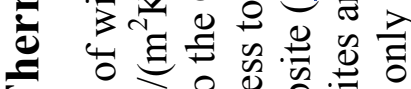

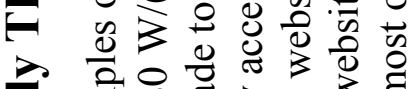

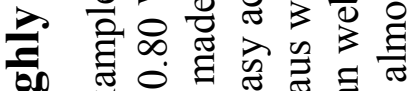

政

홍

5 政

1 कo

1 施

若

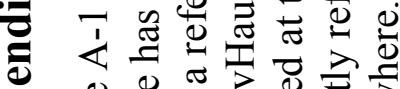

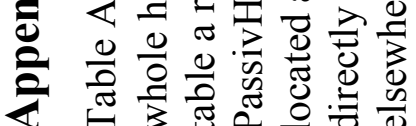

\begin{tabular}{|c|c|c|}
\hline$\underset{\mathscr{\Phi}}{\mathbb{\Phi}}$ & 竞 & 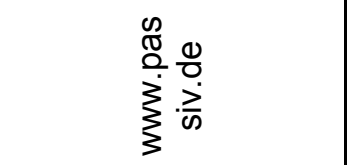 \\
\hline 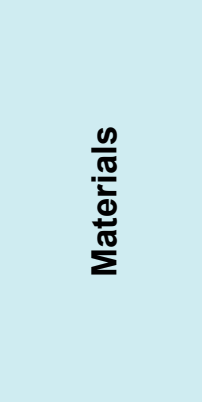 & 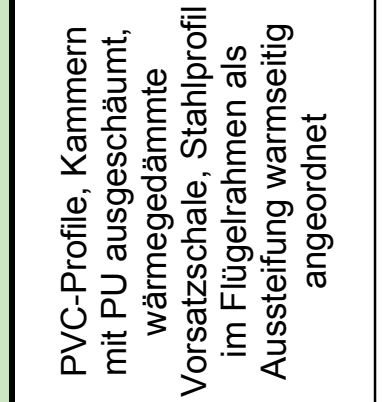 & 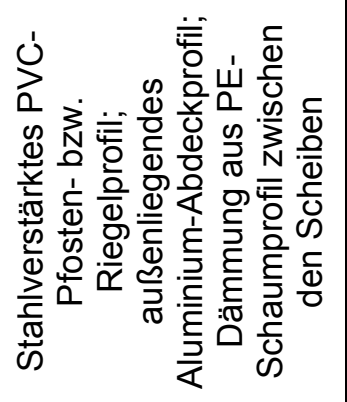 \\
\hline 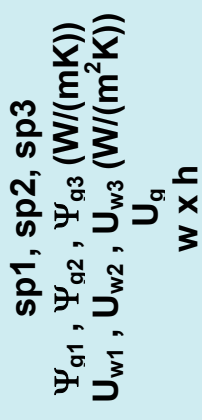 & 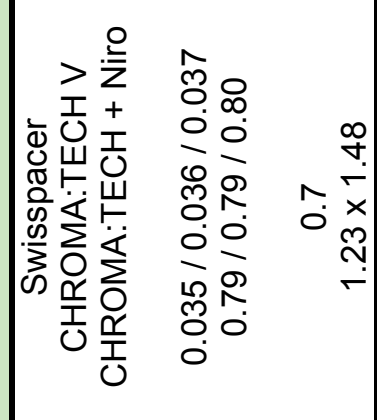 & 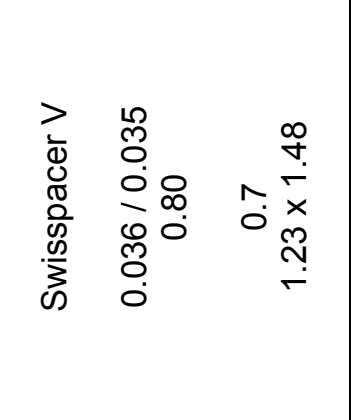 \\
\hline 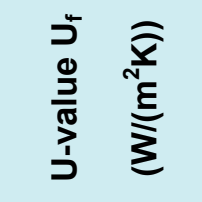 & ז̊ & $\begin{array}{l}\stackrel{2}{R} \\
0 \\
0 \\
0 \\
0 \\
0\end{array}$ \\
\hline 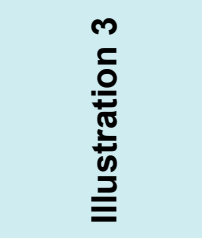 & & 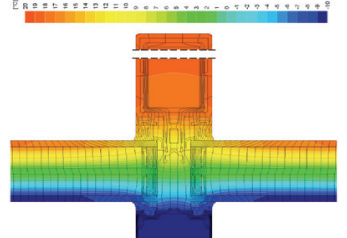 \\
\hline 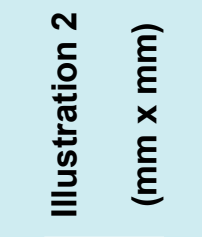 & $=$ & 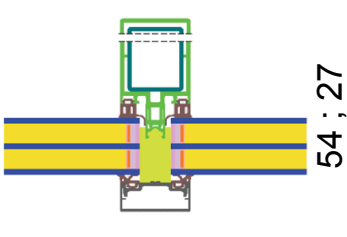 \\
\hline 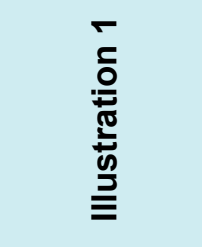 & & \\
\hline 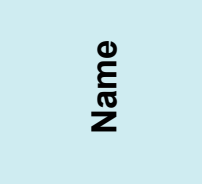 & 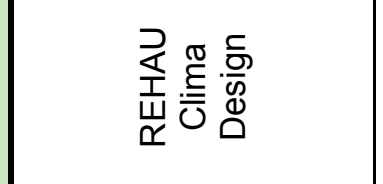 & 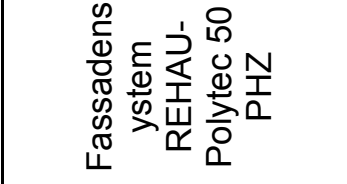 \\
\hline 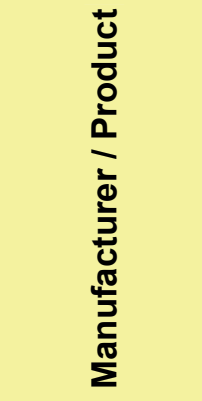 & 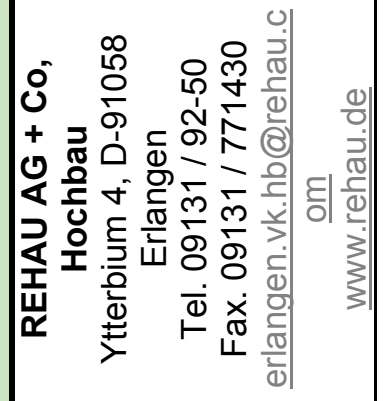 & \\
\hline
\end{tabular}




\begin{tabular}{|c|c|c|c|c|}
\hline 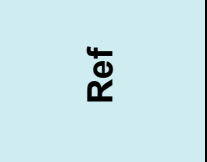 & 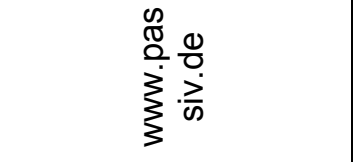 & $\begin{array}{l}\frac{1}{0} \\
\stackrel{0}{0} \\
30 \\
\sum_{3}^{0}\end{array}$ & 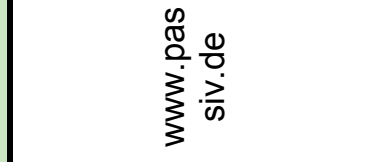 & 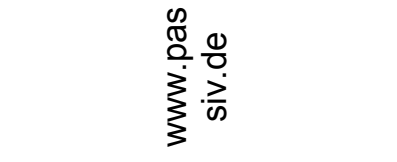 \\
\hline 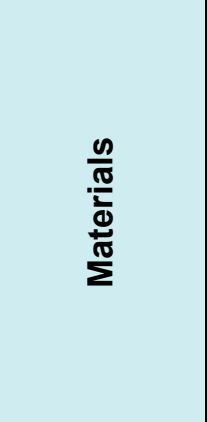 & 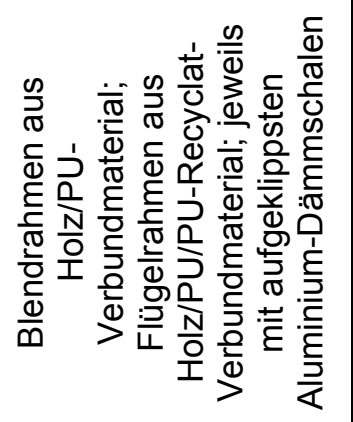 & & 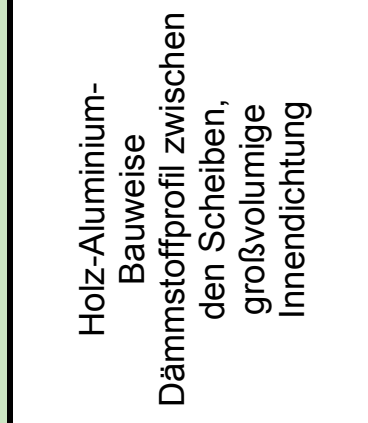 & 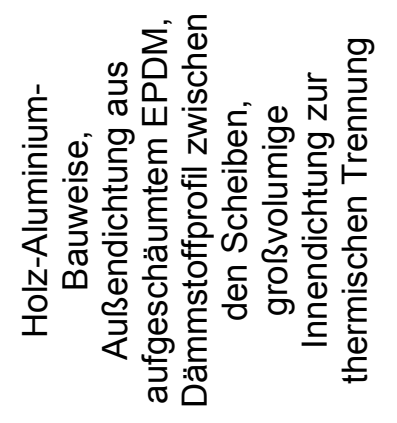 \\
\hline 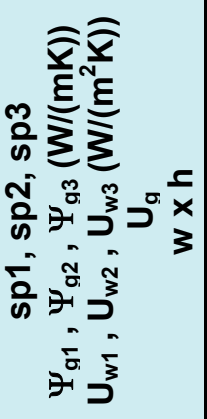 & 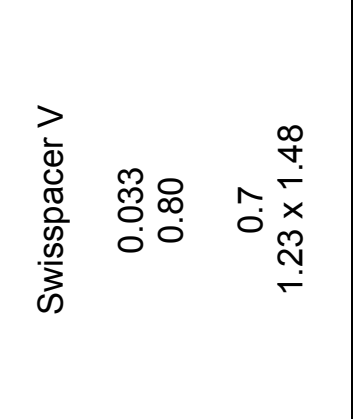 & $\begin{array}{l}\sum_{\infty}^{3} \\
0 \\
0\end{array}$ & 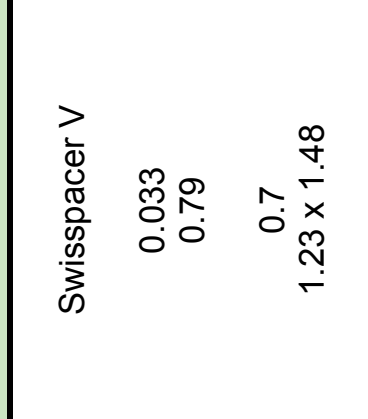 & 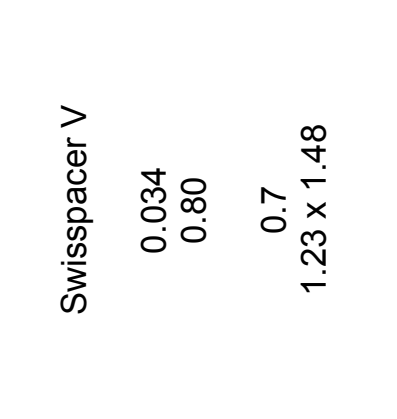 \\
\hline 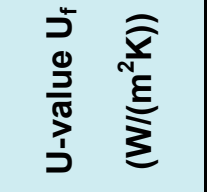 & $\begin{array}{l}\hat{A} \\
0\end{array}$ & & $\begin{array}{l}0 \\
\stackrel{0}{0} \\
0\end{array}$ & 5 \\
\hline 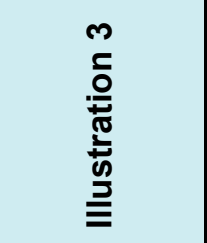 & 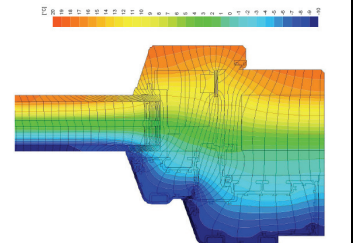 & & $\square$ & $\underbrace{20}$ \\
\hline 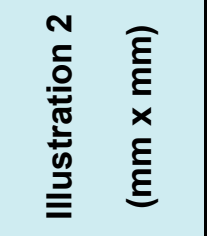 & N & & $\frac{N}{\square}$ & 的 \\
\hline 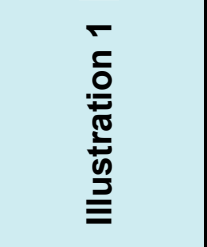 & & $=\ln [\mathrm{I}$ & & 口in \\
\hline 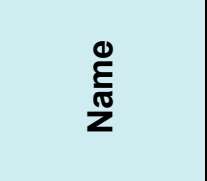 & 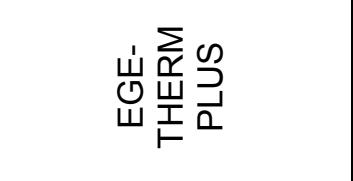 & 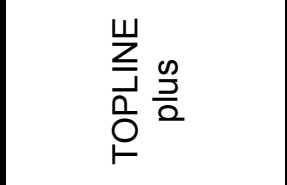 & 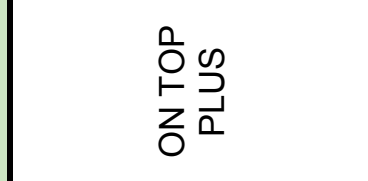 & 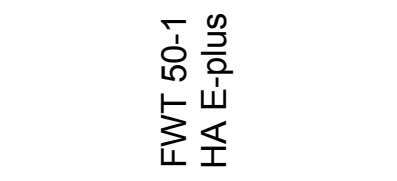 \\
\hline 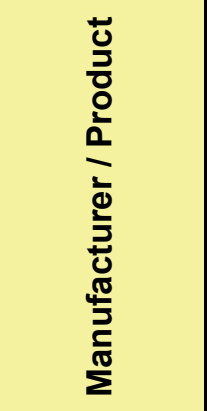 & 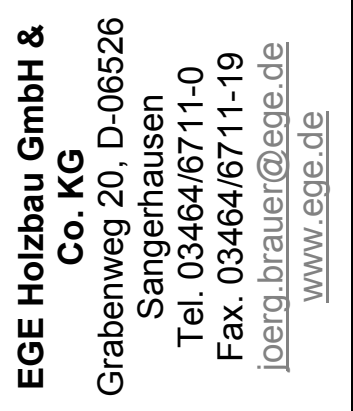 & 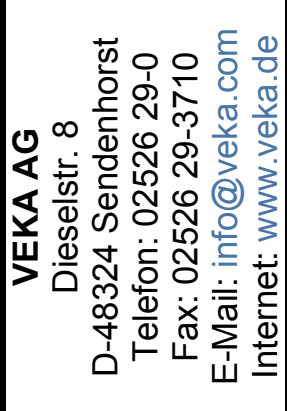 & 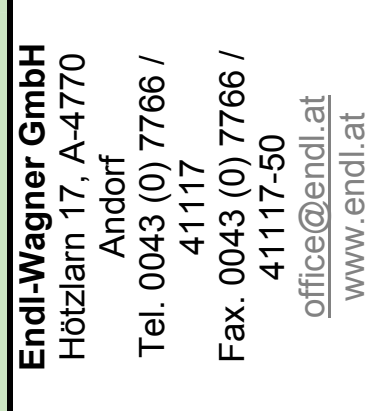 & 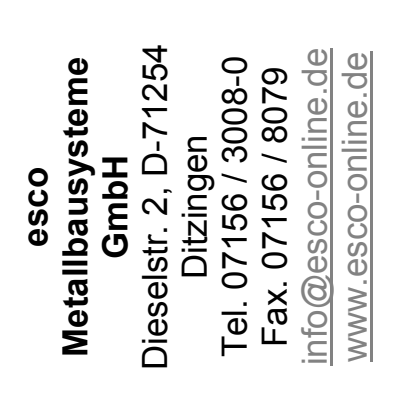 \\
\hline
\end{tabular}




\begin{tabular}{|c|c|c|c|}
\hline 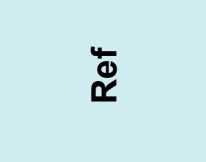 & 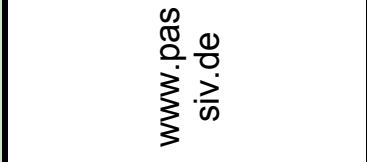 & 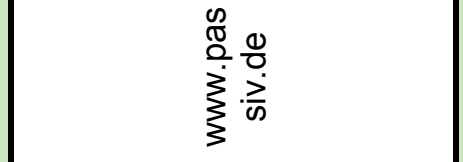 & 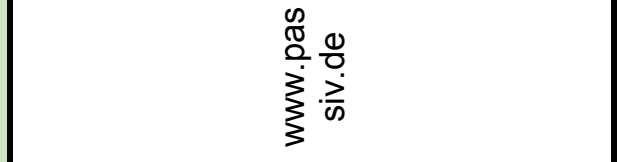 \\
\hline $\begin{array}{l}\frac{\infty}{\sigma \frac{\pi}{2}} \\
\frac{\infty}{\infty \pi} \\
\frac{\pi}{\Sigma}\end{array}$ & 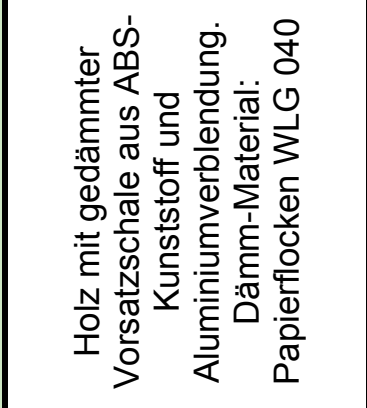 & 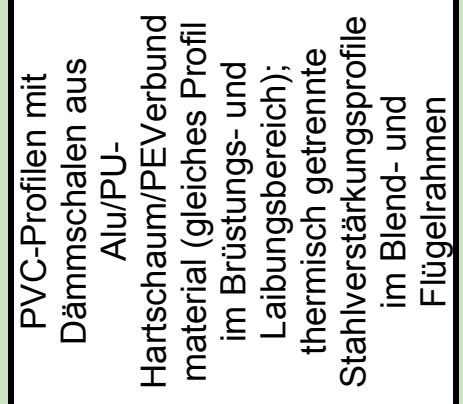 & 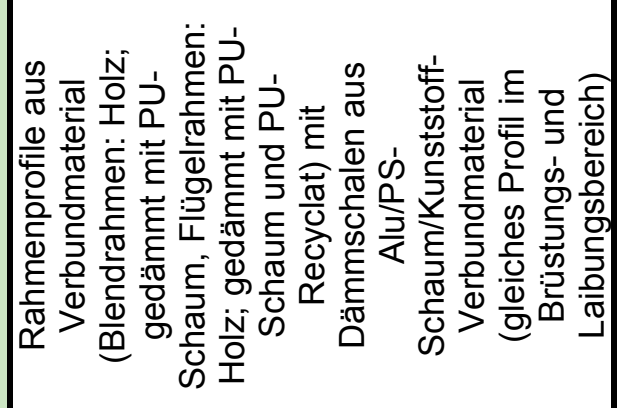 \\
\hline 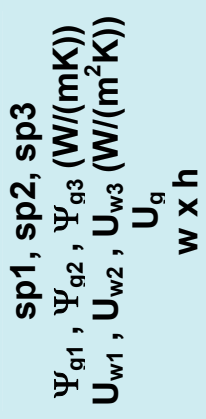 & 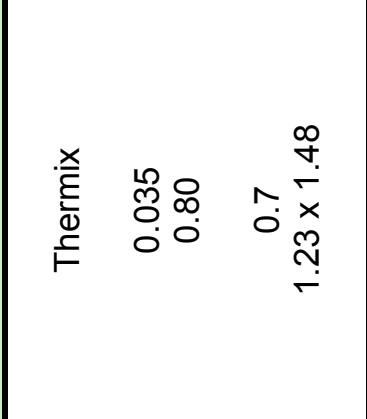 & 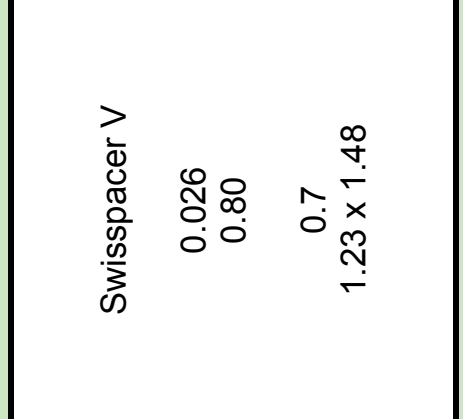 & 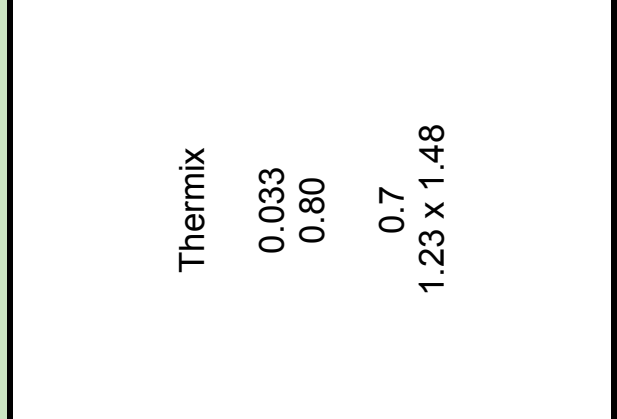 \\
\hline 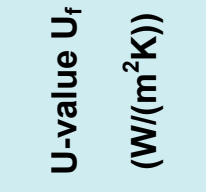 & $\begin{array}{l}\stackrel{0}{2} \\
\stackrel{0}{\circ}\end{array}$ & $\begin{array}{l}\underset{\infty}{\infty} \\
\stackrel{0}{\circ}\end{array}$ & 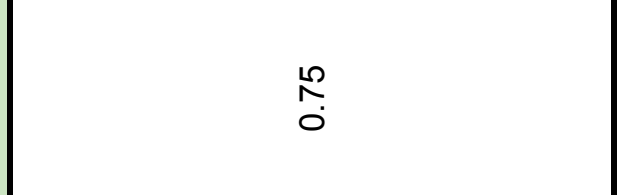 \\
\hline 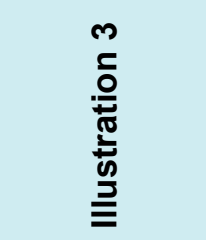 & & Ex & 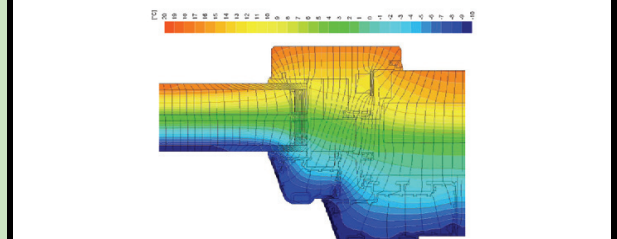 \\
\hline 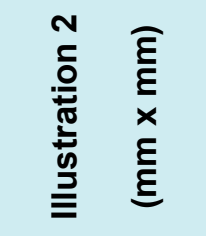 & 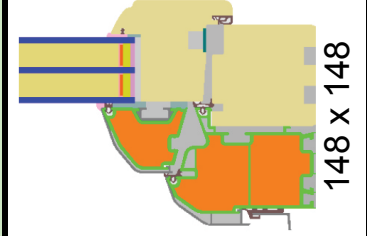 & -1 & $\stackrel{S}{V}$ \\
\hline 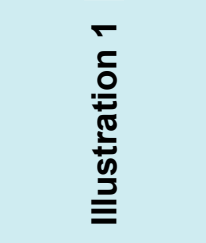 & & & \\
\hline $\begin{array}{l}\stackrel{0}{E} \\
\text { ¿ } \\
\mathbf{z}\end{array}$ & 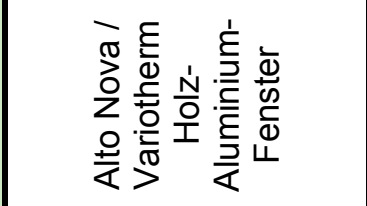 & 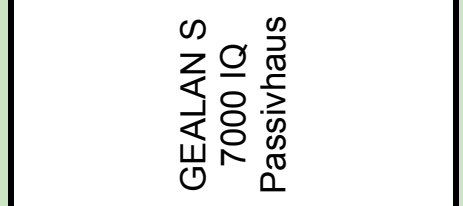 & 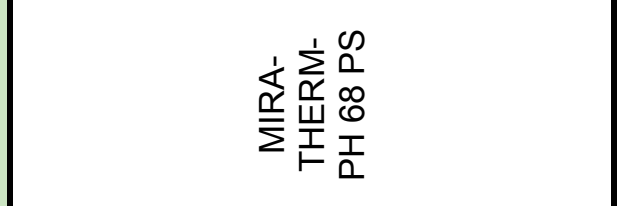 \\
\hline 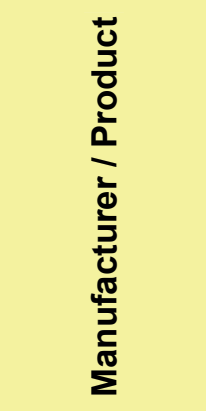 & 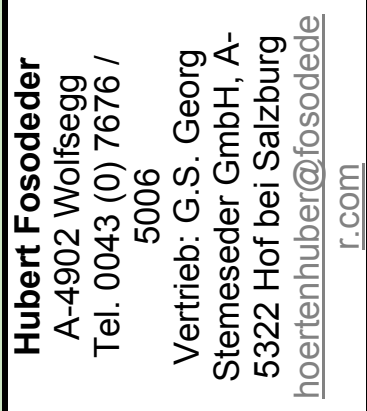 & 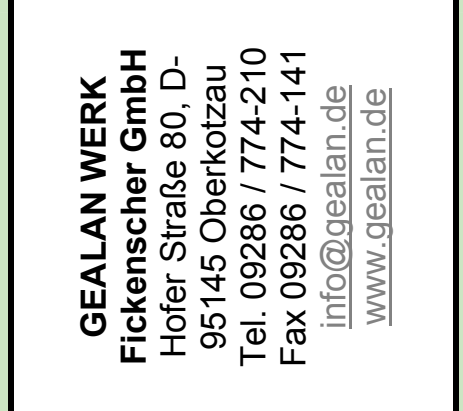 & 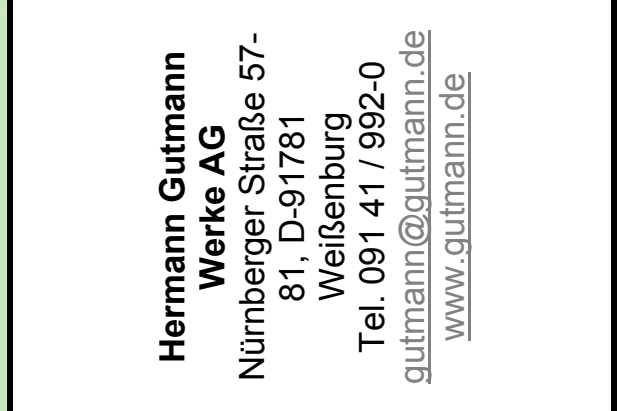 \\
\hline
\end{tabular}




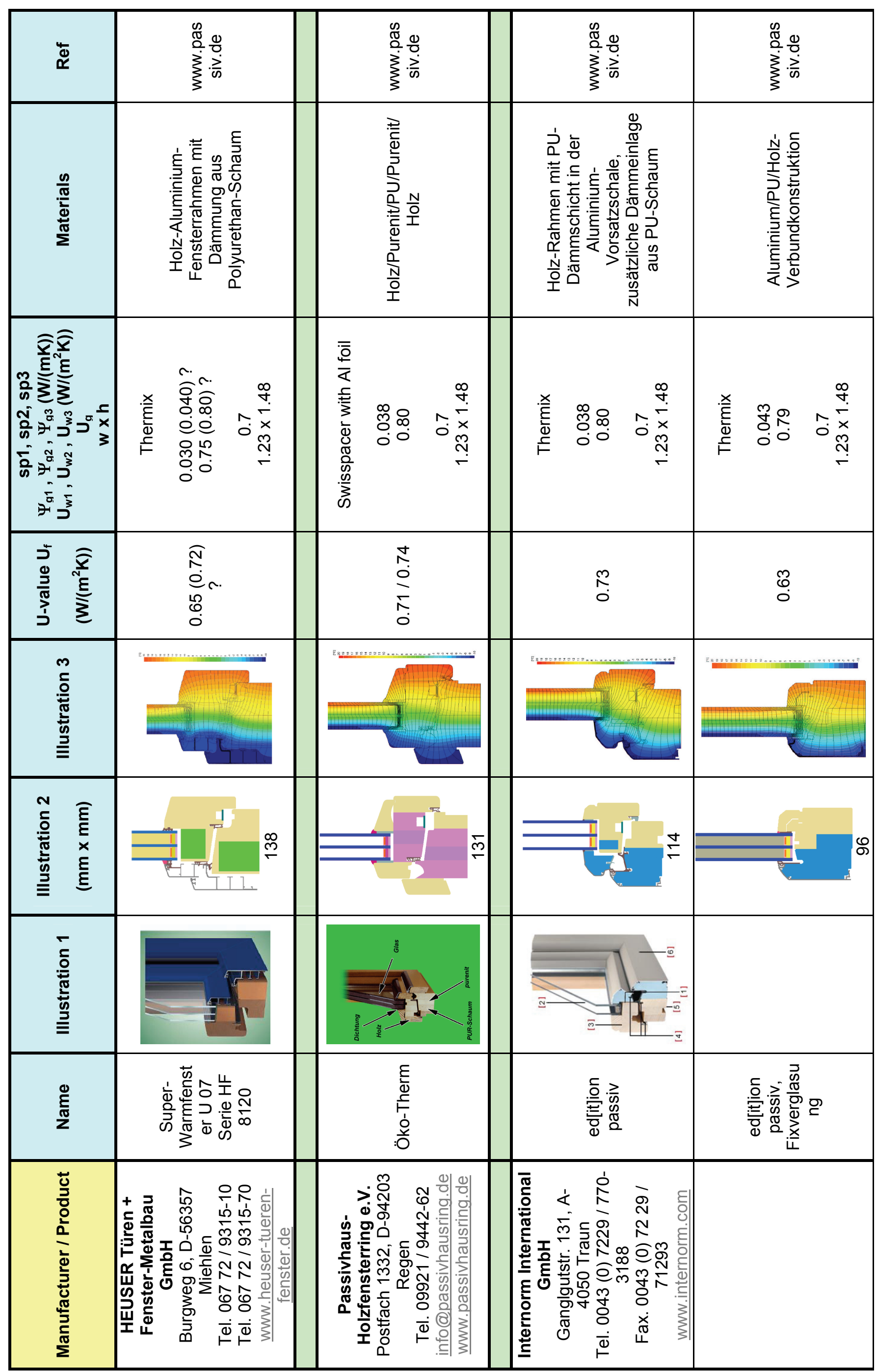




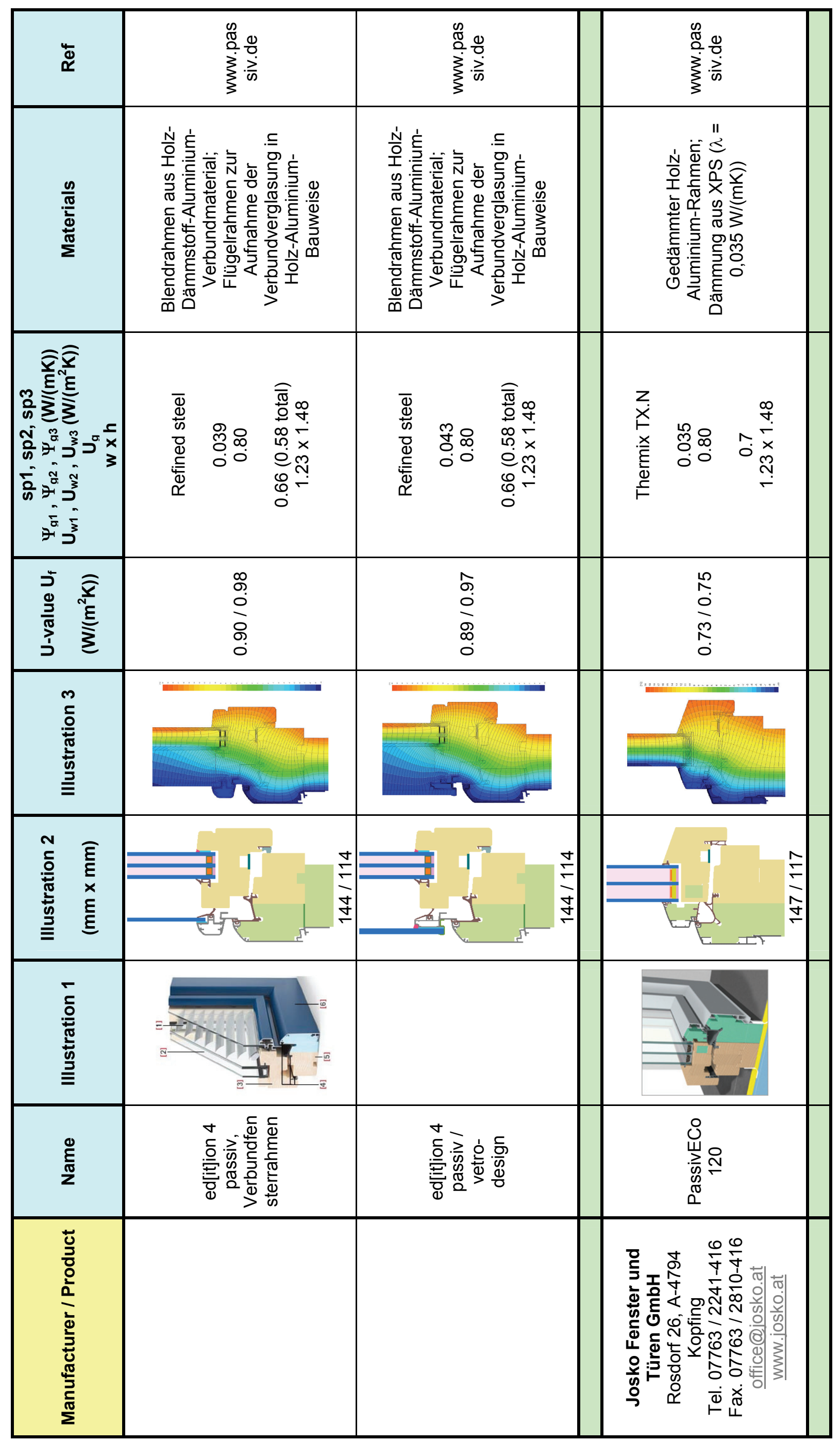




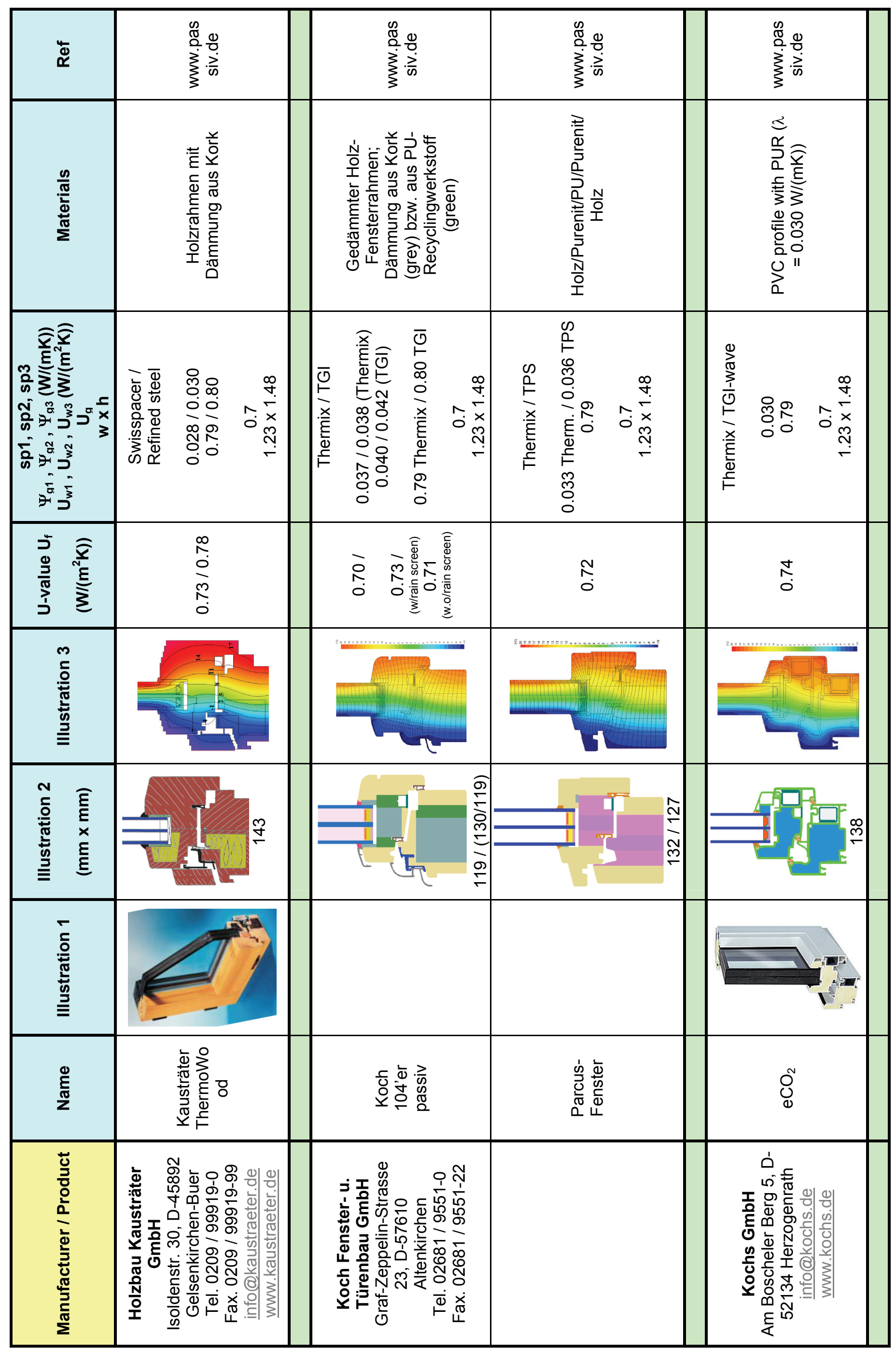




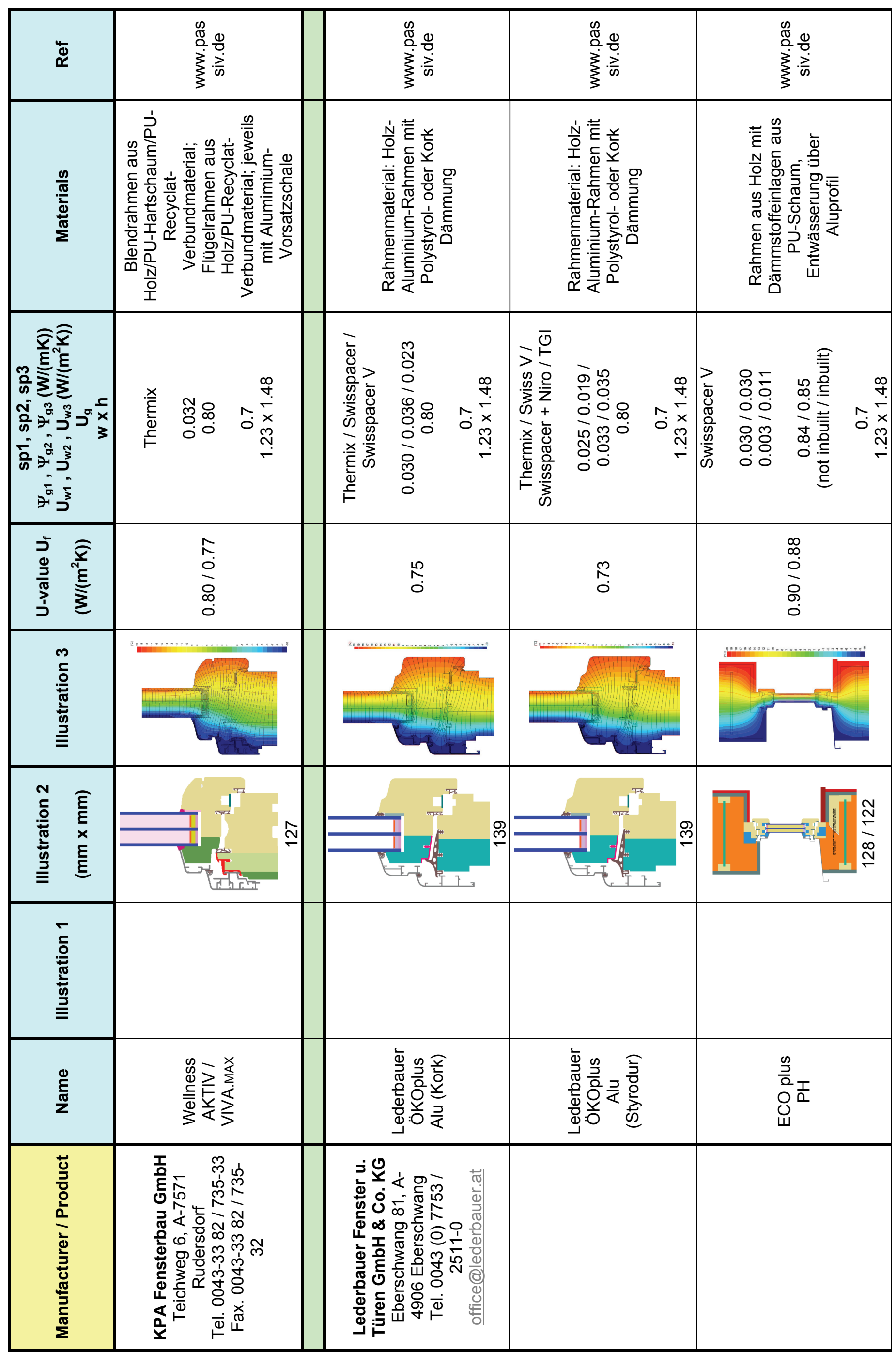




\begin{tabular}{|c|c|c|c|c|}
\hline 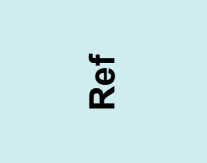 & 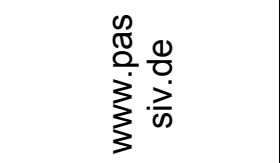 & 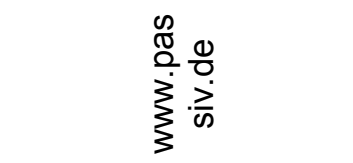 & 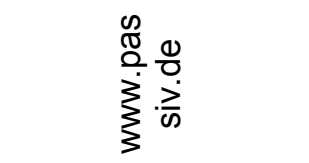 & 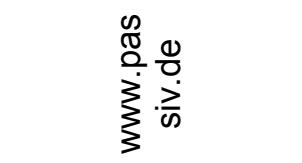 \\
\hline 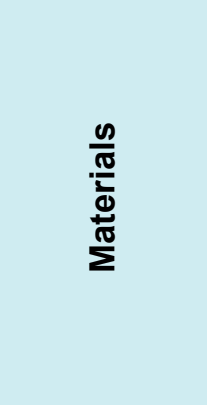 & & 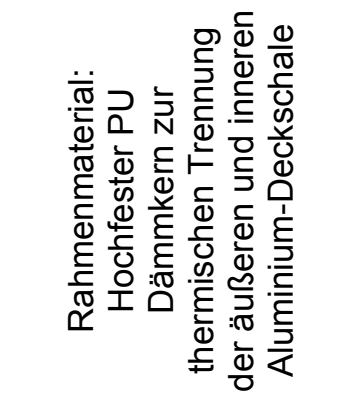 & 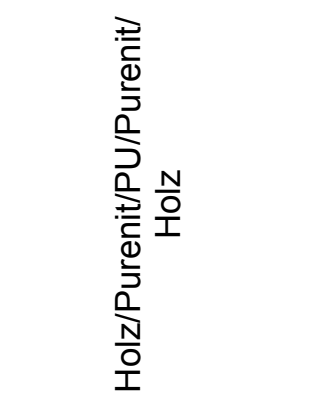 & 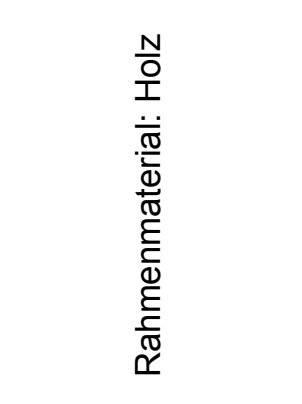 \\
\hline 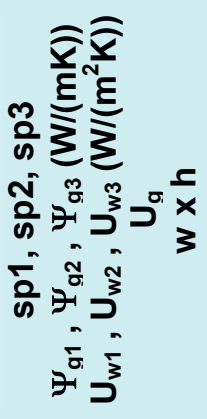 & 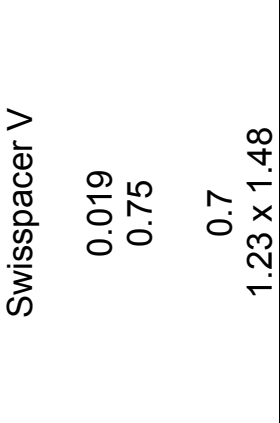 & 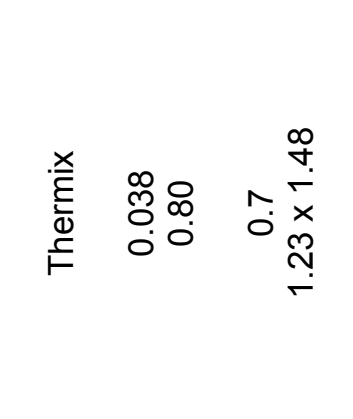 & 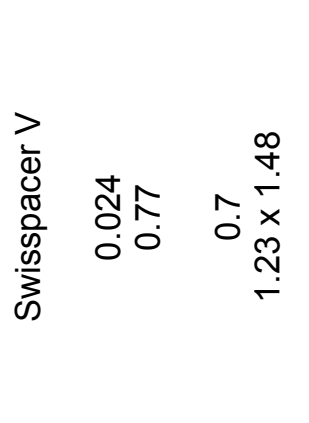 & 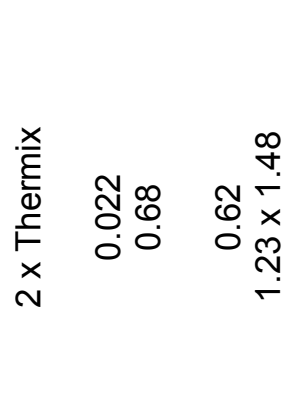 \\
\hline 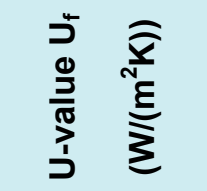 & $\begin{array}{l}2 \\
0 \\
0\end{array}$ & 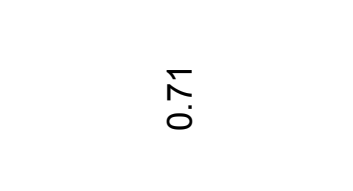 & $\begin{array}{l}\infty \\
\infty \\
0 \\
m \\
0 \\
0\end{array}$ & 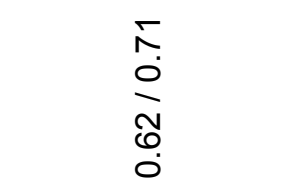 \\
\hline 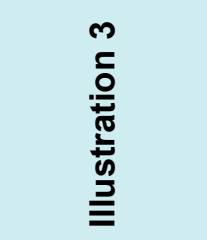 & & 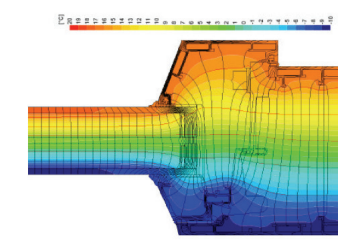 & $\begin{array}{l}-1 \\
\end{array}$ & (I) \\
\hline 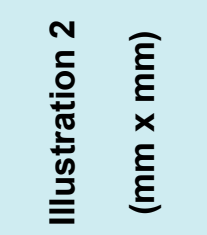 & $\stackrel{\text { m్ }}{\leftarrow}$ & & 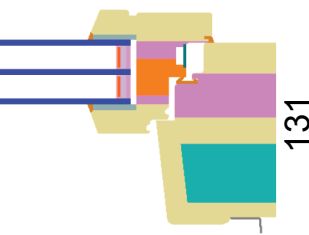 & 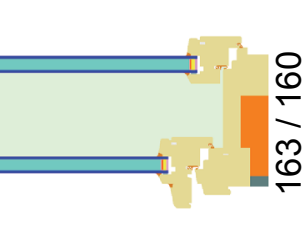 \\
\hline 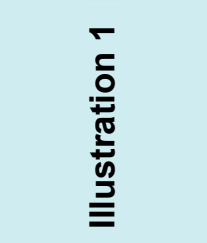 & & & & \\
\hline 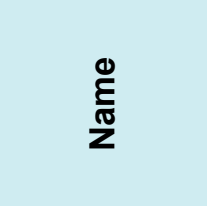 & 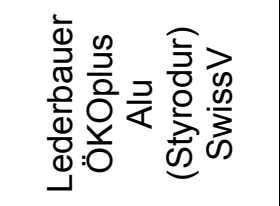 & 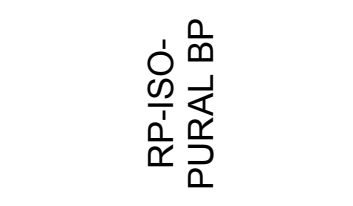 & 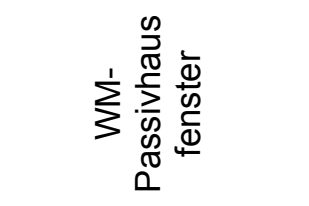 & 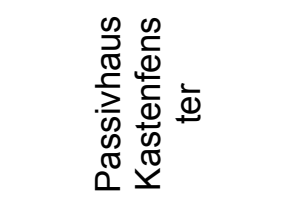 \\
\hline 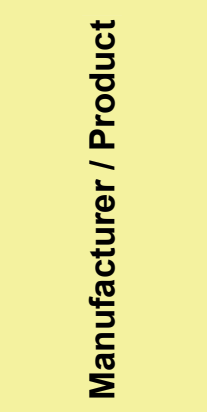 & & 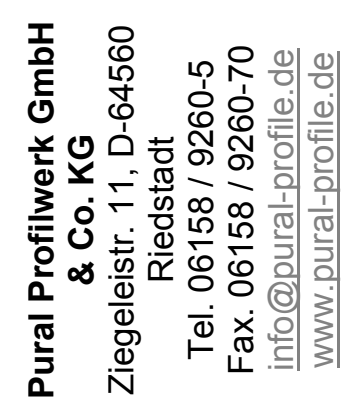 & 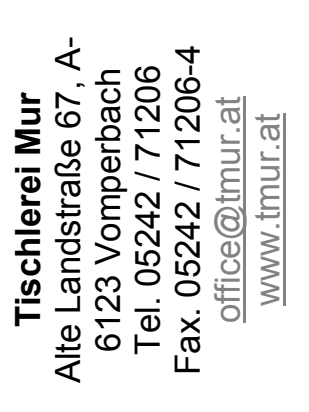 & 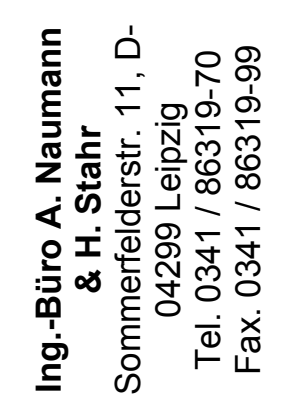 \\
\hline
\end{tabular}




\begin{tabular}{|c|c|c|c|c|}
\hline$\stackrel{\overleftarrow{\Phi}}{\mathscr{\Phi}}$ & 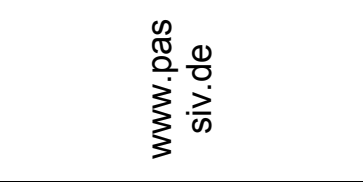 & 骂 & 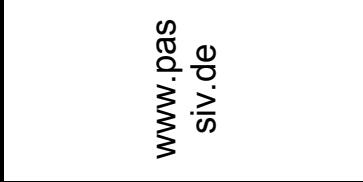 & 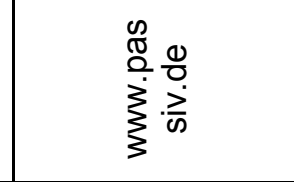 \\
\hline 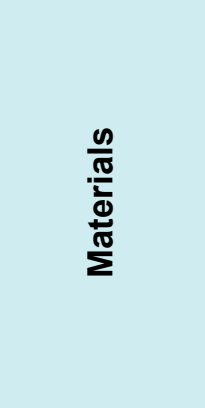 & 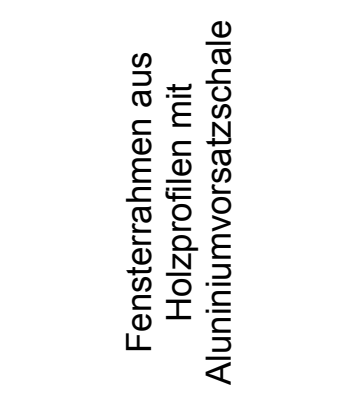 & 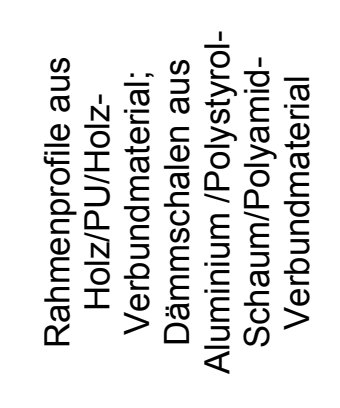 & 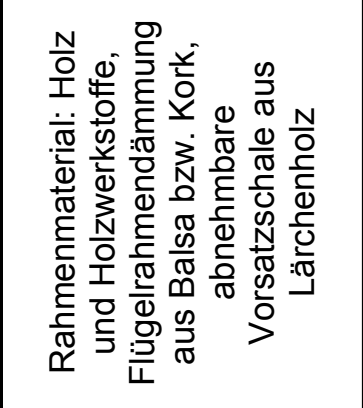 & 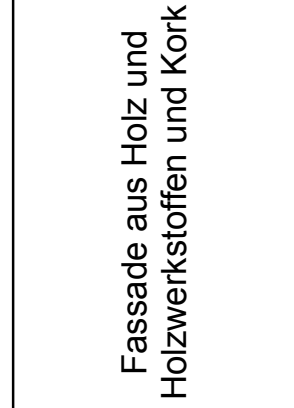 \\
\hline 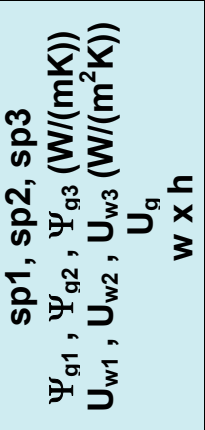 & 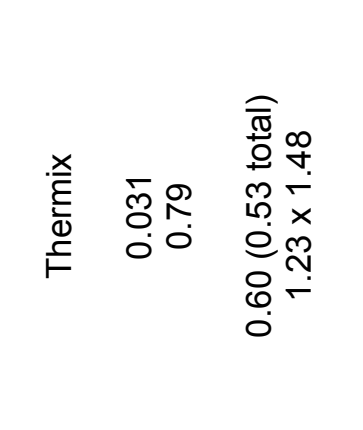 & 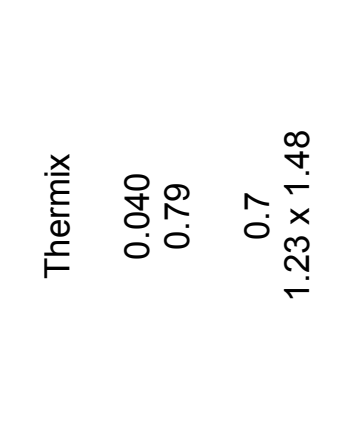 & 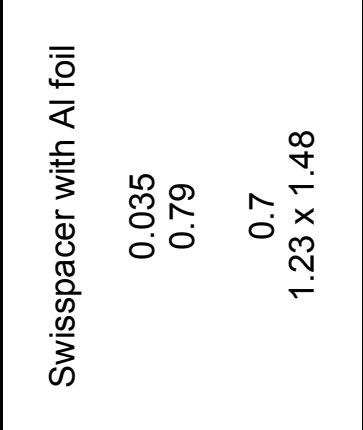 & 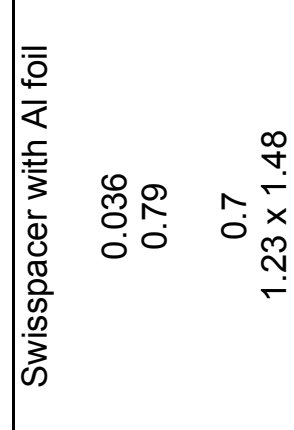 \\
\hline 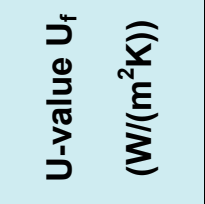 & 䓠 & $\stackrel{\infty}{\circ}$ & م. & $\stackrel{\circ}{\circ}$ \\
\hline 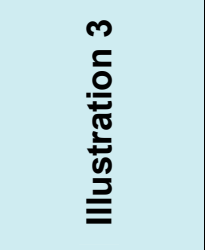 & $\sqrt{3}+\sqrt{2}$ & 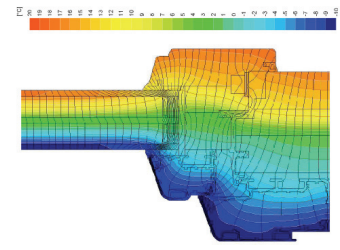 & & \\
\hline 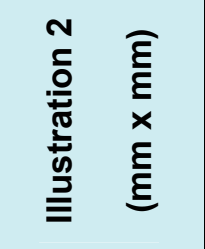 & $+\frac{0}{\frac{1}{c}}$ & $\pm \quad 4^{\circ}$ & & D \\
\hline 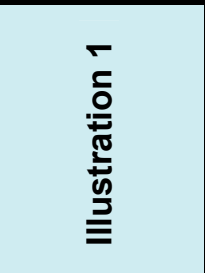 & 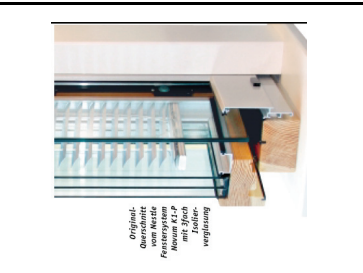 & & $\forall$ & $\frac{7}{4}+\frac{1}{1}$ \\
\hline 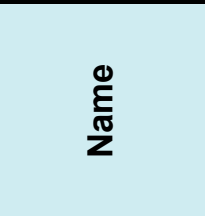 & 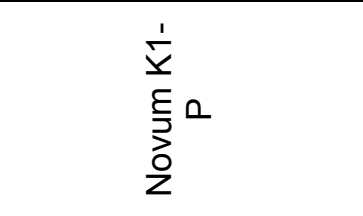 & 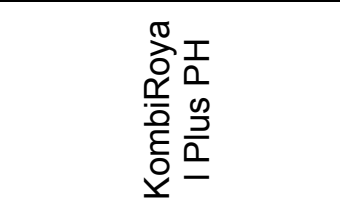 & 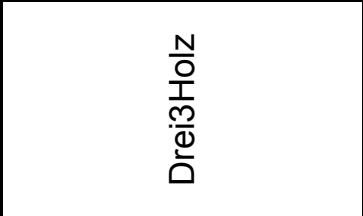 & 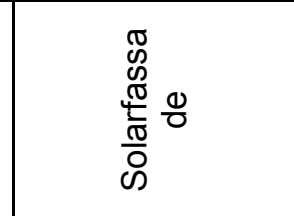 \\
\hline 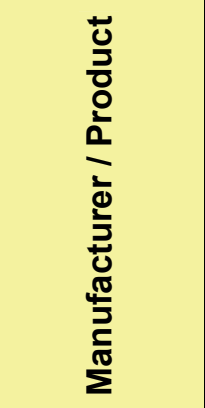 & 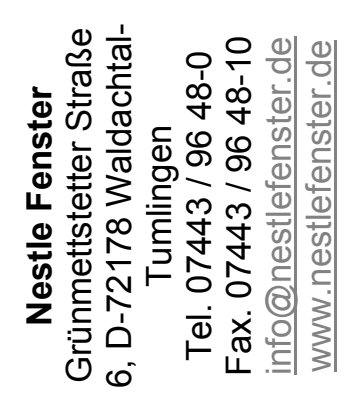 & 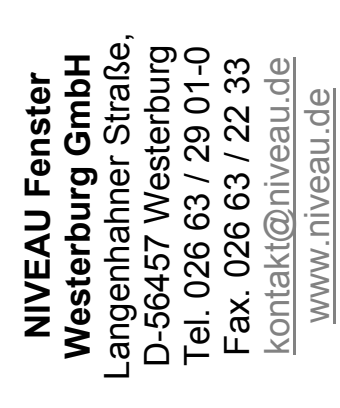 & 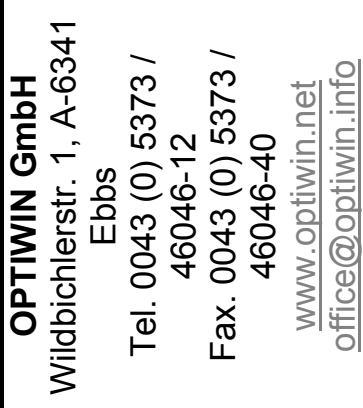 & \\
\hline
\end{tabular}




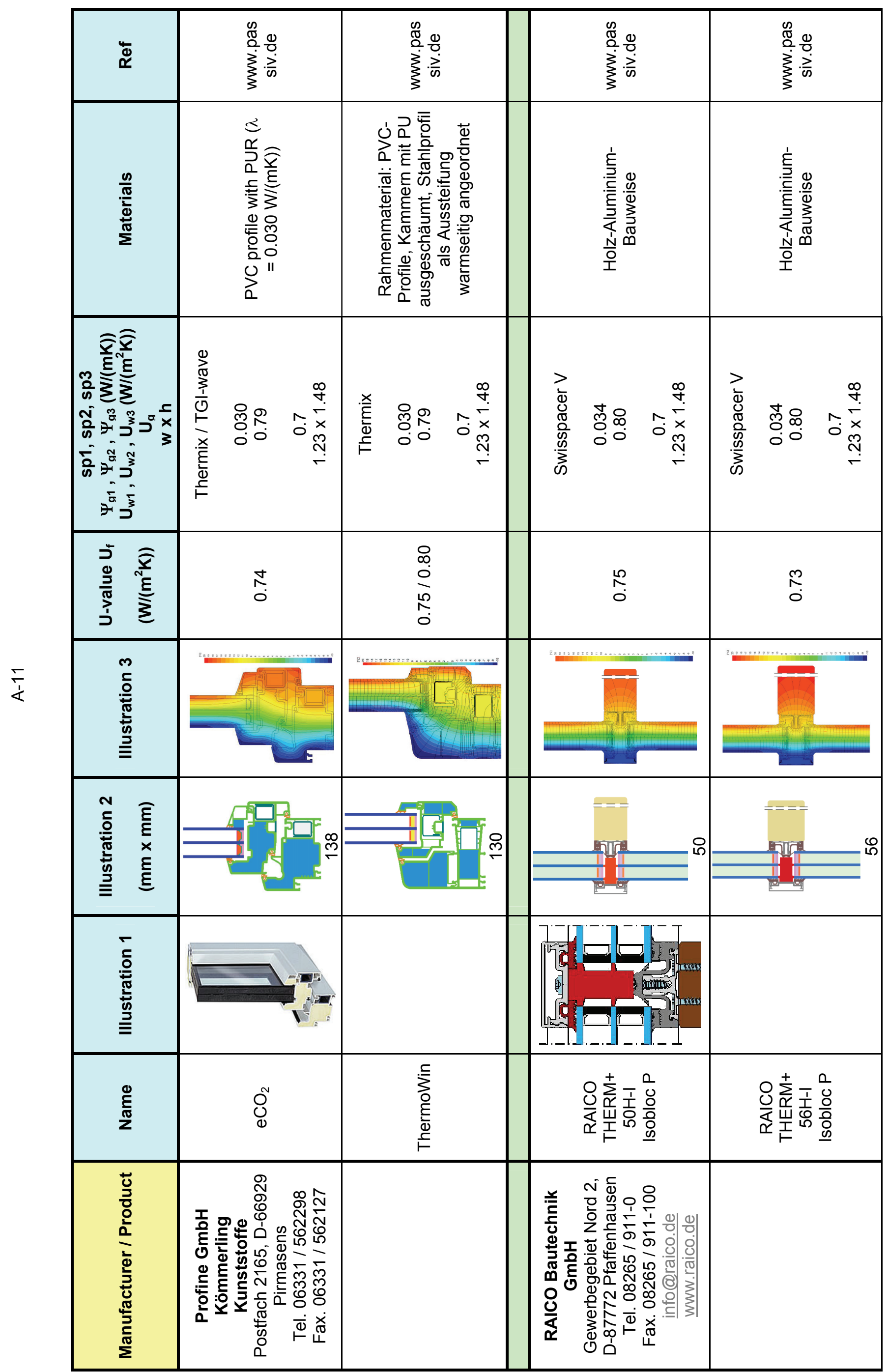




\begin{tabular}{|c|c|c|}
\hline 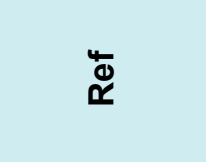 & 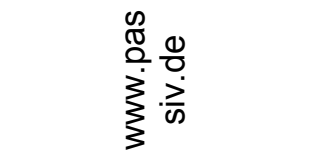 & 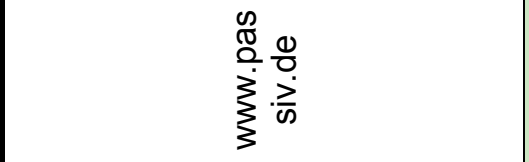 \\
\hline $\begin{array}{l}\frac{\infty}{\sigma \frac{\pi}{2}} \\
\frac{0}{\frac{\pi}{\pi}} \\
\frac{\pi}{\Sigma}\end{array}$ & 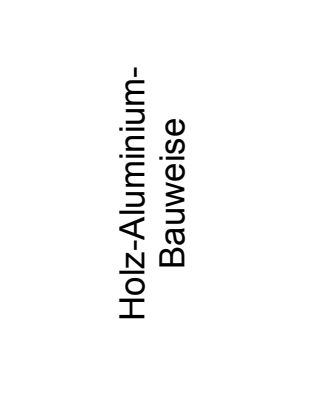 & 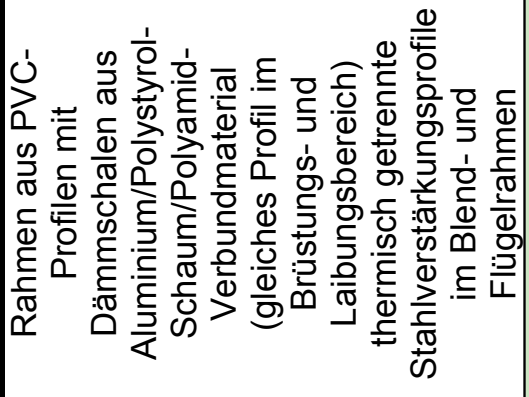 \\
\hline 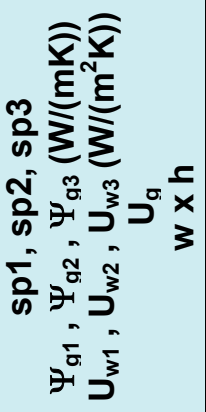 & 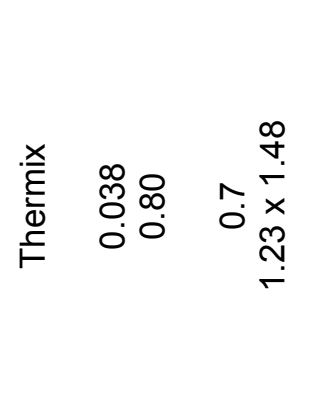 & 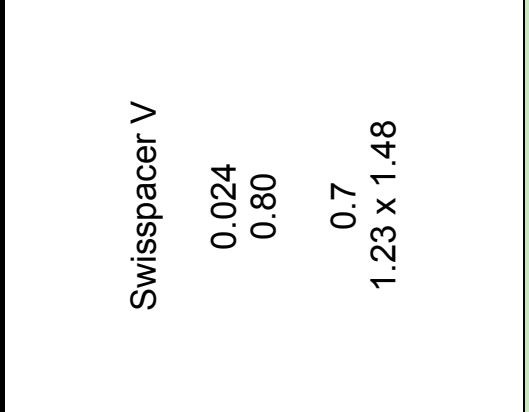 \\
\hline 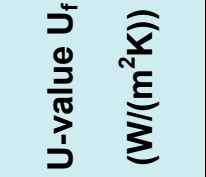 & @̊ & $\begin{array}{l}\infty \\
\infty \\
0\end{array}$ \\
\hline 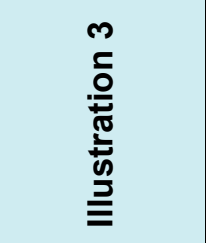 & $\sum^{7}$ & ${ }_{1}^{2}$ \\
\hline 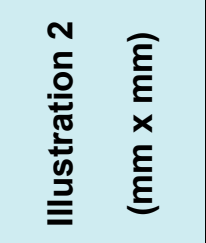 & inli & $\frac{1}{2}$ \\
\hline 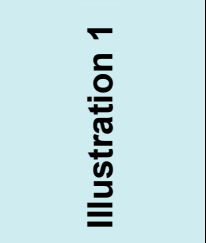 & & \\
\hline$\stackrel{\stackrel{0}{\pi}}{\frac{N}{Z}}$ & 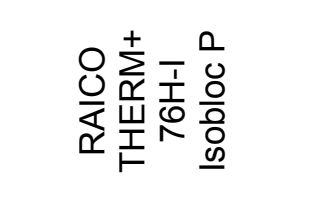 & 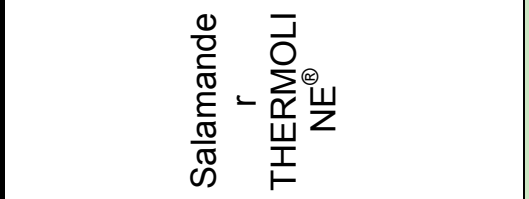 \\
\hline 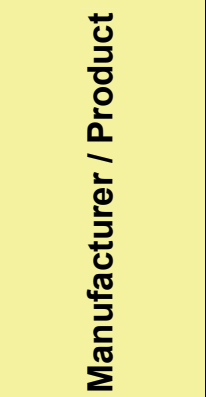 & & 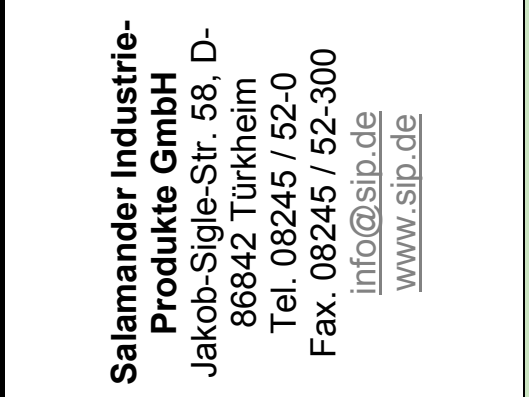 \\
\hline
\end{tabular}




\begin{tabular}{|c|c|c|c|}
\hline$\underset{\mathscr{\Phi}}{\mathscr{\Phi}}$ & 竞 & 离 & 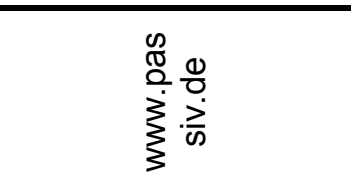 \\
\hline 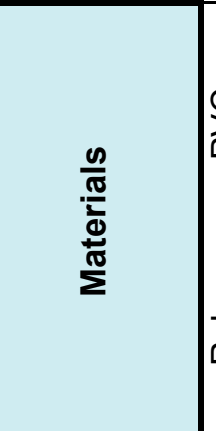 & 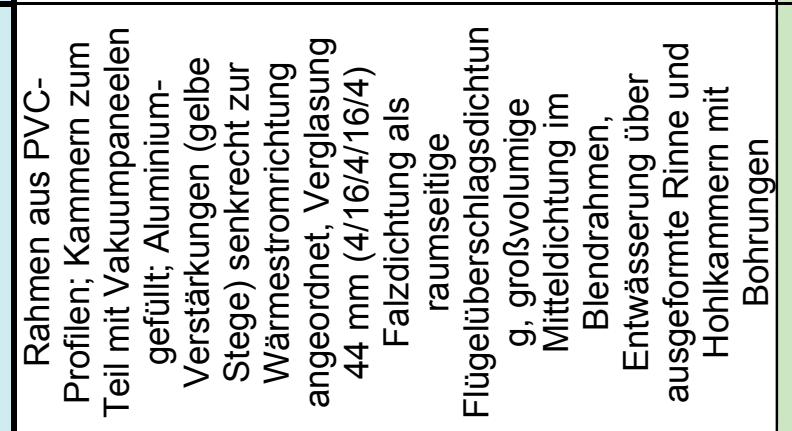 & 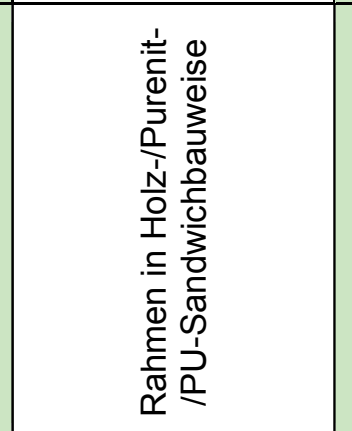 & 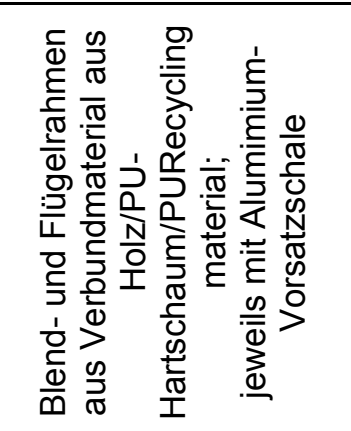 \\
\hline 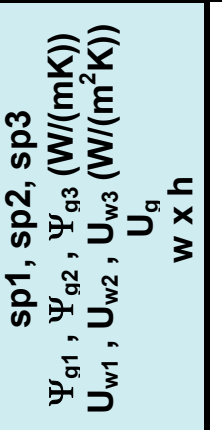 & 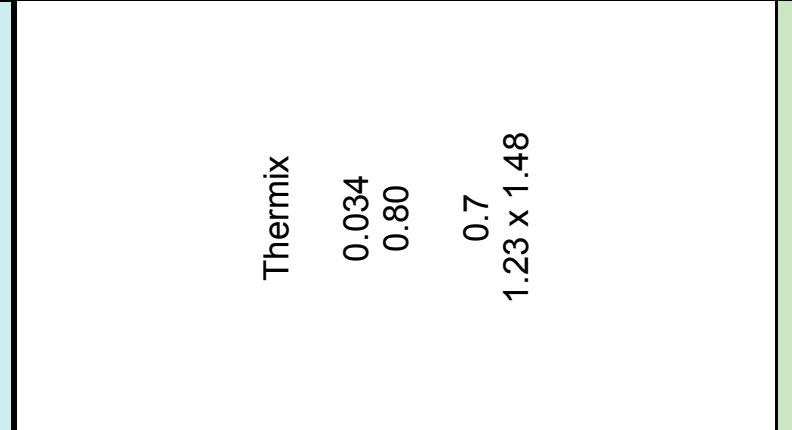 & 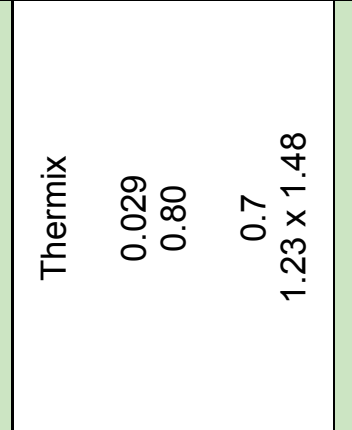 & 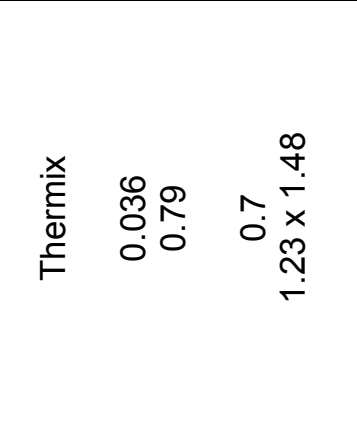 \\
\hline 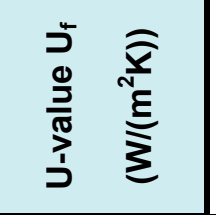 & $\stackrel{\mathscr{L}}{\circ}$ & $\stackrel{\infty}{\stackrel{\infty}{\circ}}$ & $\underbrace{}_{0}$ \\
\hline 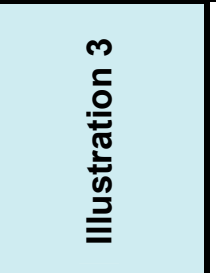 & 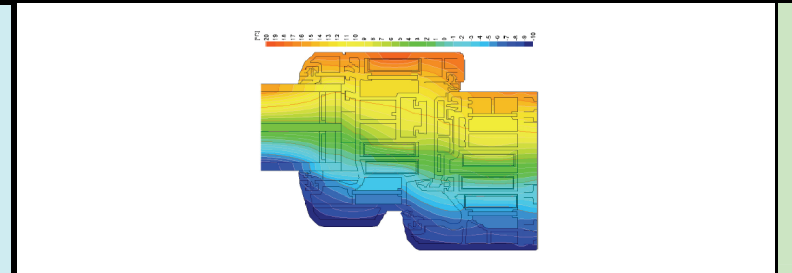 & & $\sum_{4}^{4}$ \\
\hline 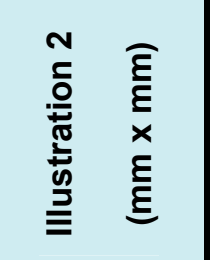 & $\frac{1}{1}$ & & $\frac{\sqrt{2}}{\sqrt{2}} \frac{\int^{2}}{9}$ \\
\hline 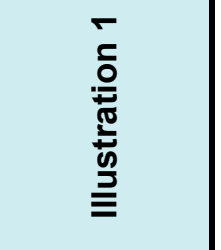 & $=$ & & \\
\hline 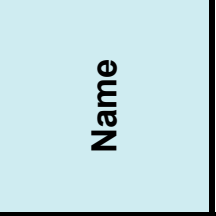 & 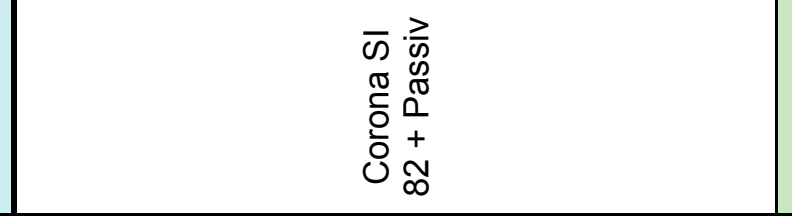 & 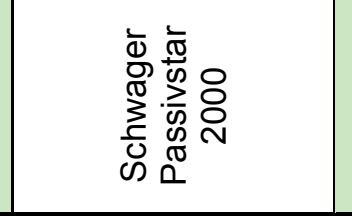 & 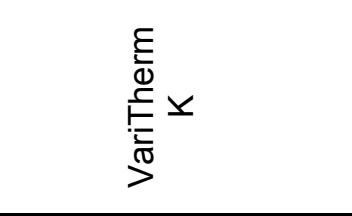 \\
\hline 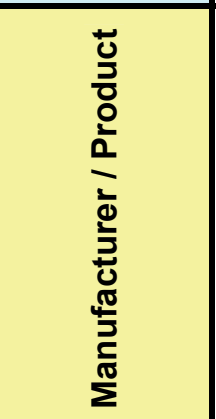 & 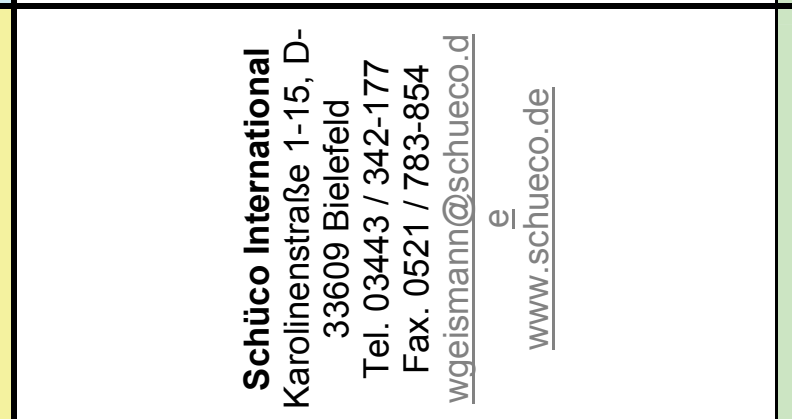 & 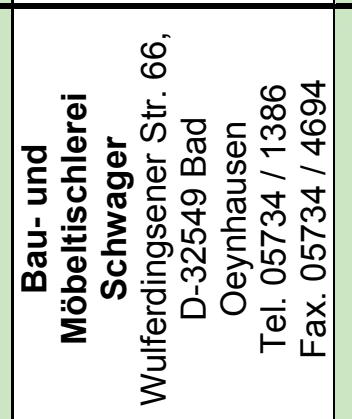 & 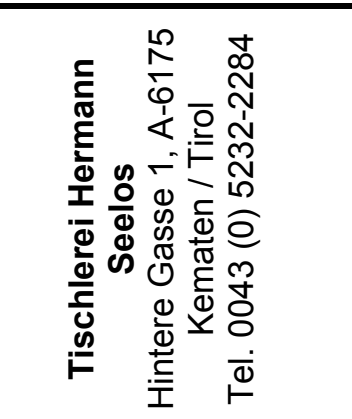 \\
\hline
\end{tabular}




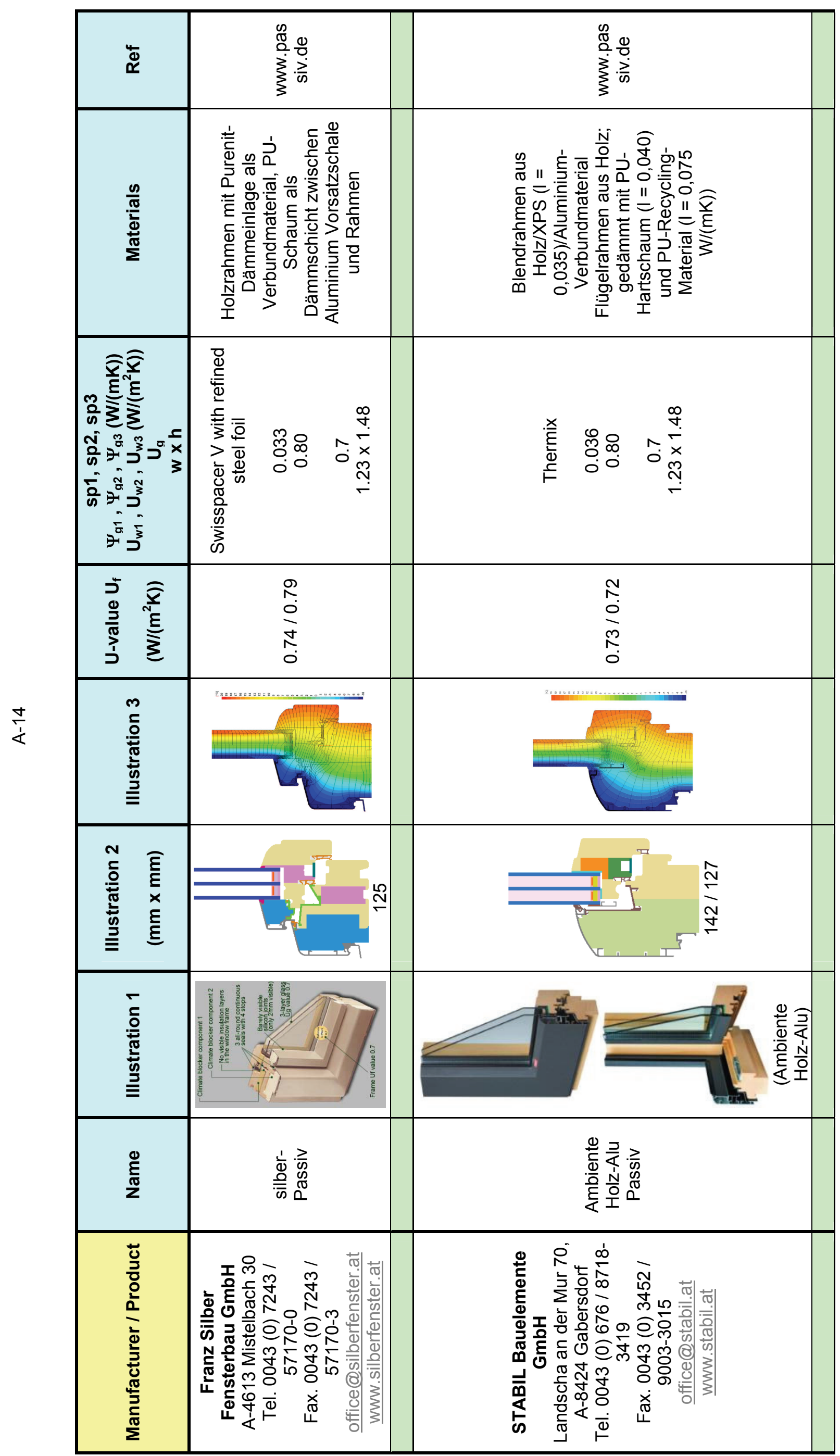




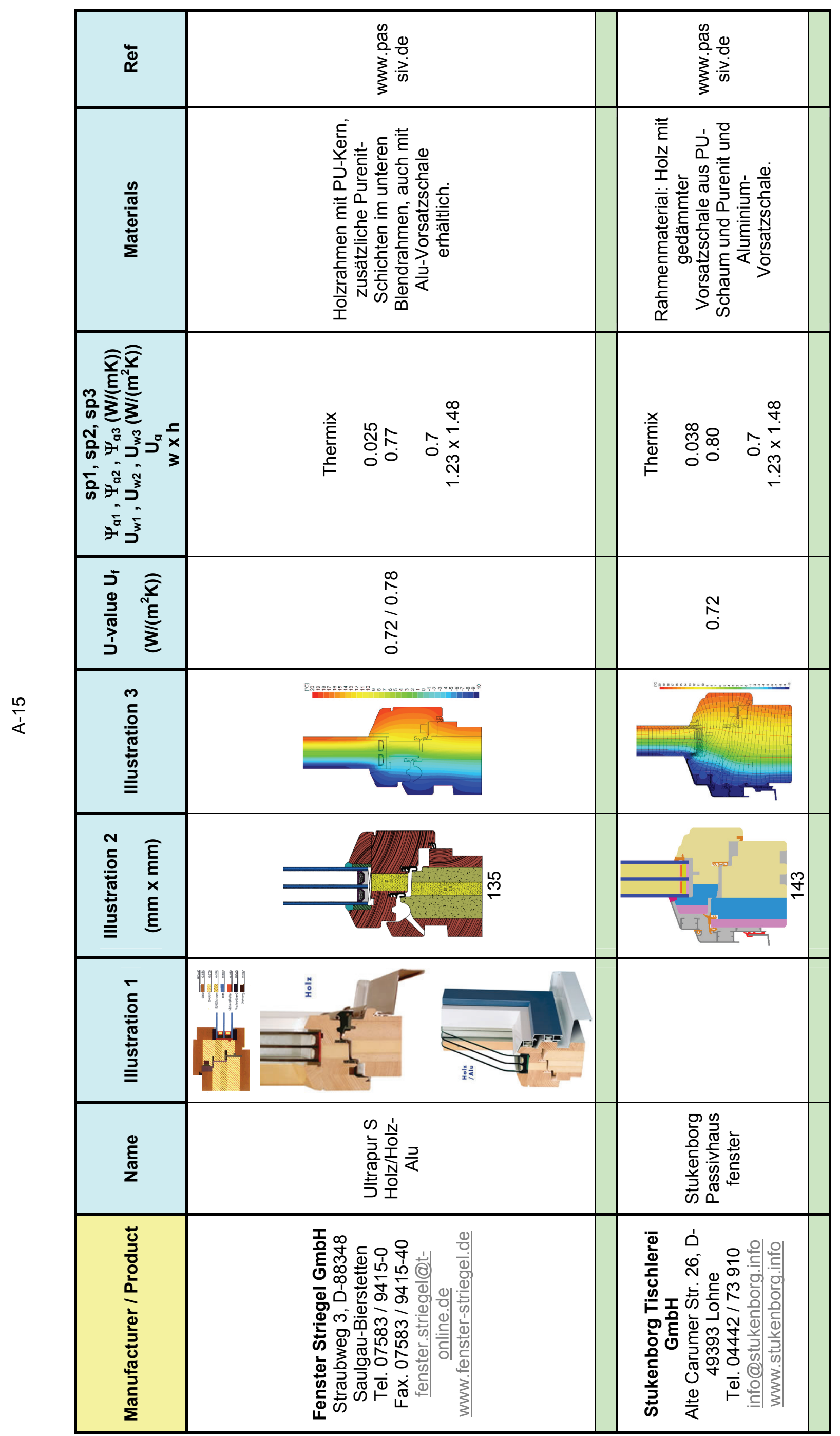




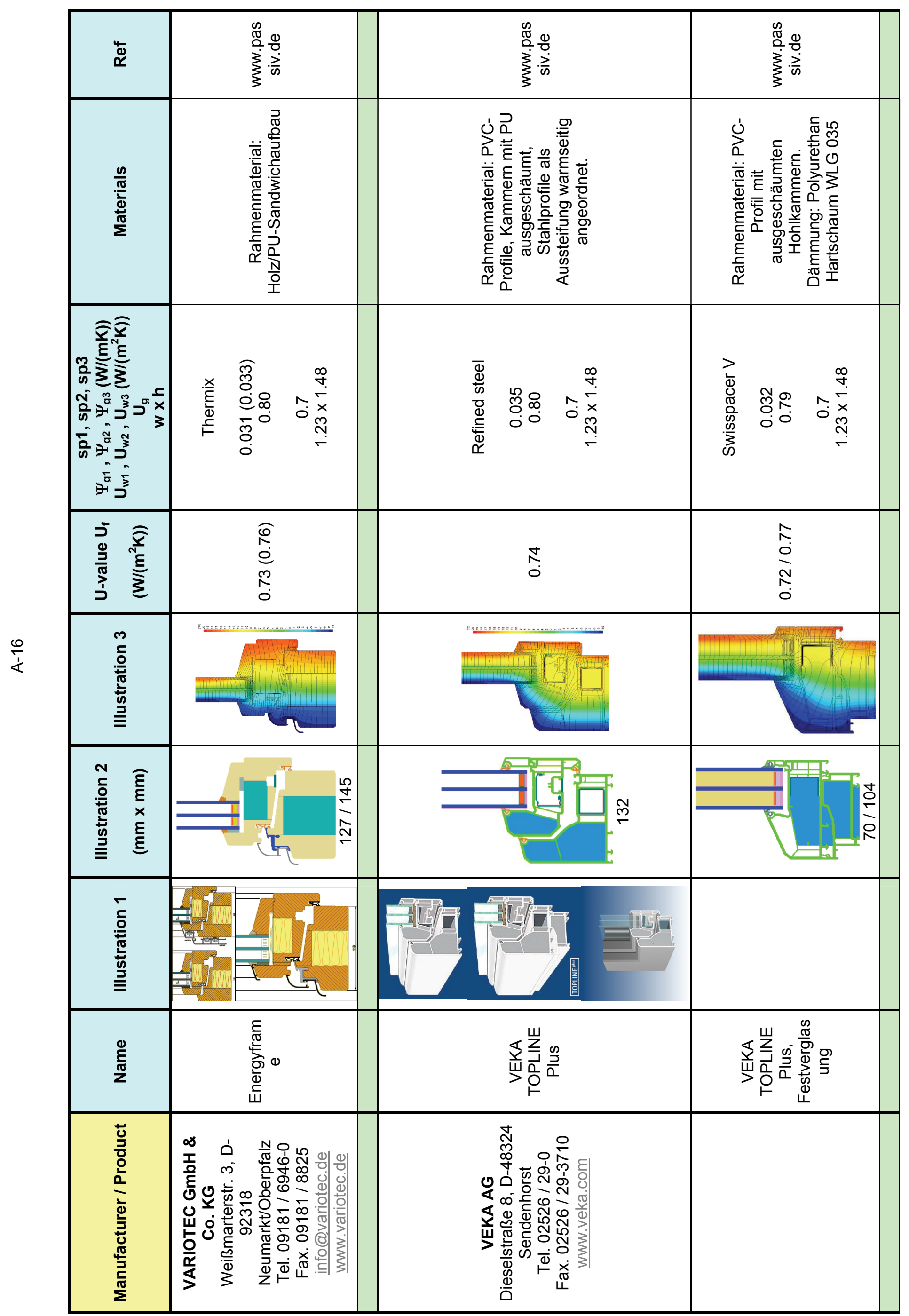




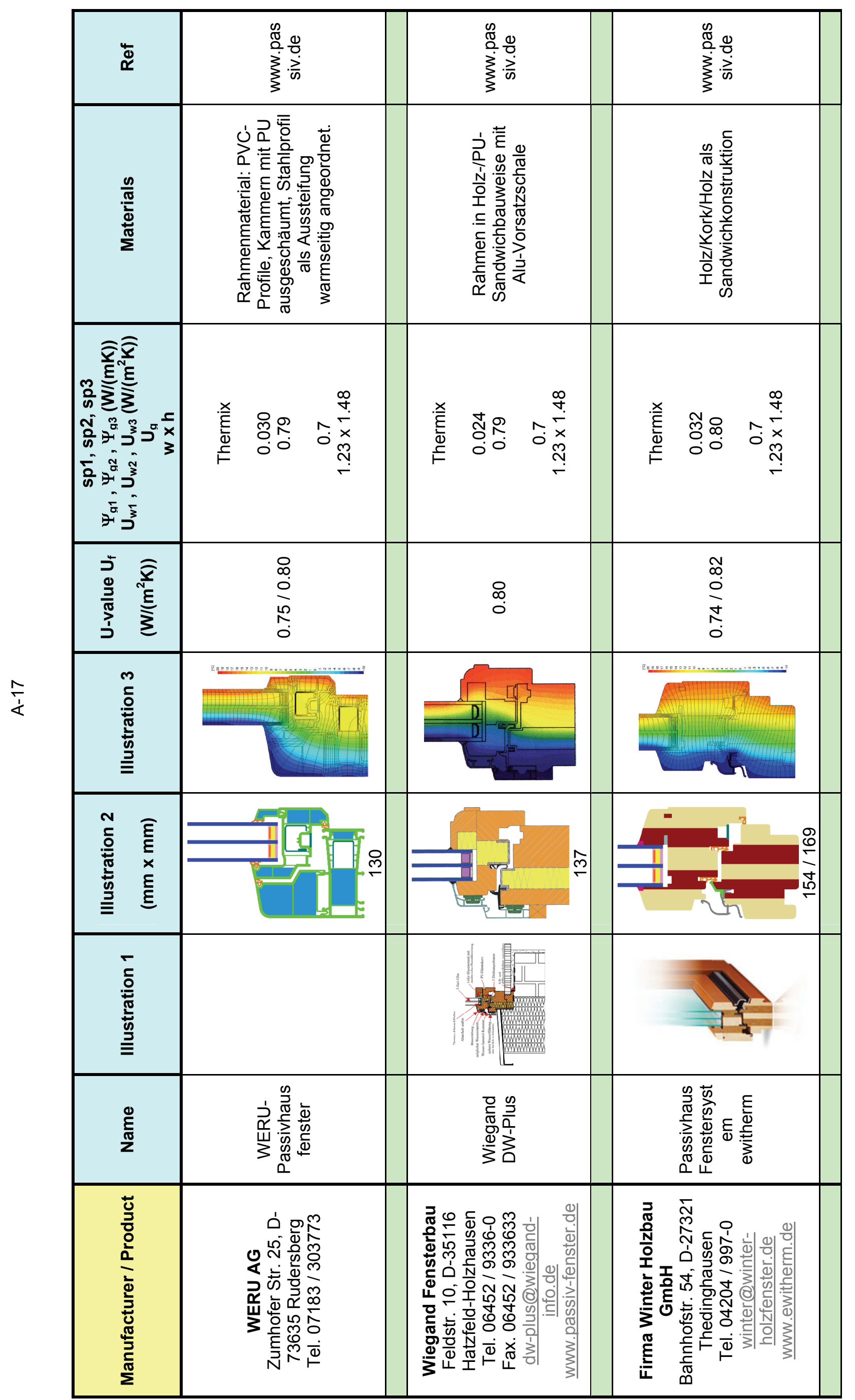




\begin{tabular}{|c|c|c|c|}
\hline ֶֻّ & 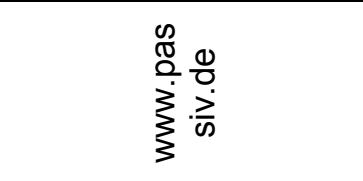 & 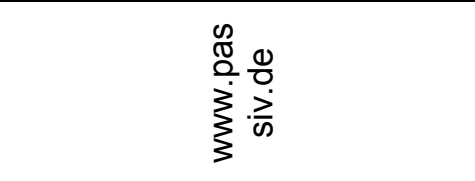 & 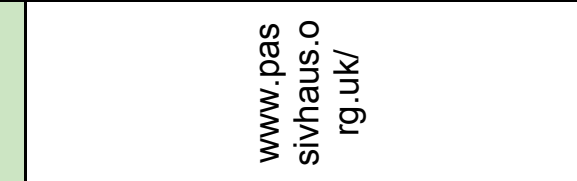 \\
\hline 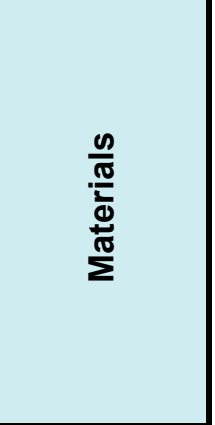 & 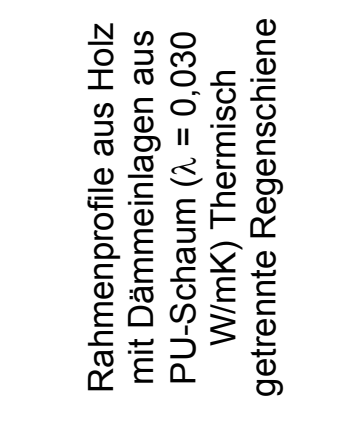 & 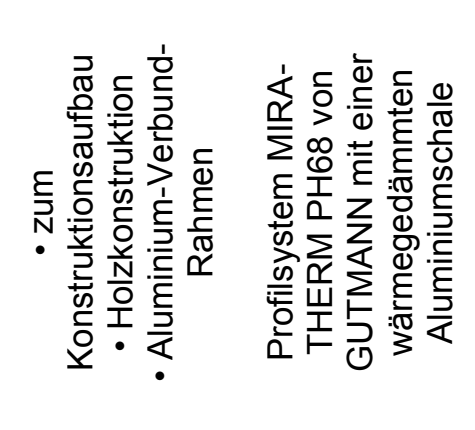 & 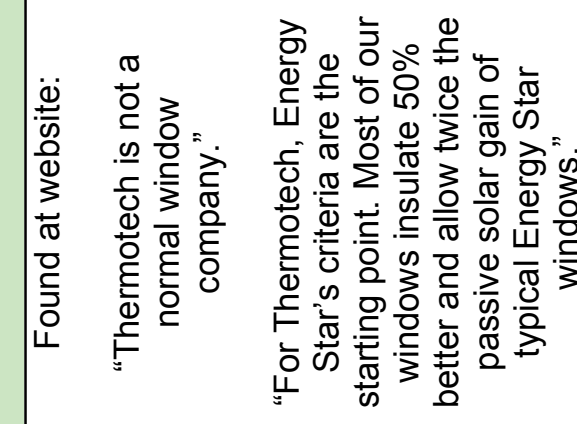 \\
\hline 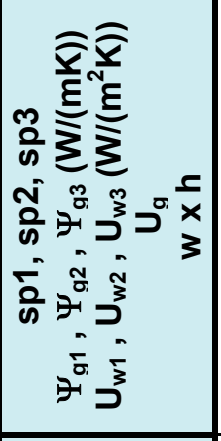 & 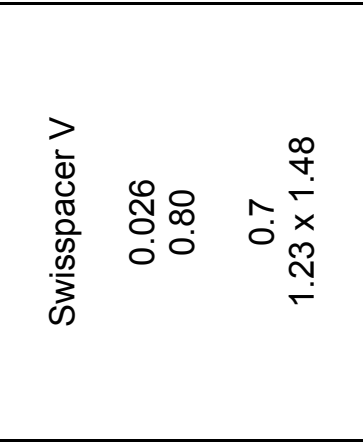 & 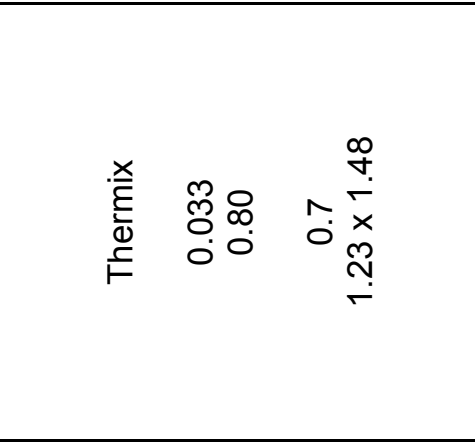 & \\
\hline 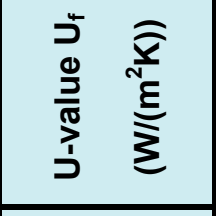 & $\begin{array}{c}\infty \\
\stackrel{\infty}{0} \\
\stackrel{0}{\infty} \\
\infty \\
0 \\
\end{array}$ & $\stackrel{\substack{\mathfrak{o} \\
0}}{0}$ & \\
\hline 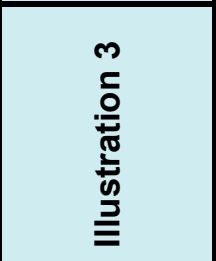 & $x^{2}$ & & \\
\hline 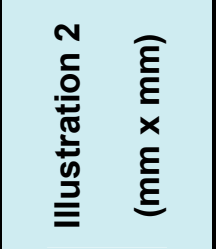 & & $\stackrel{\mathbb{N}}{\mathrm{N}}$ & \\
\hline $\begin{array}{l}\stackrel{0}{E} \\
\stackrel{5}{\tilde{5}}\end{array}$ & 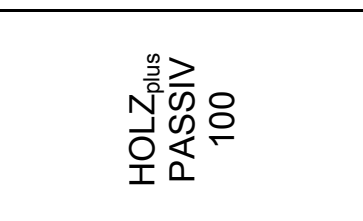 & 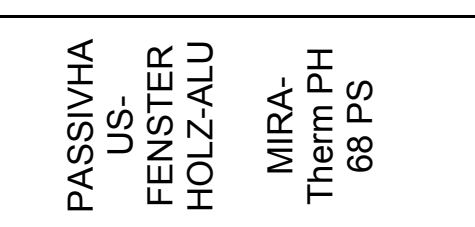 & \\
\hline 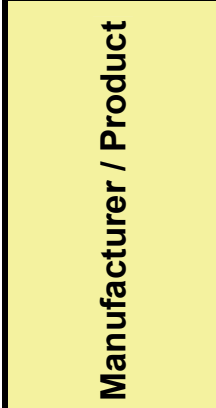 & 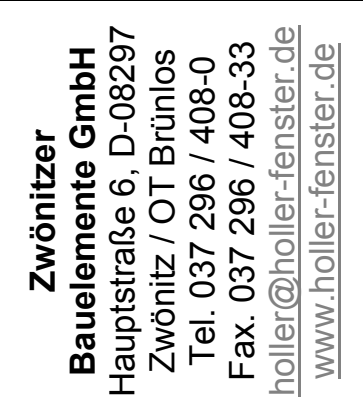 & & 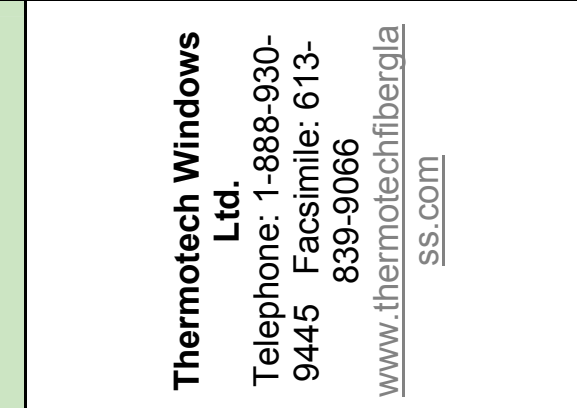 \\
\hline
\end{tabular}




\begin{tabular}{|c|c|c|}
\hline 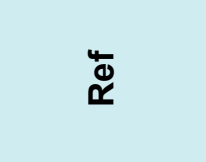 & 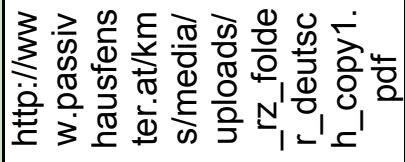 & 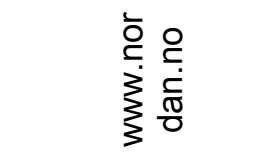 \\
\hline 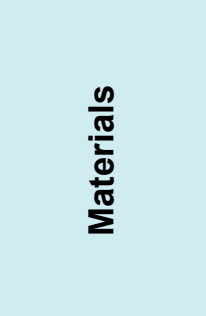 & 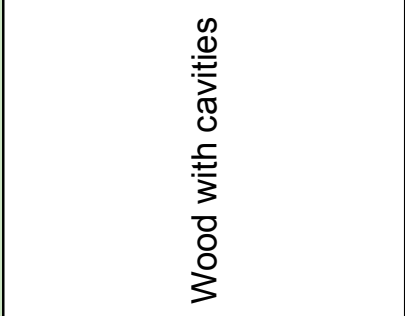 & $\begin{array}{l}\frac{r}{\partial} \\
\frac{1}{0} \\
\frac{1}{3} \\
\frac{1}{8} \\
8 \\
3\end{array}$ \\
\hline 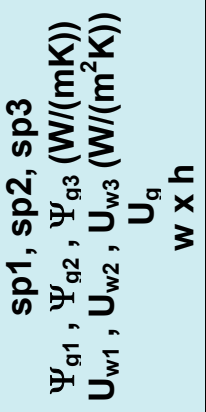 & 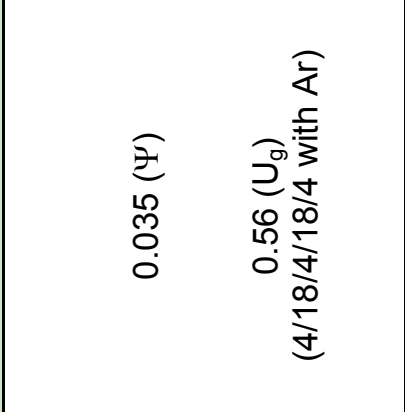 & 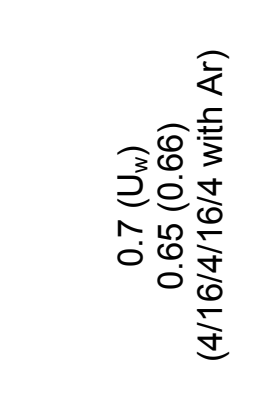 \\
\hline 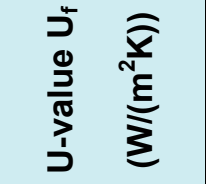 & 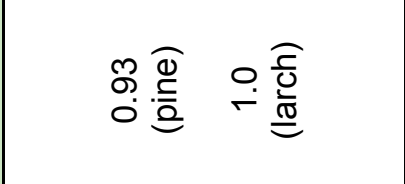 & \\
\hline 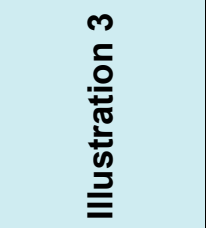 & & \\
\hline 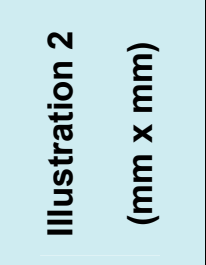 & $L$ & 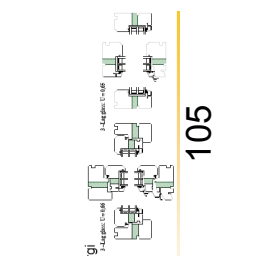 \\
\hline 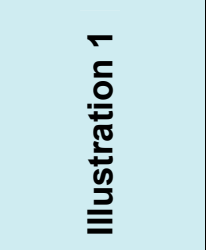 & 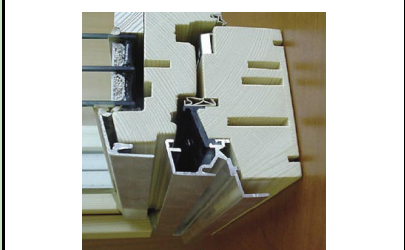 & \\
\hline 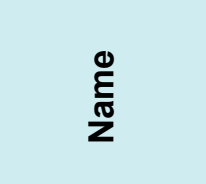 & 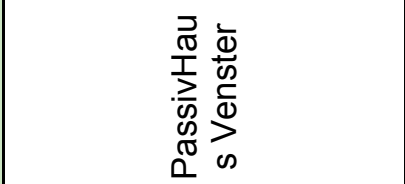 & 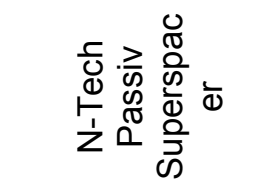 \\
\hline 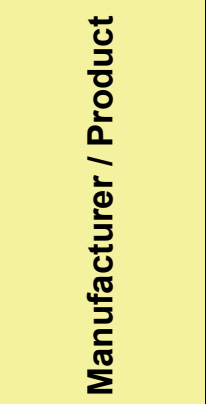 & 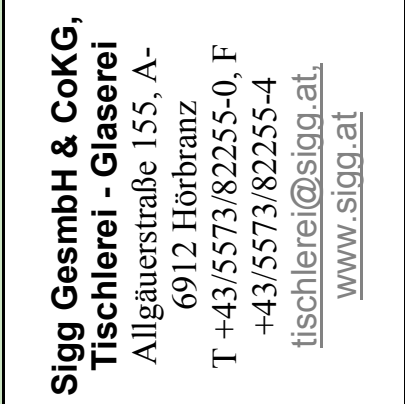 & 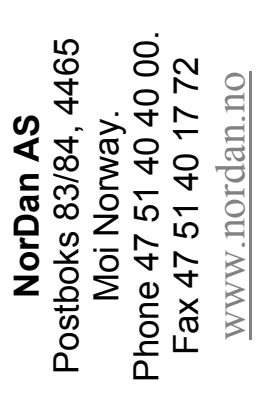 \\
\hline
\end{tabular}

